\title{
Aerodynamic Aspects in the Development of Morphing Winglet for a Regional Aircraft
}

\author{
by \\ Prakash Paudel \\ Bachelor of Engineering, Ryerson University, 2013
}

\author{
A thesis \\ presented to Ryerson University \\ in partial fulfillment of the \\ requirements for the degree of \\ Master of Applied Science \\ in the Program of \\ Aerospace Engineering
}

Toronto, Ontario, Canada, 2015

(C)Prakash Paudel 2015 


\section{AUTHOR'S DECLARATION FOR ELECTRONIC SUBMISSION OF A THESIS}

I hereby declare that I am the sole author of this thesis. This is a true copy of the thesis, including any required final revisions, as accepted by my examiners.

I authorize Ryerson University to lend this thesis to other institutions or individuals for the purpose of scholarly research.

I further authorize Ryerson University to reproduce this thesis by photocopying or by other means, in total or in part, at the request of other institutions or individuals for the purpose of scholarly research.

I understand that my thesis may be made electronically available to the public. 
Aerodynamic Aspects in the Development of Morphing Winglet for a Regional Aircraft

Master of Applied Science 2015

Prakash Paudel

Aerospace Engineering

Ryerson University

\begin{abstract}
An aerodynamic analysis is conducted for morphing winglets on a regional aircraft. The optimum drag, bending moment, stall angle and maximum lift coefficient are evaluated for various mission segments by varying winglet design parameters. Aero-elastic studies are conducted in order to incorporate wing deformation effects in addition to exploring maneuver load alleviation capability of the morphing winglet. The results show drag benefit up to $1 \%$ in cruise and wing bending moment and winglet bending moment benefits of $2.4 \%$ and $63 \%$ at $2.5 \mathrm{~g}$ symmetric maneuver conditions. The total aircraft drag benefit translates to additional allowable structural weight that can be applied to the design of winglet actuation system. The morphing winglet shows superior stall behavior and attenuates high wing loads. The estimated wing-winglet loads will help in proper selection of actuators. This study is also expected to help in elevating technology readiness level of the morphing winglet technology.
\end{abstract}




\section{Acknowledgements}

I would like to acknowledge all the support and encouragement from everyone who have made this thesis work possible. First and foremost, I should thank my parents and my brother for believing in me and supporting me every step of the way. Their hard work and unwavering dedication to enrolling me into one of the best schools is an example to everyone in Nepal where the literacy rate is one of the lowest in the world. The supreme quality of education that I received in Nepal, thanks to my parent's selfless contribution, has been the backbone of my academic life.

Secondly, thank you Linh for encouraging and supporting me to obtain a Master's degree. Without Linh's unending support and her sacrifice, I cannot imagine finishing my Master's degree. Not to forget, thanks for making me warm meals and being generous with hugs when I needed them the most.

I would also like to express my sincere gratitude to my thesis supervisors Dr. Fengfeng (Jeff) Xi and Dr. Paul Walsh for giving me the opportunity to work in this project. Thank you for being there to answer any questions that I had throughout my Masters degree at Ryerson University. With the quality of education I received under your care at the University, I strongly believe that I have the ability to work in the field of my study anywhere in the world.

This thesis work has been made possible due to financial contributions made by Natural Sciences and Engineering Research Council of Canada and Bombardier Aerospace in the form of Industrial Postgraduate Scholarship. I would like to show my sincere gratitude to David LeBlond and Pascal Bochud in Advanced Aerodynamics department of Bombardier Aerospace for being the mentors and guiding me throughout my thesis work term in Montreal. You helped make the thesis work fun and one of the best working experiences in such a reputatable company.

My sincere thanks to Jonathan Hack and Fassi Kafyeke for arranging funds and logistics for me to conduct my thesis work. Special thanks to Francois Pepin and Patrick Germain for all the planning and valuable inputs during the course of this work.

Lastly, I would like to thank all my friends who have supported me in this endeavor. 


\section{Dedication}

To my beautiful kids Dylan Kieran and Lucas Kien and to my birthplace Nepal 


\section{Table of Contents}

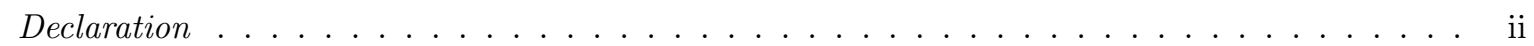

Abstract . . . . . . . . . . . . . . . . . . . . . iii

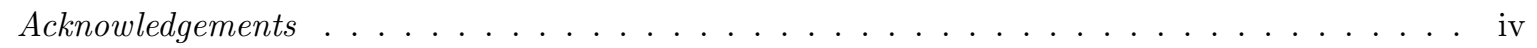

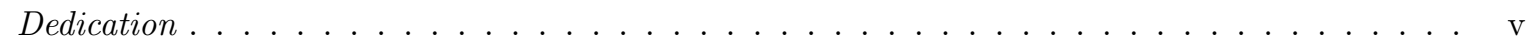

List of Tables . . . . . . . . . . . . . . . . . . . . . . . . viii

List of Figures . . . . . . . . . . . . . . . . . . . . . ix

$\begin{array}{lll}1 & \text { Purpose and Organisation } & 1\end{array}$

1.1 Introduction . . . . . . . . . . . . . . . . . . . . . . . . 1

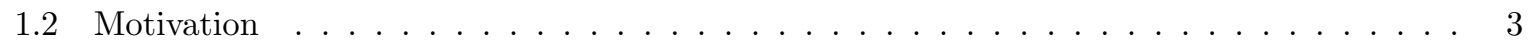

1.3 Purpose of the Research $\ldots \ldots \ldots \ldots \ldots \ldots \ldots$

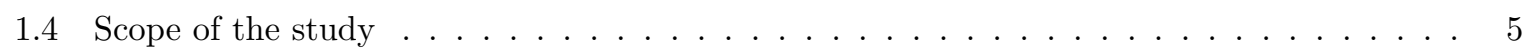

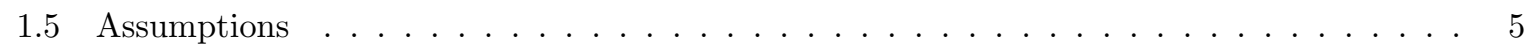

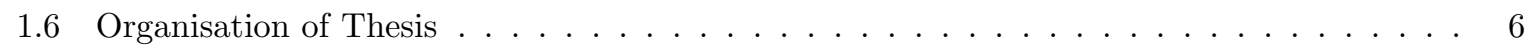

\begin{tabular}{|lll}
\hline 2 & Literature Review & 7
\end{tabular}

2.1 Introduction . . . . . . . . . . . . . . . . . . . . . . . . 7

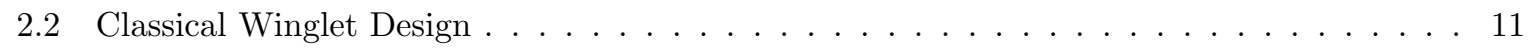

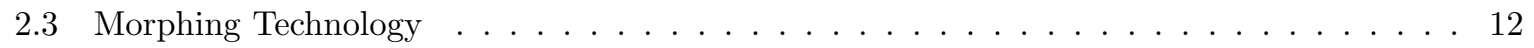

2.4 A Survey of Morphing Winglet $\ldots \ldots \ldots \ldots \ldots \ldots$

$2.4 .1 \quad$ Project SMORPH $\ldots \ldots \ldots \ldots \ldots \ldots \ldots \ldots$

2.4 .2 MORPHing WingLET (MORPHLET) $\ldots \ldots \ldots \ldots \ldots \ldots \ldots$

2.4 .3 Variable Cant Angle Winglet . . . . . . . . . . . . . . . . . . . . . 15

$2.4 .4 \quad$ Variable Height Wingtip Device. . . . . . . . . . . . . . . . . . . . . . . . . . . . . . . . . . . .

2.4 .5 Articulating Winglets $\ldots \ldots \ldots \ldots \ldots \ldots \ldots$

$2.4 .6 \quad$ Active Multiple Winglets $\ldots \ldots \ldots \ldots \ldots \ldots$

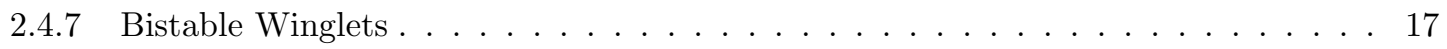

2.5 Morphing Skins . . . . . . . . . . . . . . . . . . . . . . . . . . . . 18

$2.6 \quad$ Active Flow Control $\ldots \ldots \ldots \ldots$

2.7 Summary $\ldots \ldots \ldots \ldots \ldots \ldots \ldots$ 


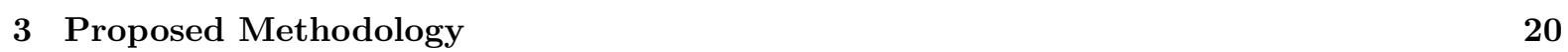

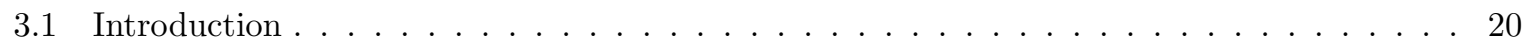

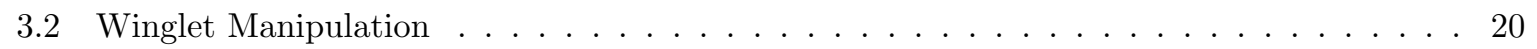

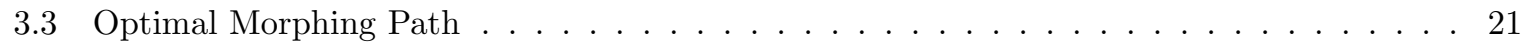

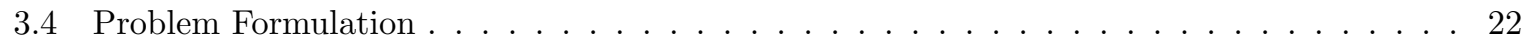

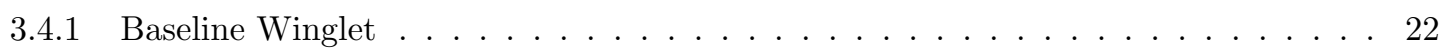

$3.4 .2 \quad$ High Speed Design Space Exploration $\ldots \ldots \ldots$. . . . . . . . . . . . . 23

$3.4 .3 \quad$ Far-Field Drag Prediction and Decomposition . . . . . . . . . . . . . . . 25

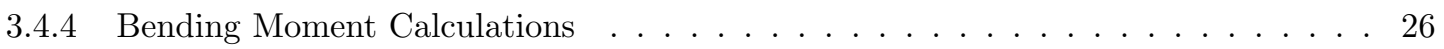

3.4 .5 Aero-elastic Effects on Wing Loading . . . . . . . . . . . . . . . . . . 27

3.4 .6 Low Speed Considerations . . . . . . . . . . . . . . . . . . . . . . 29

3.4 .7 Maneuver Load Alleviation $\ldots \ldots \ldots \ldots$. . . . . . . . . . . . 31

3.4 .8 Impact on Aircraft Structural Weight $\ldots \ldots \ldots \ldots \ldots$. . . . . . . . . 34

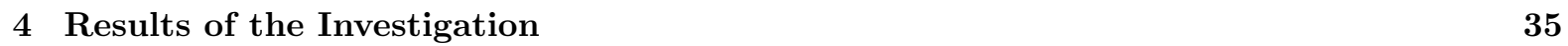

4.1 High Speed Design Space Exploration $\ldots \ldots \ldots$

4.1 .1 Optimum Drag . . . . . . . . . . . . . . . . . . . . . 35

4.1 .2 Drag Components $\ldots \ldots \ldots \ldots \ldots \ldots \ldots \ldots$

$4.1 .3 \quad$ Optimum Bending Moment . . . . . . . . . . . . . . . . . . . . . . . . . 40

$4.1 .4 \quad$ Optimum Drag with Constraint on Bending moment . . . . . . . . . . . . . . . . 40

4.2 Aero-elastic effects . . . . . . . . . . . . . . . . . . . . . . 46

$4.2 .1 \quad$ Aero-elastic Effects on Drag and Bending Moment . . . . . . . . . . . . . . . 46

$4.2 .2 \quad$ Aero-elastic Effects on Wing Loading . . . . . . . . . . . . . . . . . . . 47

4.3 Low speed characteristics $\ldots \ldots \ldots \ldots \ldots$

$4.3 .1 \quad$ Stall angle $\ldots \ldots \ldots \ldots \ldots \ldots$

$4.3 .2 \quad$ Maximum Lift Coefficient . . . . . . . . . . . . . . . . . . . . . . . 50

4.4 Maneuver Load Alleviation $\ldots \ldots \ldots$. . . . . . . . . . . . . . . . . 52

4.4 .1 Bending Moment Considerations . . . . . . . . . . . . . . . . 52

4.4 .2 Spanload Considerations $\ldots \ldots \ldots \ldots \ldots \ldots \ldots \ldots$

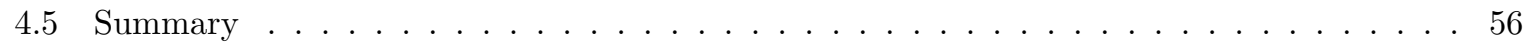

5 Conclusions and Recommendations $\quad 59$

5.1 Conclusions . . . . . . . . . . . . . . . . . . . . . . . . . . . . 59

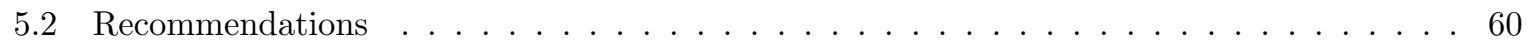

\begin{tabular}{ll}
\hline Bibliography & 64
\end{tabular} 


\section{List of Tables}

3.1 Loadcases under consideration for static aero-elastic trade studies . . . . . . . . . . . . 29

$4.1 \quad$ Aero-elastic effect on optimum toe-out winglets at Mach $0.85, C_{L} 0.45 \ldots \ldots$. . . . . 46

4.2 Aero-elastic effect on optimum toe-out winglets at Mach $0.90, C_{L} 0.3 \ldots \ldots$

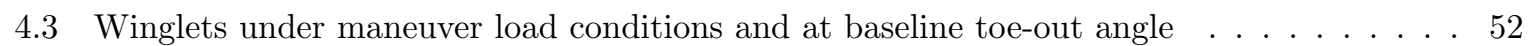

$4.4 \quad$ Wing-winglet loads and center of pressure at 2.5g symmetric maneuver conditions; $\Delta$ Cant $=0^{\circ} 55$

4.5 Wing-winglet loads at $2.5 \mathrm{~g}$ symmetric maneuver conditions; $\Delta$ Cant $=-40^{\circ} \ldots \ldots \ldots$

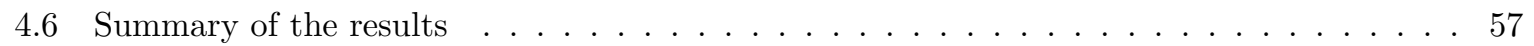




\section{List of Figures}

1.1 Comparison of aircrafts with and without winglets [1] . . . . . . . . . . . . 2

1.2 Four common wing shapes in birds (from left to right and top to bottom; (a) Elliptical or short, rounded wings in Gray hawk (b) Long pointed wings without slots in Falcon (c) Long narrow wing in Gull (d) Broad, slotted wings in Golden Eagle [2] . . . . . . . . . . . 4

$1.3 \quad$ A typical mission profile selected for the study $\ldots \ldots \ldots \ldots \ldots \ldots$

2.1 Velocity vectors in a cross flow behind a lifting wing $[3] \ldots \ldots \ldots$

2.2 Aerodynamic forces on a wing $[4] \ldots \ldots \ldots \ldots \ldots \ldots \ldots$

2.3 Vortex sheet rollup $[3] \ldots \ldots \ldots \ldots \ldots \ldots$

2.4 Drag polar showing dependence of drag components on speed. Published with permission

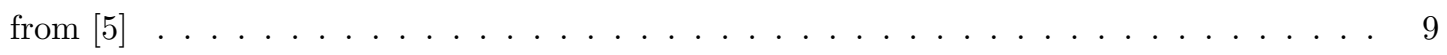

$2.5 \quad$ A selection of wingtip devices (a) wingtip fence (b) hybrid winglet (c) raked wingtip and (d) blended winglet . . . . . . . . . . . . . . . . . . . . 10

2.6 Basic winglet design parameters [6. Note that cant angle is measured from horizontal. This is opposite to the convention used in this report in which cant angle is measured

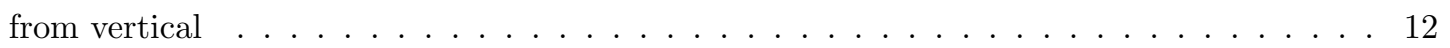

2.7 Wingtip detail with the servo and mechanism $([7] \ldots \ldots \ldots \ldots \ldots$

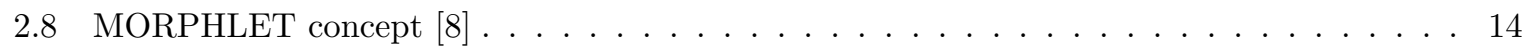

2.9 Experimental model of variable cant angle wingtip device in wind tunnel; left: both winglets planar; right: both winglets upright $([9] \ldots \ldots \ldots \ldots \ldots$

2.10 A variable height telescopic winglet $[10] \ldots \ldots \ldots \ldots \ldots$

2.11 Multiple actively controlled winglets fitted on a UAV [1] $\ldots \ldots \ldots \ldots$. . . . . 17

2.12 The bistable winglet concept proposed by Gatto et al. [12] . . . . . . . . . . . . . . . 17

2.13 The bistable winglet concept proposed by Kim et al. [13] . . . . . . . . . . . . . 18

3.1 The proposed modular morphing winglet to be fitted on the wingtip . . . . . . . . . . 21

$3.2 \quad$ Motion paths of proposed winglet to morph from one mission point to another. The arrow indicates the change in cant or toe-out . . . . . . . . . . . . . . . . 21

3.3 Surface mesh on the baseline winglet as seen from inboard wing . . . . . . . . . . . . . 23

3.4 Variation of cant angle for DOE-based trade studies. Cant angle is measured from vertical which is opposite of generally used convention in the literature. . . . . . . . . . . . . 24 
3.5 Variation of toe-out angle for DOE-based trade studies (Green: $\Delta T o e=+3^{\circ}$, Red: $\Delta T o e=0^{\circ}$, Blue: $\left.\Delta T o e=-4^{\circ}\right)$. Flow direction is into the plane of the paper. . . . . . . . . . 24

3.6 Control volume for a immersed body in a flowstream $14 . \ldots \ldots \ldots . \ldots . . \ldots 25$

$3.7 \quad$ Flowchart depicting the procedure used in aero-elastic studies $\ldots \ldots \ldots \ldots$

$3.8 \quad$ Pressure difference rule for maximum lift [15] $\ldots \ldots \ldots \ldots \ldots \ldots$

3.9 Prediction of onset of stall for baseline winglet at Mach 0.2 using Valarezo method. Red

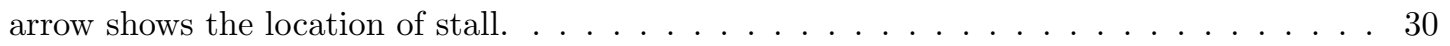

3.10 Prediction of onset of stall for low cant winglet $\left(\Delta\right.$ Cant of $\left.-40^{\circ}\right)$ at Mach 0.2 using Valarezo method. Red arrow shows the location of stall. . . . . . . . . . . . . . . 31

3.11 Pressure contour and velocity streamlines with increasing angle of attack. Increasing angle \begin{tabular}{|c|}
\hline of attack from left to right; top to bottom. Note that $C_{p}$ values are not shown due to \\
\hline
\end{tabular}

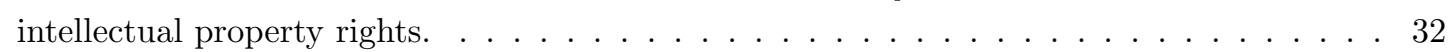

3.12 Flight Maneuvering Envelope as Outlined in Code of Federal Regulations [16] . . . . . . . 32

3.13 Lift distribution with and without MLA at same load factor [17] . . . . . . . . . . . 33

4.1 Comparison of total drag at high speed conditions $\ldots \ldots \ldots \ldots$

4.2 Drag components and total tail-off drag at Mach $0.85, C_{L} 0.45$ and $\Delta$ Cant $=0^{\circ}$. Note

that viscous drag is shown on the right axis. Whereas wave drag, induced drag and total

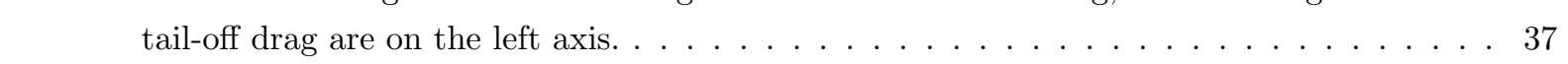

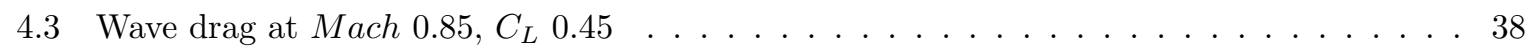

$4.4 \quad$ Induced drag at Mach $0.85, C_{L} 0.45 \ldots \ldots \ldots \ldots \ldots \ldots \ldots \ldots$

4.5 Viscous drag at Mach $0.85, C_{L} 0.45 \ldots \ldots \ldots \ldots \ldots \ldots \ldots$

$4.6 \quad$ Trim drag at Mach $0.85, C_{L} 0.45 \ldots \ldots \ldots \ldots \ldots \ldots \ldots$

$4.7 \quad$ Wing bending moment $(W B M)$ at high speed conditions $\ldots \ldots \ldots \ldots \ldots$. . . . . . . . . . .

4.8 Winglet bending moment $(W L E T B M)$ at high speed conditions $\ldots \ldots \ldots$. . . . . . . 42

4.9 Total drag with and without $W B M$ constraint; Mach=0.85, $C_{L}=0.45 \ldots \ldots$. . . . . 43

4.10 Total drag with and without $W B M$ constraint; Mach=0.90, $C_{L}=0.30$. . . . . . . . 43

$4.11 C_{p}$ contours for various winglet configurations at baseline toe-out angle. Top: Mach 0.85 ,

\begin{tabular}{|c|c|}
\hline$C_{L} 0.45$, Bottom: Mach 0.90, $C_{L}$ 0.30. Increasing cant from left to right. The darker \\
\hline
\end{tabular} regions in the contour plots indicate higher loading . . . . . . . . . . . . 44

$4.12 C_{p}$ contours for various winglet configurations at baseline cant angle. Top: Mach 0.85 ,

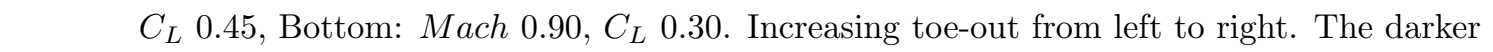
regions in the contour plots indicate higher loading . . . . . . . . . . . . 45

4.13 Comparison of normal force between rigid and elastic winglets at Loadcase L2 . . . . . . 48

4.14 Comparison of wing twist at various spanwise positions at Loadcase L2 $\ldots . \ldots$

4.15 Aeroelastic effect on low cant and high cant winglets compared with baseline winglet . . . 49

4.16 Stall characteristics for low cant to high cant winglet at Mach $0.2 \ldots \ldots$. . . . . 50

4.17 Stall characteristics for optimum toe-out winglets at Mach $0.2 \ldots \ldots$. . . . . . . 51

4.18 Variation of maximum lift coefficient $C_{L_{\max }}$ with winglet design parameters $\ldots . . .551$

4.19 Wing root bending moment relief due to load vector [18] . . . . . . . . . . . . . 52 
4.20 Wing-winglet deformation under $2.5 \mathrm{~g}$ symmetric maneuver load. Higher cant winglet deforms more than lower cant winglet under the same load. . . . . . . . . . . . . . . . 53

4.21 Spanload distribution for both rigid and elastic wing under $2.5 \mathrm{~g}$ maneuver conditions. . . 54

4.22 Closer look at spanload distribution on the inboard wing under 2.5g maneuver load. . . . 54

4.23 Effect of increasing toe-out on spanload distribution at $\Delta$ Cant $=0^{\circ} \ldots \ldots \ldots$. . . . 55

4.24 Effect of increasing toe-out on spanload distribution at $\Delta C a n t=-40^{\circ} \ldots \ldots \ldots$. . . . 56

4.25 Drag vs. wing bending moment diagram $\ldots \ldots \ldots \ldots \ldots \ldots$

4.26 A typical mission profile with best winglet configurations $\ldots \ldots \ldots \ldots$ 


\section{List of Symbols}

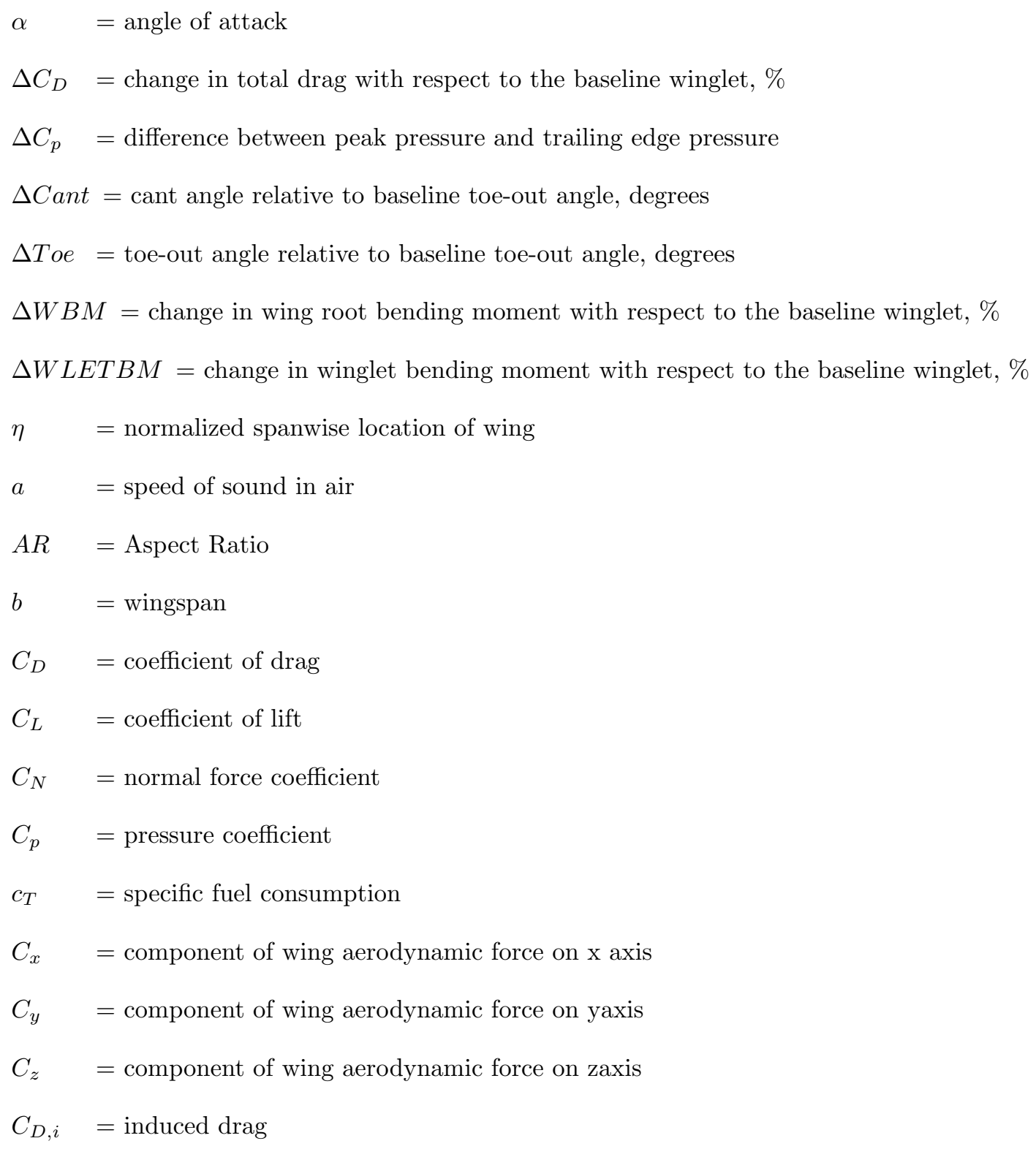




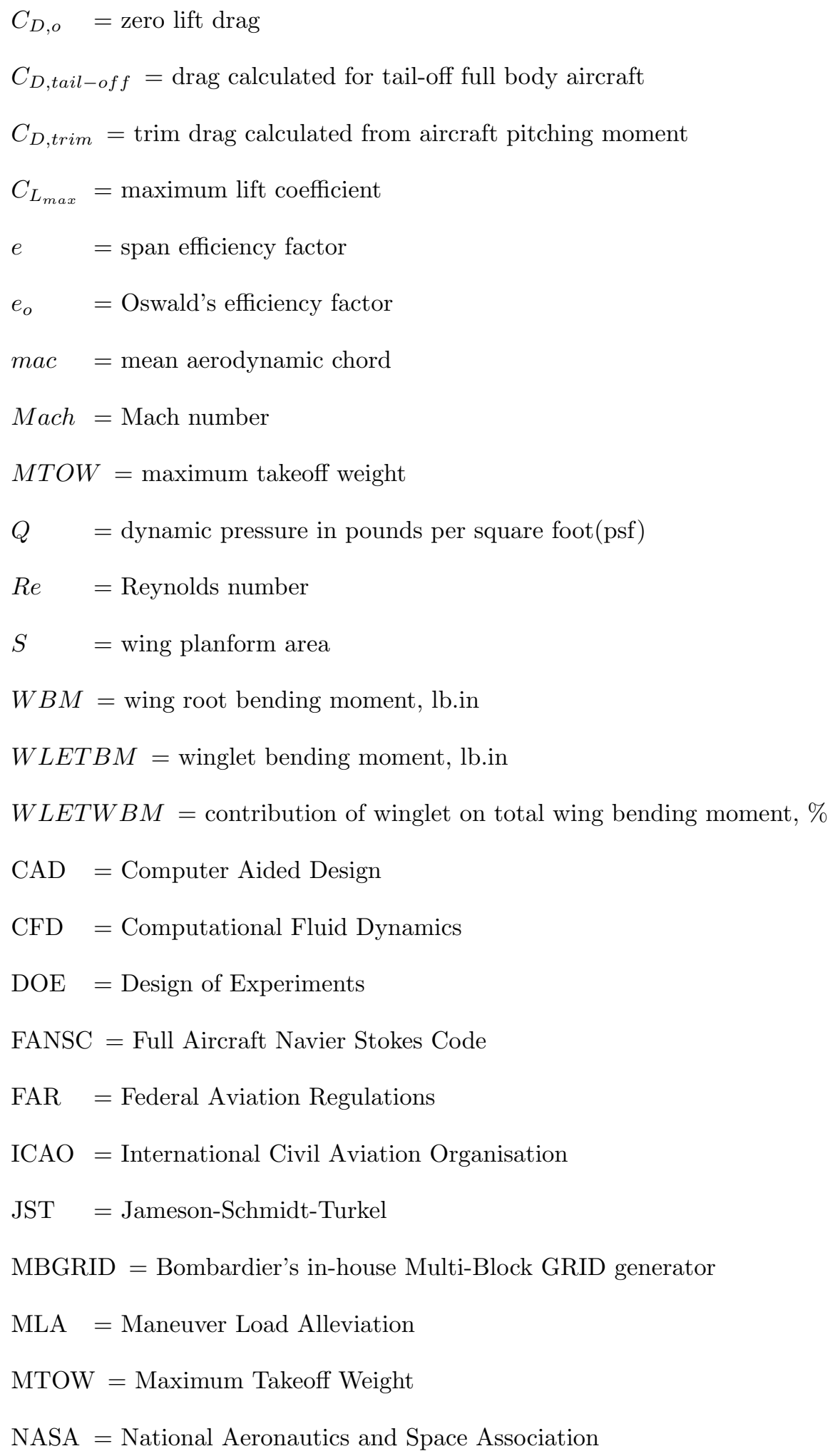




\author{
RANS $=$ Reynolds-Averaged Navier-Stokes \\ SAR $=$ Specific Air Range \\ TRL = Technology Readiness Level \\ UAV = Unmanned Aerial Vehicle
}




\section{Chapter 1}

\section{Purpose and Organisation}

\section{$1.1 \quad$ Introduction}

ICREASING fuel prices demand highly fuel efficient aircrafts in today's economy. Designers and re-

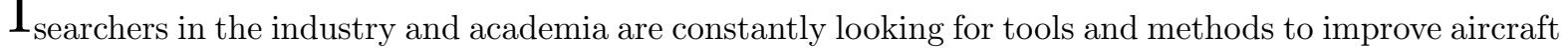
performance and fuel efficiency. Apart from enhancing proplusion efficiency, one of the effective ways of reducing fuel consumption is by reducing total aircraft drag thereby improving aerodynamic efficiency without compromising aircraft structural integrity. This is directly beneficial to the airline operators as this ensures more frequent flights with reduced fuel usage. This could also benefit the passengers by potentially reducing airline fares. One of the most widely visible method in enhancing aerodynamic efficiency in recent days is the use of wingtip devices. Although there are several types of wingtip devices and they function in different ways, their purpose is to reduce drag experienced by the aircraft by partially recovering the tip vortex energy.

Winglet is one of the wingtip devices that has shown to serve this purpose of reducing fuel consumption. First introduced by Richard Whitcomb at NASA's Langley research center [19], winglets are traditionally used as upward swept or canted extensions to the wing. Winglets have shown a range of benefits to the designers, researchers and ultimately to airline operators. The potential benefits are but not limited to improved takeoff and climb performance, reduced fuel consumption and increased payload range. Reduced fuel consumption also translates to reduced pollutant emissions which contributes to realizing a sustainable aviation industry.

Another significant improvement in winglet design is the introduction of blended winglet which is a technology first patented by Dr. L. B. Gratzer of Aviation Partners Inc. Gratzer describes blended winglet as a wing-like device comprising a blended lifting surface attachable to each airplane wingtip so as to achieve minimum induced drag for a given surface size [20]. When designing a wingtip device, one of the most important considerations is the flexibility and ease of retrofitting it into already existing wings in service. A blended winglet serves this purpose as it requires fewer changes to the wing structure. A well designed blended winglet allows for the chord distribution to change smoothly from the wingtip 
to the winglet, which optimizes the distribution of the spanload lift and also minimizes any aerodynamic interference or airflow separation. Figure. 1.1(a) shows the difference in strength of wingtip vortices between the blended winglet and conventional wingtip. It is clear that the blended winglet reduces the strength of the vortex which in turn reduces drag. In addition, Fig. 1.1(b) shows comparison of lift profiles across the wingspan as seen in Boeing 737 technical guide [1. The blended winglet shows higher spanload at the outboard wing compared to the aircraft with no winglet, thereby suggesting more lift near the wingtip.

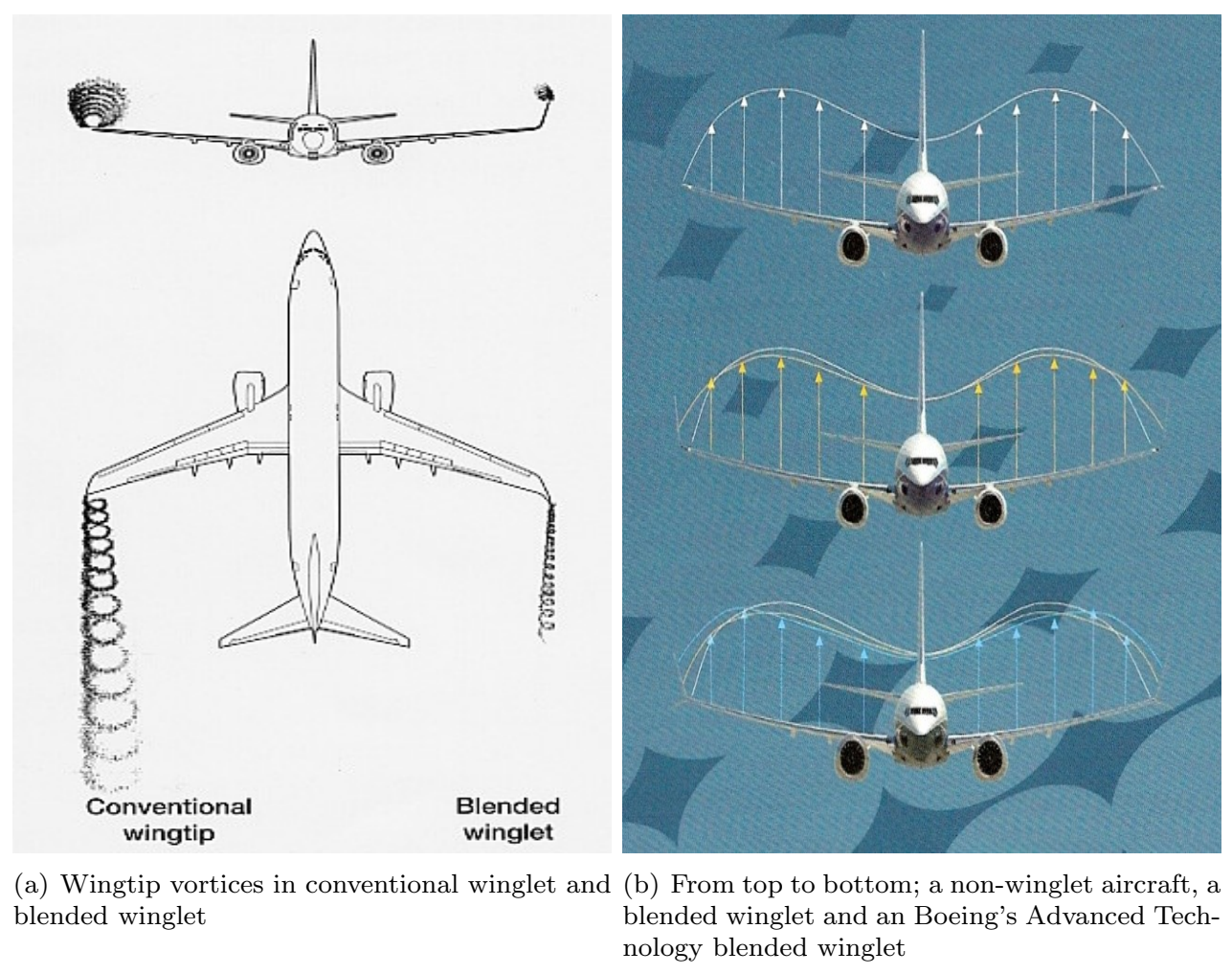

Figure 1.1: Comparison of aircrafts with and without winglets [1]

Although winglets provide optimum drag reduction and improved lift-to-drag ratio under cruise flight conditions, they may not provide optimal performance and/or fuel efficiency during non-cruise mission segments, such as during climbs, takeoffs and landings. Since non-cruise conditions generally make up significant portions of a flight, maximum overall efficiency and performance may not be realized by such winglet designs [21. As such, a winglet that can change its shape or morph as per mission requirements has the potential for much improved performance compared to conventional winglet. Hence, several approaches to such winglets capable of changing their shape, size or form have been investigated by researchers.

Morphing winglets have potential for a multitude of benefits. Airline operators and designers may benefit from task-specific morphing winglet design such as mitigating aircraft's wake turbulence so as to 
allow closer spacing of aircrafts during landing and takeoff, improving dynamic characteristics such as flutter behavior, controlling shock wave formation/propagation and rapidly changing aircrafts rates of yaw and roll [7. Morphing winglets that can be folded can also permit span increases while conforming with ICAO gate clearance requirements. A morphing winglet concept presented by [8] demonstrated 4-5\% improvement in specific air range. Morphing winglets are also seen as promising alternatives to conventional control surfaces [22]. A morphing winglet concept based on telescopic variable height wingtip device showed significant reduction in fuel consumption in cruise, climb and descent and overall reduction in global warming potential through reduction in carbon dioxide emissions by $12,600 \mathrm{~kg}$ per flight [10. Other notable morphing winglet solutions seen in the literature are variable sweep winglet [23] and active multiple winglets [11].

\subsection{Motivation}

Birds are undoubtedly excellent flyers. They are able to manipulate the shape and size of their wings and feathers to make their flight as efficient as possible. Manipulating wings and feathers during flight adjusts wind forces depending on the demand of flight conditions. Bio-mimicking, a term used for mimicking elements of nature, is hence becoming a very important aspect of wing design. There are four common wing shapes in birds as depicted in Fig. 1.2 They are (1) elliptical wings, (2) high-speed wings, (3) passive soaring and (4) active soaring [2]. They all serve specific purpose as their names suggest.

Elliptical or short, rounded wings allow for fast takeoff speeds, sprinting ability, and great manoeuvrability. These are found in forest and ground-living birds, especially pheasants, doves, woodpeckers and the true hawks. Long pointed wings without slots give high speed and fast, level flight. These wings are found on birds that rely on high speed to feed in the air, such as swifts, swallows, and falcons. Long, narrow wings allow high speed gliding in the strong winds and help birds take advantage of short spurts of updrafts. These high aspect ratio wings are characteristic of soaring sea birds such as gulls and albatrosses. Broad, slotted wings are best for soaring and gliding. Birds with these types of wings include hawks, eagles, and vultures [2. Careful study and consideration of bird's wing and various aspects of their flight can help us design wings with improved aerodynamic efficiency.

\subsection{Purpose of the Research}

Although advanced design methodologies are applied to generate optimal winglet designs, the design of conventional static winglets involves compromise between the performance requirements at low speed, high lift coefficient climb/descent mission segment and high speed, low lift coefficient cruise mission segment [6]. The resulting design may offer sub-optimal performance at a specific mission point compared to a winglet designed specifically for that mission point. The winglet designs that have the potential to provide the best performance for specific mission segments are explored in this paper by mapping the winglet design space.

The purpose of this research is to conduct aerodynamic analysis of such a winglet that is able to 


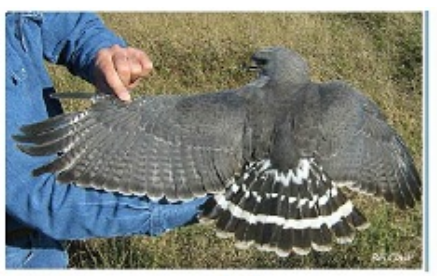

(a)

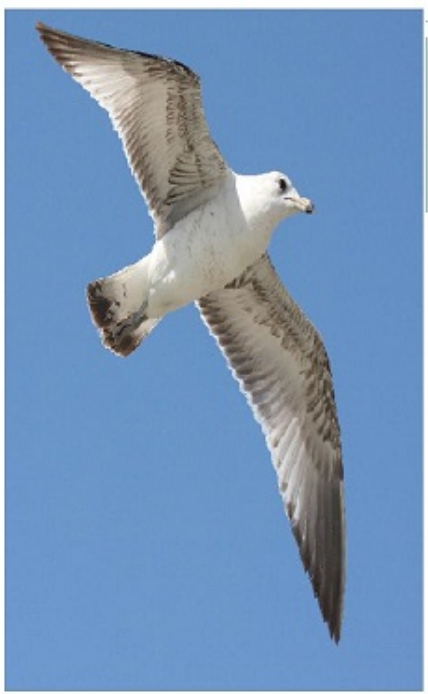

(c)

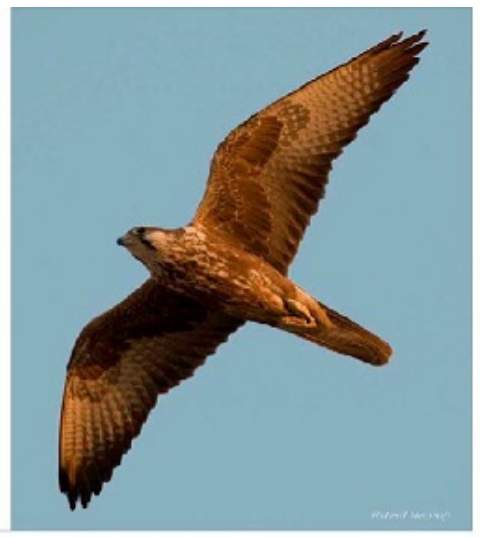

(b)

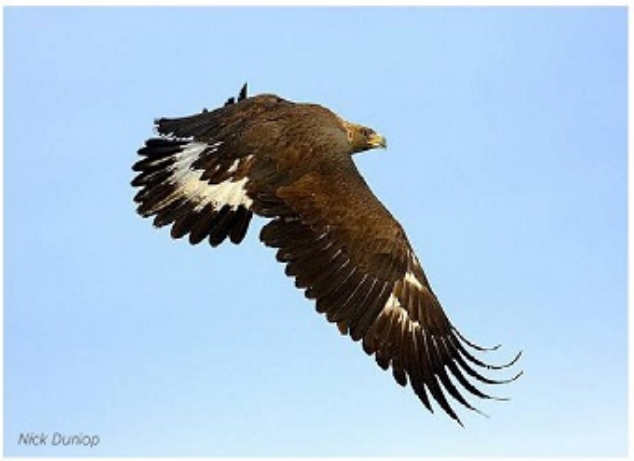

(d)

Figure 1.2: Four common wing shapes in birds (from left to right and top to bottom; (a) Elliptical or short, rounded wings in Gray hawk (b) Long pointed wings without slots in Falcon (c) Long narrow wing in Gull (d) Broad, slotted wings in Golden Eagle [2]

use two levers (cant angle and toe-out angle) for morphing capabilities. The report includes findings from high speed and low speed design space exploration studies for a production winglet on a research aircraft. The potential of using morphing winglet for maneuver load alleviation (MLA) is also explored. The impact of these studies on the design and selection of morphing winglet actuation mechanism is highlighted. The lessons learned is expected to be influential in wind tunnel tests and in efffective design of structure and kinematic mechanism for morphing winglet.

In order to quantify the overall impact of morphing winglet on a typical aircraft mission, a mission profile from takeoff to landing is selected as shown in Fig. 1.3. The primary purpose of this research is to determine the best winglet configuration in each of these mission points. With those results in hand, it is possible to find overall drag, fuel and weight benefits of using morphing winglet over conventional static winglets. 


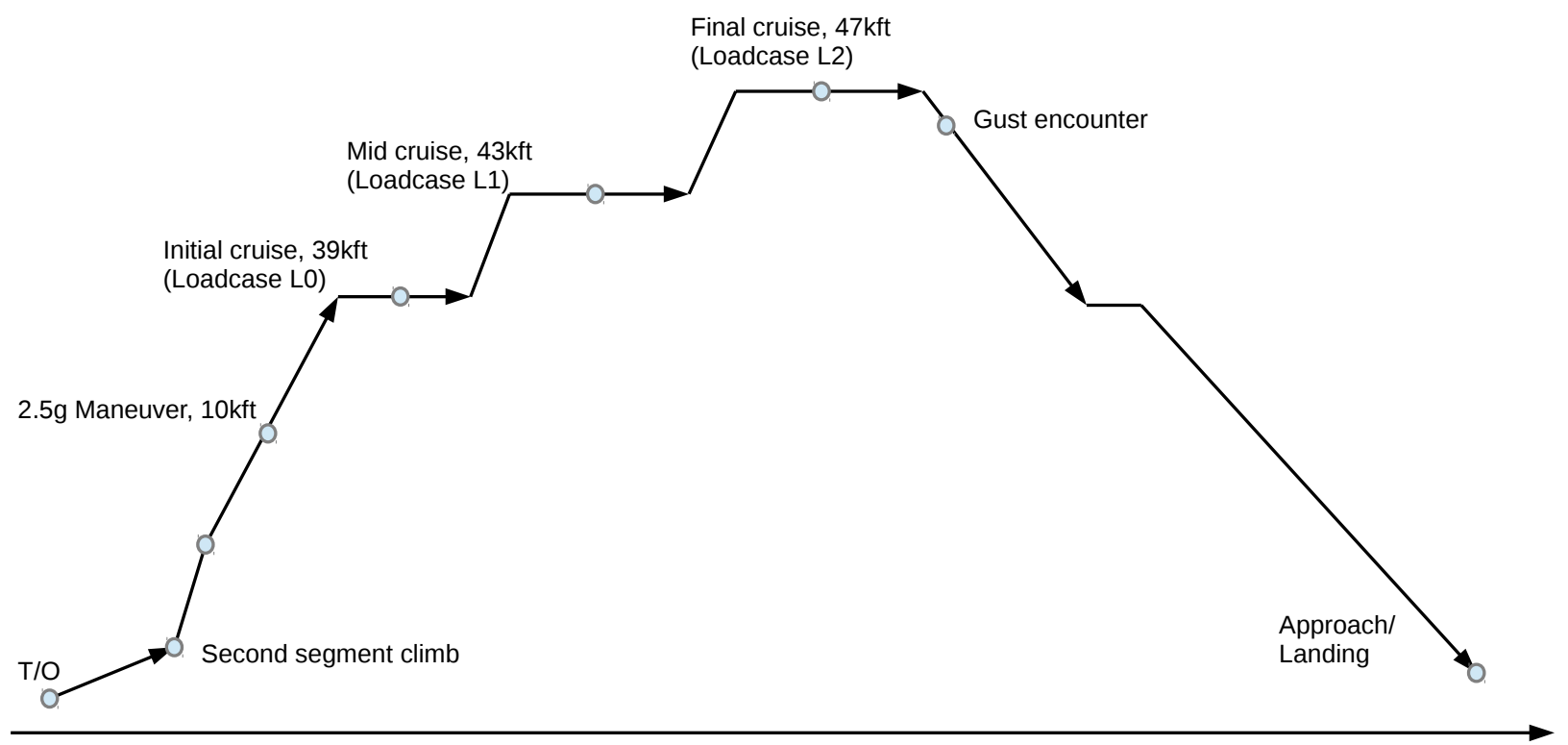

Figure 1.3: A typical mission profile selected for the study

\subsection{Scope of the study}

The study is focused on a Bombardier research aircraft. The results obtained in this research work are limited to the specific aircraft under consideration but the trend observed in the results is considered valid for any aircraft designed today.

In addition, all but two mission points from the mission profile depicted in Fig. 1.3 are considered for the study. Second segment climb and gust encounter are not included in this research work due to limitations in time and resources.

\subsection{Assumptions}

The grid independence study for computational fluid dynamics (CFD) work has already been conducted for the aircraft under consideration and no such work is necessary for the purpose of this thesis.

Next assumption is that the wing and winglet move together under aeroelastic loads. This doesnot 
give accurate results for winglet deformations (twist and bending) but the results are considered accurate enough for this research work.

\subsection{Organisation of Thesis}

The thesis is organized into five different chapters as follows:

Chapter 1 introduces the thesis objectives, motivation and purpose of the thesis work. The scope of the research project and any assumptions made during the thesis work are also highlighted.

Chapter 2 gives readers a brief survey on current and historical morphing technology in general and morphing winglet related research work from industry and academia. This chapter also highlights state of the art current morphing winglet related patents and designs along with challenges associated with them.

Chapter 3 gives details on proposed research methods and problem formulations. This chapter introduces baseline winglet and touches upon the mode of winglet manipulation along with the significance of optimal morphing path. This chapter also introduces the equations used in the calculations and the procedure of calculating structural weight benefit by using total drag benefit.

Chapter 4 highlights the results from high speed design space exploration, aero-elastic effects on these results. The chapter also includes results from low speed design space mapping exercise and maneuver load alleviation. The dependence of design loads and center of pressure on the design variables are also highlighted.

Finally, chapter 5 concludes the thesis by discussing the implications of the results obtained in this study. Possible future work related to morphing winglet are also presented in this chapter. 


\section{Chapter 2}

\section{Literature Review}

\section{$2.1 \quad$ Introduction}

In an aircraft, lift is generated due to pressure difference between the upper surface and lower surface of the wing. The lift force causes a large-scale air motion mostly on the wing. Figure. 2.1 shows flowfield that a lifting surface causes when it passes through the atmosphere. The flowfield is shown in terms of velocity vectors in a crossflow plane behind a lifting wing. There is circulation around the wingtips, downward flow in the area between the wingtips and upward flow outboard of the tips. This flow pattern reaches full strength at a distance of about one wingspan behind the wing and tends to persist over a very long distance downstream. This is associated with shedding of vortex sheet from the trailing edge of the wing and rolling up that vortex sheet into distinct vortex cores downstream. The downwash in between the wingtips results into tilting of the lift vector. The backward component of this apparent lift is felt as induced drag [3]. The aerodynamic forces including the induced drag component on a three dimensional wing are illustrated in Fig. 2.2 .

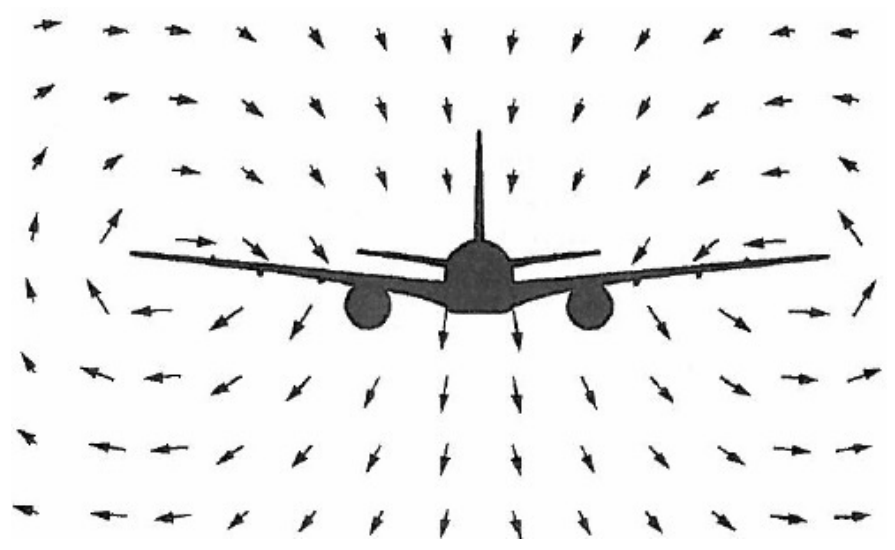

Figure 2.1: Velocity vectors in a cross flow behind a lifting wing [3] 


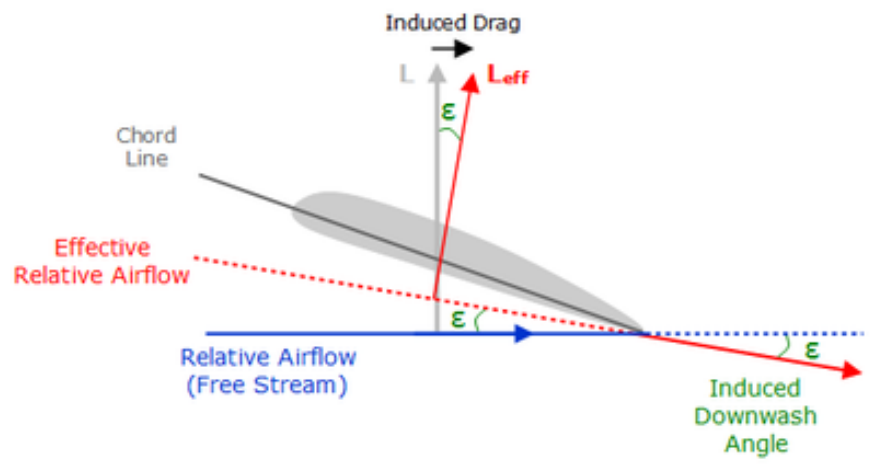

Figure 2.2: Aerodynamic forces on a wing [4]

The conservation laws of fluid mechanics dictates that the wing cannot produce the flow pattern of Fig. 2.1 without also producing a jump in spanwise velocity. The jump in velocities between the upper and lower surface flow form a shear layer after the trailing edge. The shear layer in the wake rolls up into distinct vortex cores as shown in the Fig. 2.3. The kinetic energy in rollup is related to the induced drag.

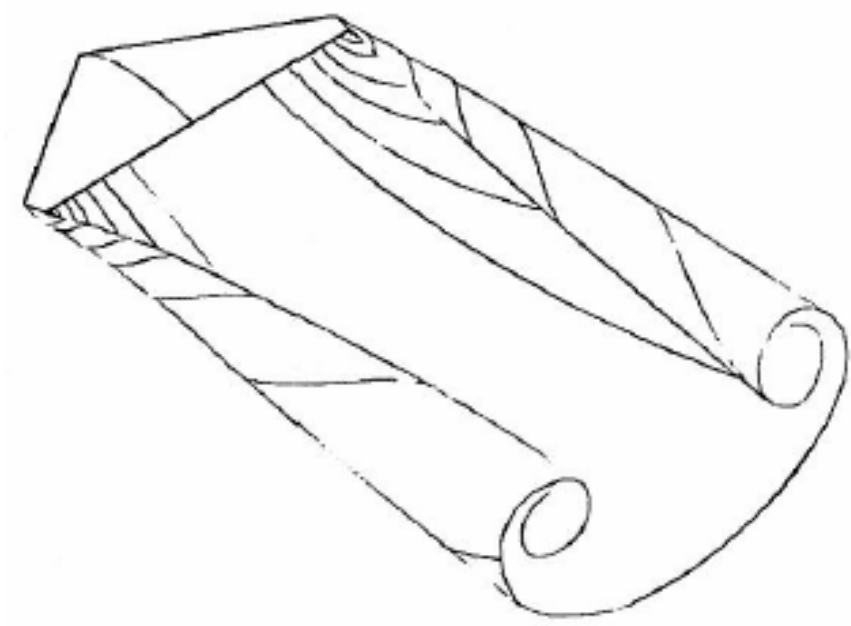

Figure 2.3: Vortex sheet rollup [3]

The induced drag of a lifting system (i.e. the wing and the wingtip device) can be calculated with reasonable accuracy using the classic "Trefftz plane theory." According to this theory, the induced drag of an aircraft wing depends only on the trailing edge trace (i.e., the "Trefftz-plane geometry") of the lifting system and the spanload. Adding a tip device to a wing changes both the trailing edge trace and the spanload which in turn changes the induced drag on the wing [24].

The magnitude of induced drag coefficient depends on the lift produced by the wing as shown by the 
following equation:

$$
C_{D, i}=\frac{C_{L}^{2}}{\pi \cdot A R \cdot e}
$$

where $A R$ is the aspect ratio and is defined by square of span $b$ divided by wing planform area $S$ and $e$ is span efficiency factor. $C_{L}$ is lift coefficient.

$$
A R=\frac{b^{2}}{S}
$$

The total drag coefficient is given by the following equation:

$$
C_{D}=C_{D, o}+\frac{C_{L}^{2}}{\pi \cdot A R \cdot e_{o}}
$$

where $e_{o}$ is Oswald's efficiency factor which represents the change in drag with lift or angle of attack of a three-dimensional wing, as compared with an ideal wing having the same aspect ratio and an elliptical lift distribution [25.

In cruise, induced drag can account for as much as $33 \%$ of the total drag [26. It's even higher at lower speed as depicted by the drag polar in Fig. 2.4 [5].

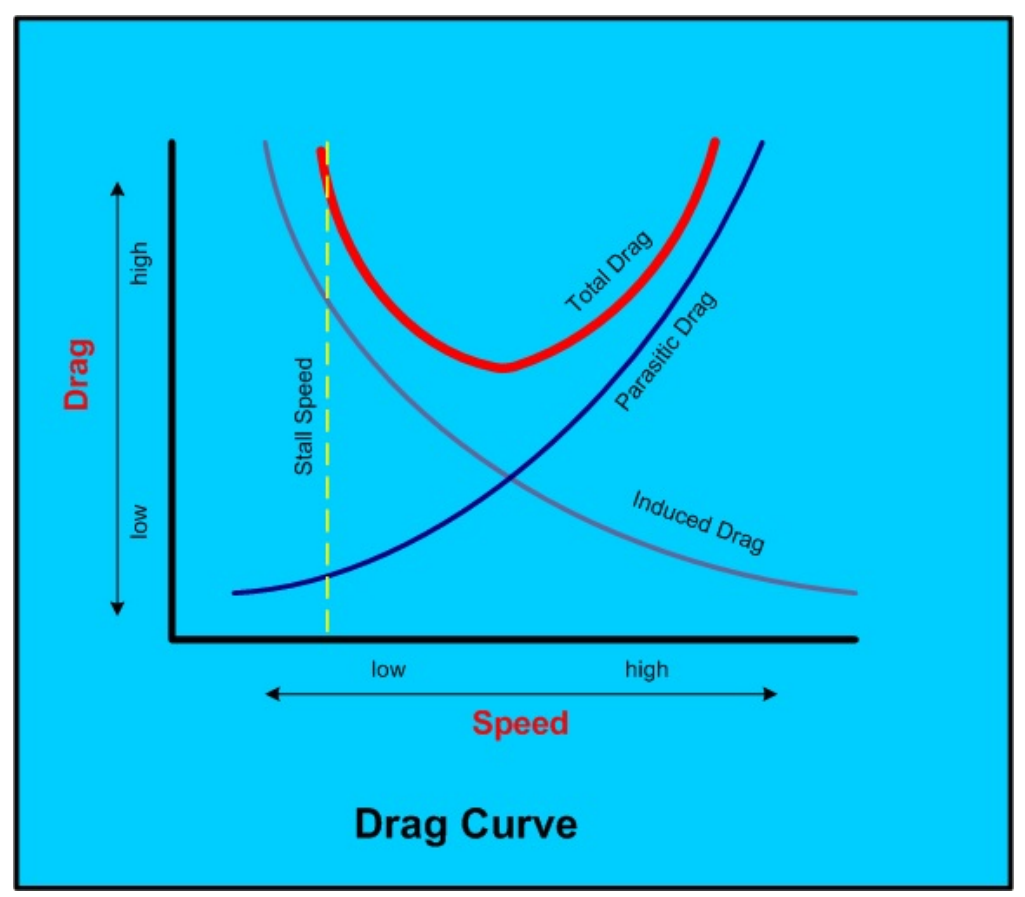

Figure 2.4: Drag polar showing dependence of drag components on speed. Published with permission from [5]

Various techniques have been investigated by researchers and designers to minimize the lift induced drag and increase aerodynamic efficiency. These techniques include the following: 
1. Increasing the wing aspect ratio: Increasing the wing aspect ratio has an effect to reduce induced drag $D_{i}$ as shown by the following relation:

$$
D_{i}=\frac{L^{2}}{\frac{1}{2} \cdot \rho_{o} \cdot V_{e}^{2} \cdot S \cdot \pi \cdot e \cdot A R}
$$

where $L$ is lift and $V_{e}$ is equivalent airspeed. A higher aspect ratio wing has lower maximum cruise speed due to structural limitations. Also, since high aspect ratio has larger surface area exposed to the air, it results into higher parasite drag. Other limitations are issues with ground handling, gate clearance, taxiways etc.

2. Use of wingtip devices: The wingtip devices include classic winglet (Whitcomb), blended winglet, endplates, raked wingtips, wingtip fence and sails, Hoerner tips, spiroid tips, wing grid etc. A selection of wingtip devices are shown in Fig. 2.5. Addition of wingtips requires strengthening the wing resulting into increase in aircraft weight compared with the wing without winglet. But a carefully designed wingtip has demostrated improved overall aircraft performance.

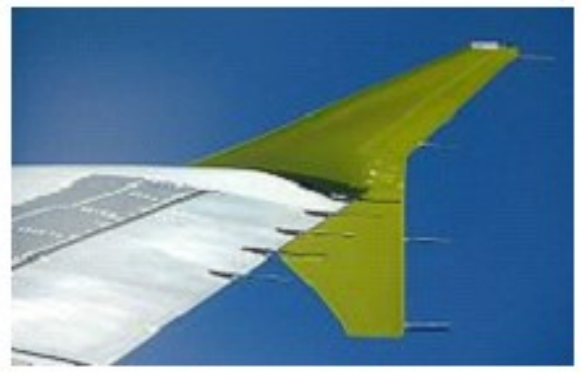

(a)

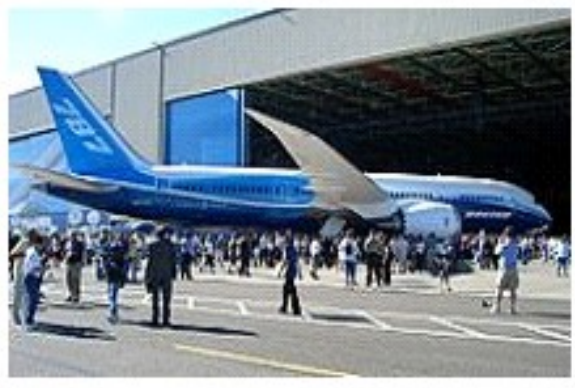

(c)

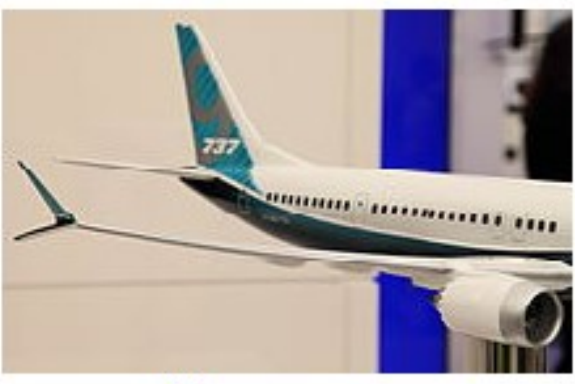

(b)

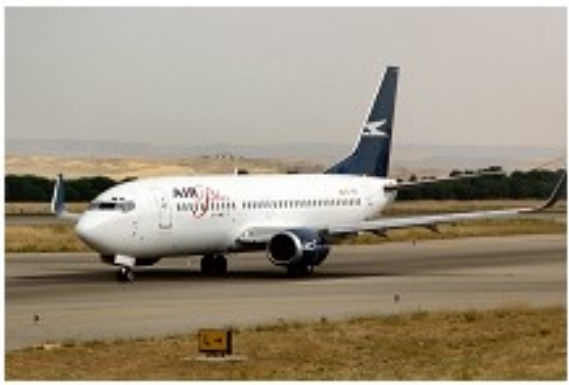

(d)

Figure 2.5: A selection of wingtip devices (a) wingtip fence (b) hybrid winglet (c) raked wingtip and (d) blended winglet

Besides induced drag, there are other sources of drag such as viscous drag and wave drag. Viscous drag is due to air flowing on the surface of an aircraft. This drag arises from the tendency of fluid 
medium to resist one layer of fluid past another. It is also due to viscosity that the fluid layer close to the surface of aircraft tends to stick to the surface creating a thin layer of fluid called boundary layer. Viscous drag is simply the result of the total viscous friction force over the aircraft.

Wave drag arises from the compressible nature of the flow. When an aircraft is flying at transonic speed or at the speed of sound, it catches up with the pressure waves of its own creation and then turns these pressure waves into shock waves. These shock waves result into high drag and are also responsible for slowing down the aircraft. Wave drag is associated with the energy lost in compressing the flow through shock waves.

In summary, the total drag depends on the size, shape and surface roughness of the aircraft. The amount of drag also depends upon aircraft speed, wing aspect ratio and density of the flow medium.

\subsection{Classical Winglet Design}

Winglets were introduced as upward swept extensions to the wing by Richard Whitcomb at NASA's Langley research center [19]. In his NASA technical note paper, he presented the design considerations of these winglets and their effects on the aerodynamic forces, moments, and loads near the design conditions for a representative first-generation, narrow-body jet transport wing. These results for winglets were also compared with the results for wingtip extension which resulted in approximately the same increase in bending moment at the wing-fuselage juncture as did the addition of the winglets. For the configuration investigated, winglets reduced induced drag by about $20 \%$ with a resulting increase in wing lift-to-drag ratio of roughly $9 \%$ for the design Mach number of 0.78 and near the design lift coefficient.

The basic winglet design parameters are shown in Fig. 2.6. Classical winglet design, such as the one employed by Whitcomb, is a trade-off between aerodynamic efficiency and structural weight or induced drag and viscous drag. It often is also a trade-off between low speed and high speed characteristics with reasonably light weight struture. In other words, the objectives of reducing drag, reducing weight, and reducing complexity (hence manufacturing and maintenance costs) are often in conflict. Adding wingtip extensions can reduce the drag of a given airplane, but will usually require increasing the structural weight. Weight increases are due to the weight of the wingtip extension member and also due to strengthening required of the existing wing structure in order to support the increased bending moments exerted by the wingtip extension member.

Balancing all these factors lead to a winglet design that offers compromised performance at offdesign conditions. As such, conventional static winglets do not provide the best possible aerodynamic performance for all mission segments. In high speed cruise, a simple wing span extension may provide the best aerodynamic efficiency whereas, during a high g maneuver, a strategically positioned winglet could potentially help alleviate maneuver load. With a morphing winglet, it will be possible to orient the winglet with respect to free stream as per mission point requirements. 

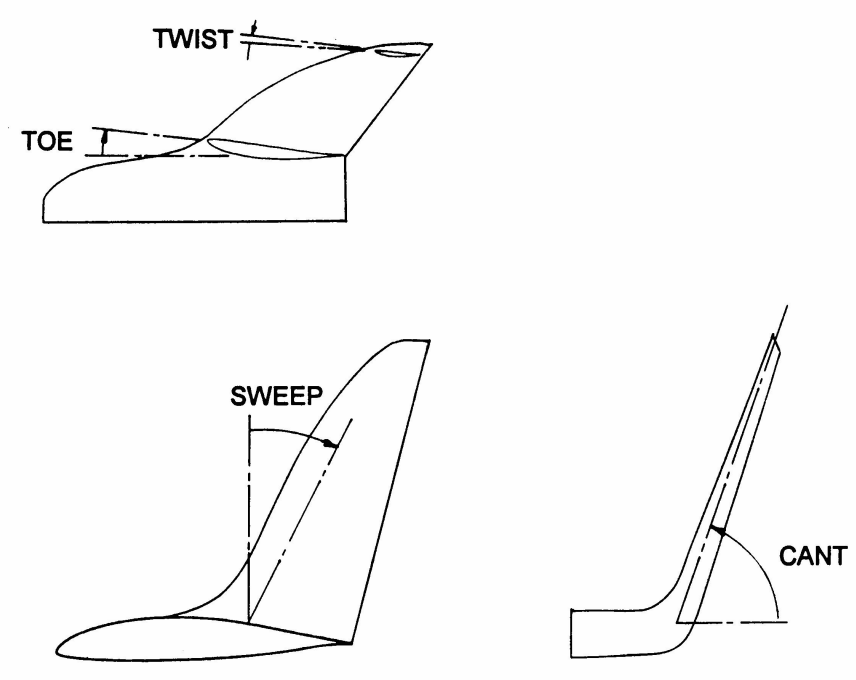

Figure 2.6: Basic winglet design parameters [6]. Note that cant angle is measured from horizontal. This is opposite to the convention used in this report in which cant angle is measured from vertical

\subsection{Morphing Technology}

Morphing technology has been utilized in aircrafts dating as far back as the time when Wright brothers used their aircraft wing that twisted in a way like a bird's wings for controlled flight. Technologies like leading edge slats and flaps have been used for a long time to increase lift by changing the effective camber of the wing. Retractable landing gears are used to reduce drag. Air brakes and spoilers are used to increase drag and swing wings (variable-sweep) are used to change planform area and aspect ratio. However, the drawbacks of these morphing methods are often increased structural weight, complexity and aerodynamic inefficiencies in off-design conditions.

Since the first aircraft by the Wright brothers, morphing wing technologies have been used in aircrafts in different forms. Most aircrafts alter camber, sweep, span, chord, twist individually or in combination in order to achieve suitable wing configuration for a particular flight. The morphing aircraft technologies today are used to improve aircraft performance, expand its flight envelope, replace conventional control surfaces, reduce drag to improve range and reduce vibration or flutter [27].

Morphing technology has also been used in wind turbine applications in order to increase the overall performance of the wind turbines [28]. In particular, morphing trailing edge flaps were introduced with a potential to create structures that have conflicting ability of being load carrying, lightweight and shape adaptive. The wind turbines with these morphing flap designs are able to undergo large deflections and high strains. Morphing technology has also been used in supersonic missiles by Jian-guo et al. [29]. By establishing a mathematical model of guidance system of the missile according to its aerodynamic characteristics, they were able to demonstrate improved guidance precision for this anti-aircraft missile with the morphing wings within limited morphing angle under supersonic velocity. 


\subsection{A Survey of Morphing Winglet}

\subsubsection{Project SMORPH}

A morphing wingtip mechanism concept similar to the concept studied in this thesis work was introduced by researchers at Instituto Superior Tecnico and is based on a servo-actuated articulating winglet. The winglet toe-out and cant angle can be controlled independently by servo-actuators as shown in Fig. 2.7 [7].

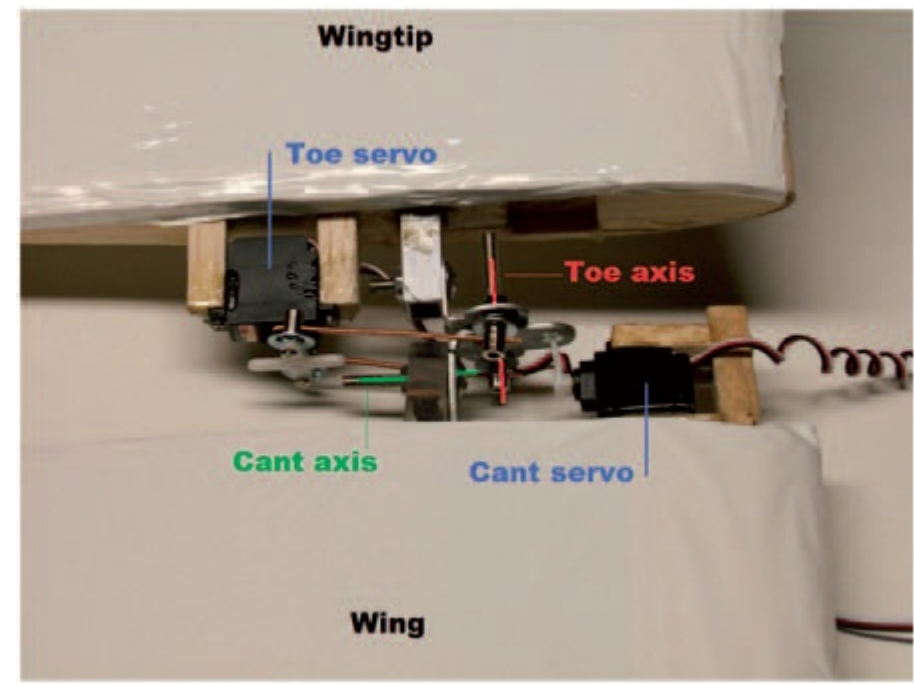

Figure 2.7: Wingtip detail with the servo and mechanism ([7]

The performance metrics for a multi-mission UAV equipped with morphing wingtip showed that morphing wingtip outperforms fixed wingtip by upto $25 \%$. The experimental and computational work showed improvement in climb performance, stall characteristics, range, endurance and fuel consumption and extended aircraft flight envelope. They demonstrated a major improvement in stall speed due to adaptive wingtip and claimed subsequent reduction of takeoff ground roll by $20 \%$ and also demonstrated $4 \%$ drag reduction at maximum speed.

\subsubsection{MORPHing WingLET (MORPHLET)}

Ursache et al. investigated the MORPHing wingLET concept to enhance the flight performance of narrow body aircraft $[8]$. The MORPHLET system consisted of four partitions at the outboard region of the wing as shown in Fig. 2.8(a). The cant, twist, and span of each partition were adjusted to maximize the vehicle performance across the entire flight envelope. Low-fidelity tools, Tornado and WEIR (wing equivalent in-plane representation) were used for a multidisciplinary design optimization study in an attempt to maximize specific air range at three different points of the flight envelope: start of initial cruise, start of final cruise, and end of descent. 


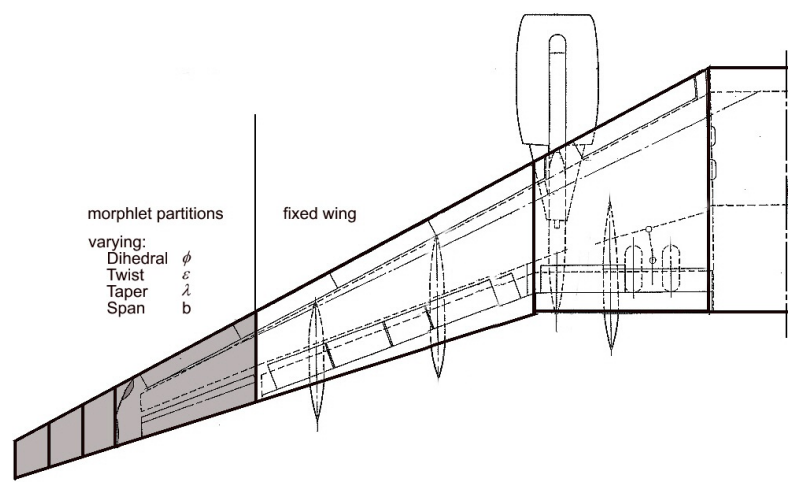

(a) Wing planform schematic of baseline and MORPHLET

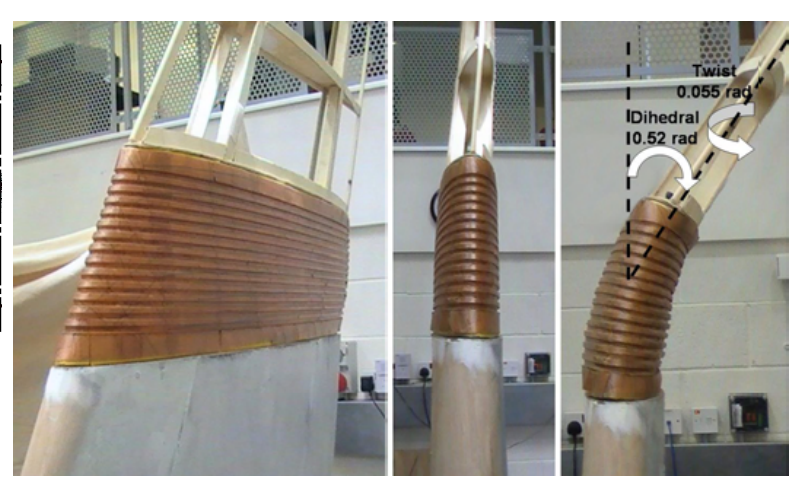

(b) Rolled out and canted MORPHLET mechanical demonstrator

Figure 2.8: MORPHLET concept [8]

A mechanical prototype of the MORPHLET concept was also designed, built, and tested for bending and torsion [30. The mechanical demonstror is depicted in Fig. 2.8(b). As shown in the figure, a corrugated skin was incorporated to allow the relative displacement of the MORPHLET partitions. The use of compliant materials and structures technology to change the shape, trim and incidence angle of winglets during flight was also investigated.

Smith et al. developed a multidisciplinary optimization suite to investigate the potential gains of retroactively fitting a MORPHLET wing system comprising of two outer partitions replacing the aileron and outboard section of the wing [31. The optimization studies demonstrated that the morphing system not only provides a substantial $6 \%$ specific air range (SAR) improvement over the datum aircraft but also is able to maintain a $4.5 \%$ to $5.5 \%$ SAR enhancement for all analysed flight phases, whereas for the fixed sizing geometry improvements fall to approximately $3.5 \%$. Results from also indicated substantial improvements to the lift-to-drag ratios in climb, as well as takeoff and landing field lengths.

SAR is simply defined as the distance flown per unit weight of fuel burned. SAR can be expressed in terms of specific fuel consumption by using the following equation:

$$
S A R=\frac{V}{c \cdot T}
$$

where $V$ is true airspeed, $c$ is thrust specific fuel consumption and $T$ is thrust.

Potential benefits of the MORPHLET concept listed in this reference are optimized lift-to-drag ratio during low speed flight, reduced noise and engine maintenance, improved loadability, optimized flight phases, improved initial cruise altitude (ICA) and maximum speed, improved performance during abnormal procedures, improved stability at different flight control system modes, reduced operating economics, expanded buffet and flutter envelopes, reduced vibration, ability to tailor stall, improved aero-elastic performance and span increase while maintaining conformity with ICAO regulations. 


\subsubsection{Variable Cant Angle Winglet}

Bourdin et al. investigated the use of variable cant angle winglets for morphing aircraft control [22] 9. As shown in Fig. 2.9, a pair of winglets with adaptive cant angle were mounted at the tips of a flying wing and actuated independently. This concept of variable-cant-angle winglets is a promising alternative to conventional control surfaces such as ailerons, elevators and rudders as far as basic manoeuvres are concerned.
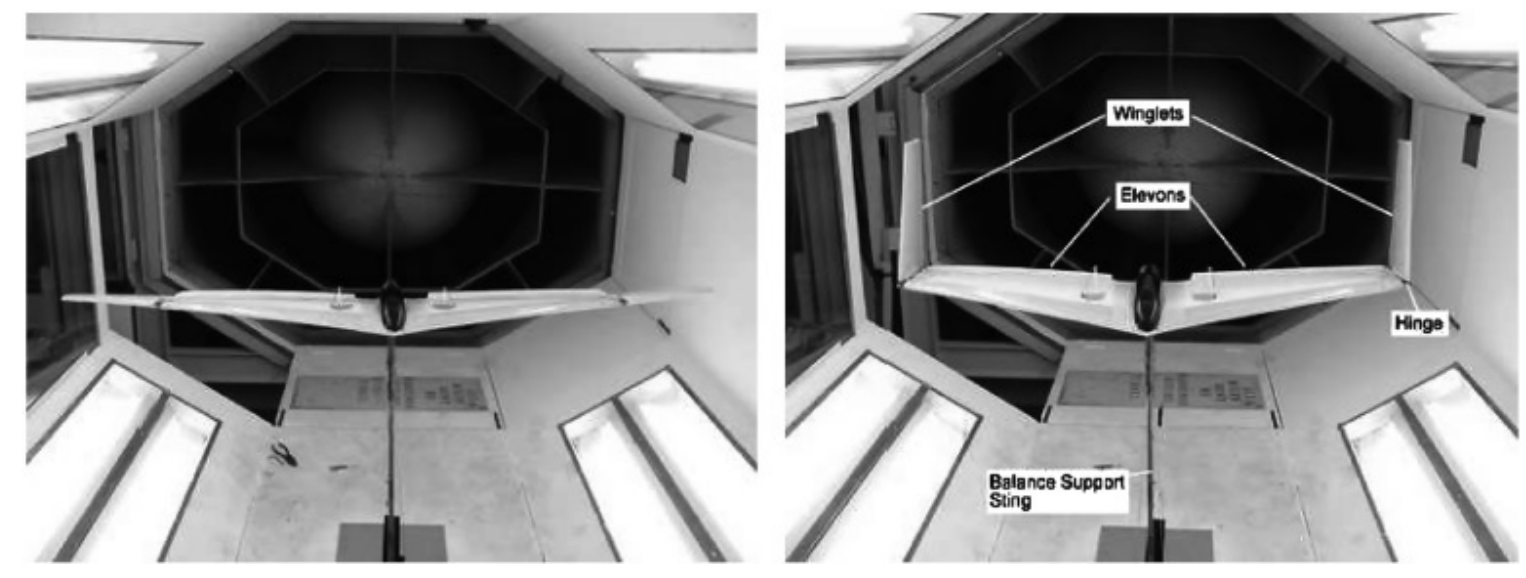

Figure 2.9: Experimental model of variable cant angle wingtip device in wind tunnel; left: both winglets planar; right: both winglets upright ( 9

A prototype of the concept was constructed with servo-driven winglets at the tips of a trapezoidal planar wing. A single pair of adaptive winglets cannot replace all the conventional control surfaces and an elevator was included to trim the aircraft. The concept was modified by adding a second pair of folding wingtips where the split wingtips are actuated independently [9]. The concept is more effective at moderate and high lift coefficients, and hence could be applied to low-speed morphing aircrafts.

\subsubsection{Variable Height Wingtip Device}

Daniele et al. [10] presented a telescopic, inflatable, variable height wingtip device to reduce pollutant emissions through an improvement of the aircraft performance. The increase in winglet height exposes a larger winglet surface area for climb and descent phases. As shown in Fig. 2.10, a hinged telescopic device was used to obtain variation in winglet span according to flight condition requirements. The inflatable system guaranteed a comfortable deployment system and minor weight penalty compared to classical winglet solutions. They were able to demonstrate a reduction in fuel weight of about $3455 \mathrm{~kg}$ and $510 \mathrm{~kg}$ for cruise and climb/descent respectively where reference conditions for the aircraft category under consideration were as follows; typical range value of $7000 \mathrm{~nm}$ for cruise flight condition and 100 $\mathrm{nm}$ for climb/descent flight condition, a specific fuel consumption of about $0.5 \mathrm{lbf} / \mathrm{h}$, and altitudes of $10,000 \mathrm{~m}$ for cruise and $5000 \mathrm{~m}$ for climb/descent.

A optimization scheme was employed in GENOA, a design tool that uses panel method, to generate 


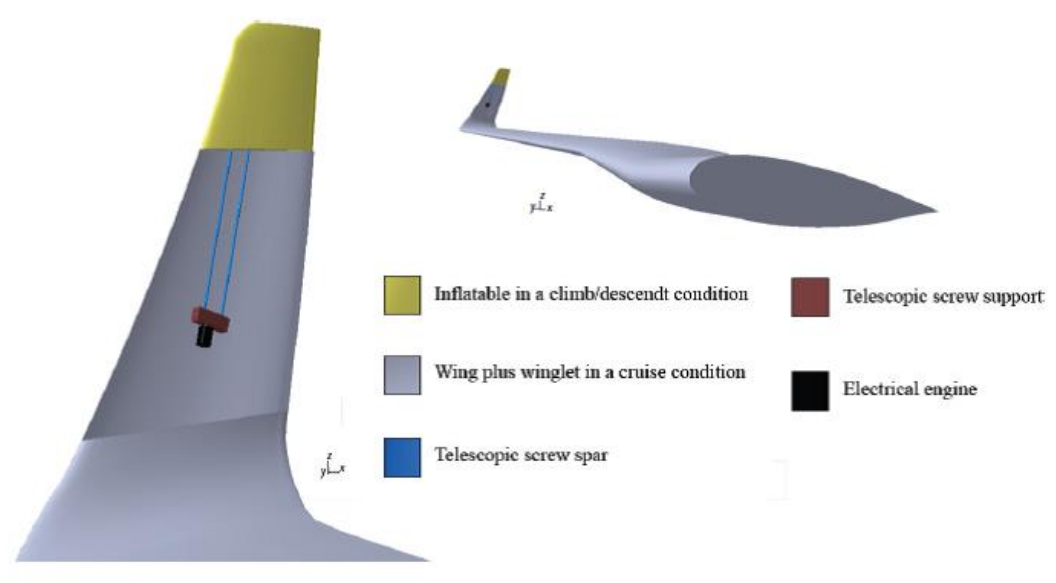

Figure 2.10: A variable height telescopic winglet [10]

winglet shape with optimal aerodynamic efficiency for three flight conditions (climb, takeoff, and cruise). Ideal winglet heights, sweep angle, and cant angle were obtained for all three flight regimes.

\subsubsection{Articulating Winglets}

Morphing winglet concept has also been applied to high performance sailplanes [32]. The effects of controllable articulating winglets on glide performance and yawing moments of high performance sailplanes were investigated experimentally by conducting tests in the Texas A \& M university lowspeed wind tunnel using a full scale model of a high performance sailplane wing. The winglet on the wing could be morphed by changing cant angle and toe-out angle. In addition, the rudder on the winglet could be also adjusted to a range of positions. The effects of boundary layer tabulators in the winglets are also presented.

\subsubsection{Active Multiple Winglets}

Another interesting study conducted by Shelton et al. 11] demonstrated the use of actively controlled multiple winglets to improve the low-speed performance and manoeuvrability of an existing unmanned aerial vehicle $(\mathrm{UAV})$. Incrementally increasing the span of active multiple winglets is also shown to increase the range and endurance by up to $40 \%$ (due to increase in lift-to-drag ratio) compared with a baseline wing. In addition, their analysis showed that active multiple winglets can be viable alternative to control surfaces and can also negate the effects of gust on the aircraft. The use of winglet control showed roughly 13

The different views for the concept of UAV equipped with active multiple winglets are shown in Fig. 2.11. 


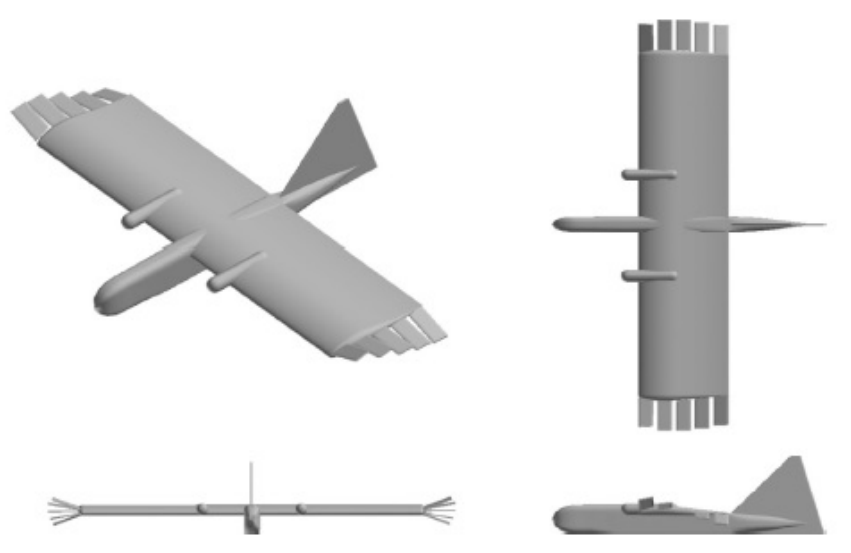

Figure 2.11: Multiple actively controlled winglets fitted on a UAV [1]

\subsubsection{Bistable Winglets}

A winglet that can snap between two stable states under different loading conditions is termed as bistable winglet. Bistable winglets have been investigated at the University of Bristol by Gatto et al. [12] to augment lift generation on a generic swept wing. The composite winglet is manufactured with an unsymmetric layup and snaps between two stable states when differently loaded. Their experimental investigation demonstrated enhanced lift characteristics of a wing transitioning from lower to higher subsonic flow speed. During low speed operation such as takeoff, the winglet is fixed in one stable state. In this state, the winglet is cambered thereby increasing lift. In high speed cruise operation, the winglet snaps to a more traditional winglet shape as shown in Fig. 2.12. Their bistable winglet shows great potentials but the experiments demonstrated production and transmission of significant dynamic loads throughout the entire wing structure, thus requiring additional systems to attenuate and control the loads.

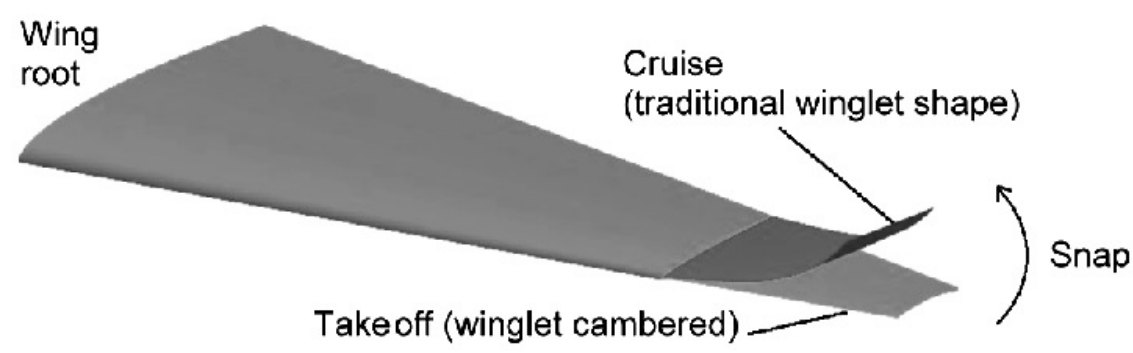

Figure 2.12: The bistable winglet concept proposed by Gatto et al. 12.

Another bistable winglet concept for UAV was investigated by Kim et al. at Seoul National University [13. A prototype of morphing winglet utilizing a metallic bistable structure and polymer was introduced. The bistable morphing winglet prototype showed two stable configurations; a flat configuration and a bent configuration (cant angle of $60^{\circ}$ ) as shown in Fig. 2.13 

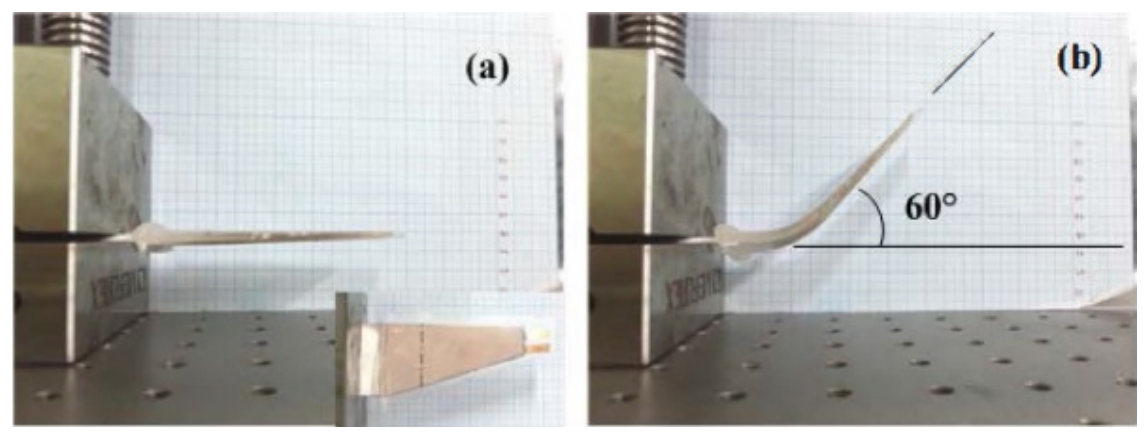

Figure 2.13: The bistable winglet concept proposed by Kim et al. [13]

The bistable winglet was found to have following drawbacks and limitations:

1. Extra weight due to the use of metal sheet and polymer in the design 13 .

2. Vibration after snap-through during shape transition which may disturb airflow near winglet and also affect stability negatively [13.

3. Added complexity due to the need to attenuate and control dynamic loads produced during snapthrough process 12 .

\subsection{Morphing Skins}

Another area of emerging aerospace technology is "Morphing Skin" technology. A morphing skin is an aerodynamic fairing that is used to cover the morphing structure. Morphing skin can potentially be used as a fairing to cover the wing-winglet junction of an aircraft equipped with morphing winglet. Thill et al. presented an extensive review of different types of morphing skin technology and concepts [33]. They highlighted the following two different modes of morphing the skin:

1. Changing the surface area: Possible candidates for morphing by changing surface area are stretchable structures (e.g. elastomers, auxetic materials etc.) and deployable structures (e.g. rollable and collapsible structures, foldable structures, inflatable structures etc.)

2. Changing the shape: Possible ways of morphing by changing shape are via stiffness tailoring (e.g. multistable composites, segmented structures, multilayered skins etc.) and variable stiffness materials or smart materials (e.g. shape memory alloys and flexible matrix composites).

The knowledge domain and maturity of morphing skin seem to be still early in their development. Further research and development work is necessary because morphing skin is important to ensuring the success of aircraft equipped with morphing wing or morphing winglet. 


\subsection{Active Flow Control}

An alternative approach to morphing for improved aerodynamic efficiency includes directly controlling the airflow, as opposed to controlling the geometry. Such methods are collectively designated as active flow control and include the following:

1. Boundary-layer suction: This method involves boundary-layer suction through holes in the wing in order to improve the lift and drag characteristics [34].

2. Synthetic jet: This is based on an oscillatory motion of a membrane in a cavity adjacent to the external flow. No air is pumped into or out of the external flow but a momentum is generated by the periodic oscillations of fluid into and out of the cavity. This mimicks a jet thereby modifying the airflow [35].

3. Dielectric barrier discharge plasma actuator: This consists of two electrodes separated by a dielectric film. One of the electrodes is immersed in the flow. The air near the electrode ionizes when excited with a voltage thereby producing a force in the surrounding air [36].

The drawbacks of active flow control method prevent its use for widespread adoption. Although boundary layer suction method suffers from high energy requirements, added weight and complexity due to the need of a pumping system, it has been used on tail surfaces of B787-900. Existing synthetic jet systems provide limited change of overall wing behavior whereas plasma actuator although ideal for lower angles of attack have demonstrated reduced effectiveness for high angles of attack [7. In addition, the knowledge domain on the materials and systems for physical deflection of aircraft components appear to be more matured and richer as compared to the active flow control systems.

Although most of the interests in morphing solutions are focused on wings, they are inherently complex and face regulatory hurdles from safety perspective among others. Hence, morphing winglets are possible solutions for improving aircraft performance as it is possible to significantly change the overall aerodynamic behavior of the wing by using simple and localized changes at the winglet. The certification of such systems involving changes restricted to a limited, low stress region can be comparatively easier 37.

\subsection{Summary}

A selection of the previous and current morphing winglet investigated by industry and academia was presented in this chapter. Morphing winglets have also been termed as variable geometry winglets, articulating winglets, controllable winglets, active winglets etc. Although several approaches to morphing winglets have been investigated, they were found to have drawbacks and limitations which were also highlighted in this chapter. MORPHing wingLET (MORPHLET) [8], variable cant-angle winglets [22], variable-weep winglet [23], telescopic variable-hight wingtip device [10, active multiple winglets [11, bistable winglets [13] 12] are some of the morphing winglet related work found in the literature. 


\section{Chapter 3}

\section{Proposed Methodology}

\section{$3.1 \quad$ Introduction}

This chapter introduces the methodology used in conducting this thesis work. This includes techniques and procedure used in prediction and decomposition of physical drag components, high speed design space exploration, mapping stall angle (low speed characteristics), aeroelastic studies and evaluating winglet loads. The approach used in evaluating maneuver load alleviation capability of the morphing winglet is also introduced. Finally, the method for evaluating the weight impact of morphing winglet over static winglet is described.

Although a number of winglet design parameters such as span, sweep, cant, toe, twist and aspect ratio should be considered during winglet design, not all of them have similar impact on the performance of wing and the winglet. In this work, only cant angle and toe-out angle are selected as primary design variables largely due to the nature of morphing winglet envisioned for the purpose of the research aircraft.

\subsection{Winglet Manipulation}

The proposed motion of winglet is by the use of an actuation system positioned at the dry section of the outboard wing as shown by a simplified diagram in Fig. 3.1. The proposed full size morphing winglet is composed of two modules. The first module consists of an actuation system that fits on wingtip section. The second module is the winglet whose orientation (cant angle and toe-out angle) is controlled by two actuators. One actuator controls the toe-out angle whereas the other actuator controls cant angle of the winglet. The power required by the actuation system is determined by aerodynamic as well as structural load on the winglet. Hence, aerodynamic analysis of the winglet is conducted at selected mission segments to calculate aerodynamic loads on the wing and winglet. 


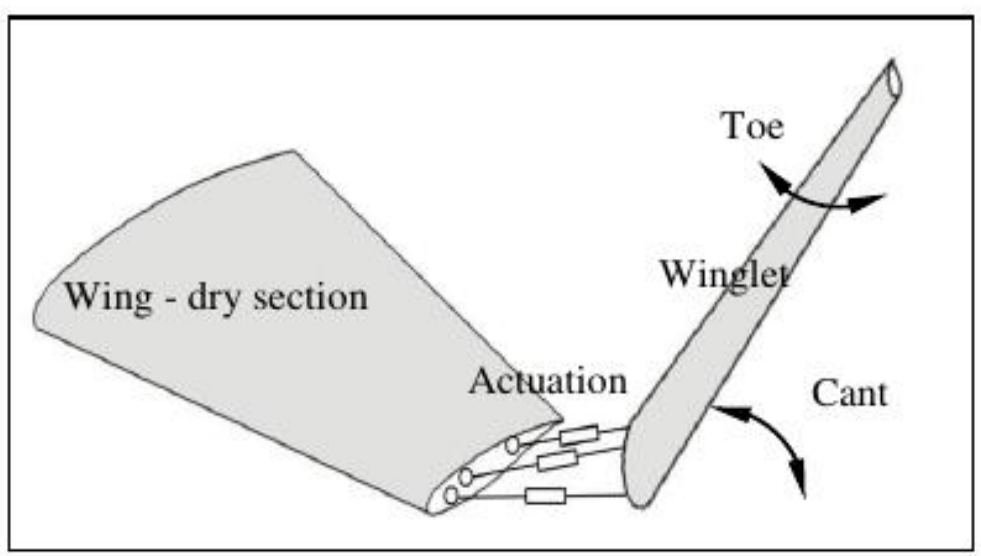

Figure 3.1: The proposed modular morphing winglet to be fitted on the wingtip

\subsection{Optimal Morphing Path}

The proposed study is also expected to help in determining an optimal path that can be adopted to "morph" the winglet by avoiding large drag and bending moment penalty as shown in Fig. 3.2 . The dashed path line in the figure could be used to morph the winglet from one orientation (e.g. A) to another orientation (e.g. D) by avoiding or minimising any additional drag or bending moment penalties associated with the path shown in solid black line. Mapping the design space may allow us to choose the most optimal morphing path that will be influential during load testing.

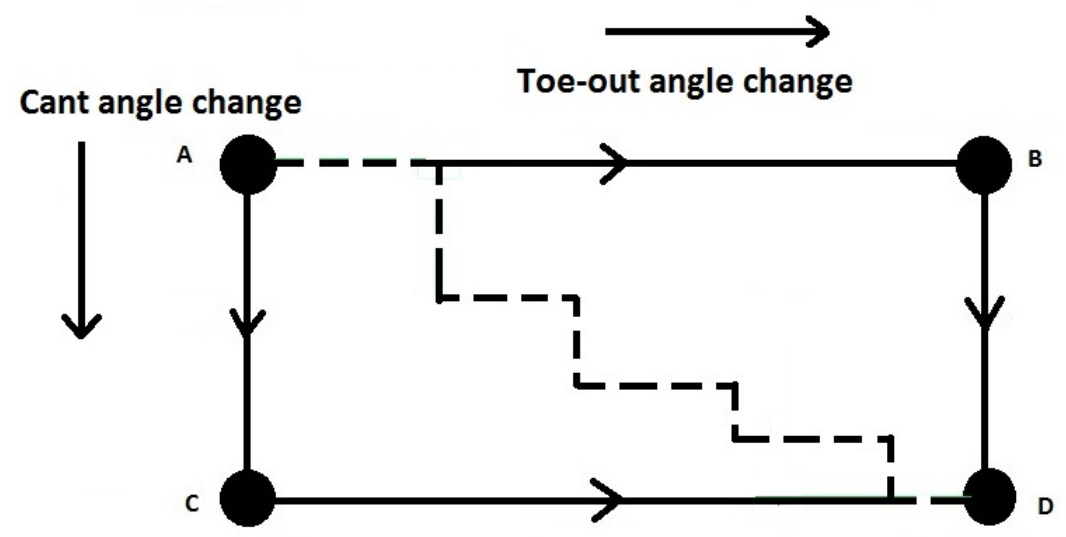

Figure 3.2: Motion paths of proposed winglet to morph from one mission point to another. The arrow indicates the change in cant or toe-out 


\subsection{Problem Formulation}

The goal of this thesis work is to find winglet configurations for optimized drag and bending moment. The former is for aerodynamic performance and the latter for the design of morphing actuation system. Ideally, it would be formulated as an optimization problem with a number of design variables, including toe-out angle, cant angle, winglet span, twist, speed, angle of attack etc. However, this work is focused on investigating the effects individually by using only two design parameters viz. cant angle and toe-out angle.

A design of experiments (DOE) based approach is used to determine best winglet orientations at different mission segments. First, the winglet cant angle and toe-out angle are varied from their nominal values in order to understand their effects on total drag $\left(C_{D}\right)$, wing root bending moment $(W B M)$ and winglet root bending moment $(W L E T B M)$ at high speed cruise conditions. Then, the best winglet configurations obtained in high speed design space exploration study are investigated further to understand aero-elastic effects on morphing. The aero-elastic studies are conducted by coupling a CFD solver with wing-winglet stick model in MSC Nastran 38. The low speed characteristic is also investigated by determining the impact of winglet design parameters on aircraft stall angle and maximum lift coefficient $\left(C_{L_{\max }}\right)$ using Valarezo method [15]. Winglet loads during high-g symmetric pullup maneuver are calculated and load alleviation capability of the morphing wing is also investigated by varying cant and toe-out angle. Finally, the overall benefit of this study over a typical mission is highlighted. The impact on the aircraft weight as well as on the design and selection of morphing winglet actuation mechanism is also considered. The proposed methodologies are described in greater detail in subsequent sections.

\subsubsection{Baseline Winglet}

The winglet installed in a research aircraft is taken as a reference winglet. For the purpose of this study, the winglet span is kept constant at $13.5 \%$ of total wing half span. Other details of the wing and winglet are not shown due to the proprietary rights by Bombardier Aerospace. The orientation of the baseline winglet is defined by a specific value of toe-out angle and cant angle that are used as baseline values. The CAD models used in the entire study are generated using generative shape design toolbox in CATIA V5.

The computational grids used for this study are generated by using a structured multi-block grid generator called MBGRID developed in the Advanced Aerodynamics department of Bombardier Aerospace [39]. Bombardier's in house CFD solver called FANSC 40] is used to find Reynolds-Averaged NavierStokes (RANS) solution for the fluid volume surrounding a tail-off full body aircraft by using SpalartAllmaras turbulence model [41]. FANSC is the solver of choice as it is able to accurately predict drag by using structured grid. The surface mesh on the baseline winglet is shown in Fig. 3.3 for reference. The grid for the full body aircraft is not shown due to the nature of research aircraft. The grid sensitivity analysis has already been completed for this aircraft. The optimal number of mesh points to obtain a Navier stokes solution for the fluid volume surrounding the full body aircraft was found to be $11 \times 10^{6}$. 


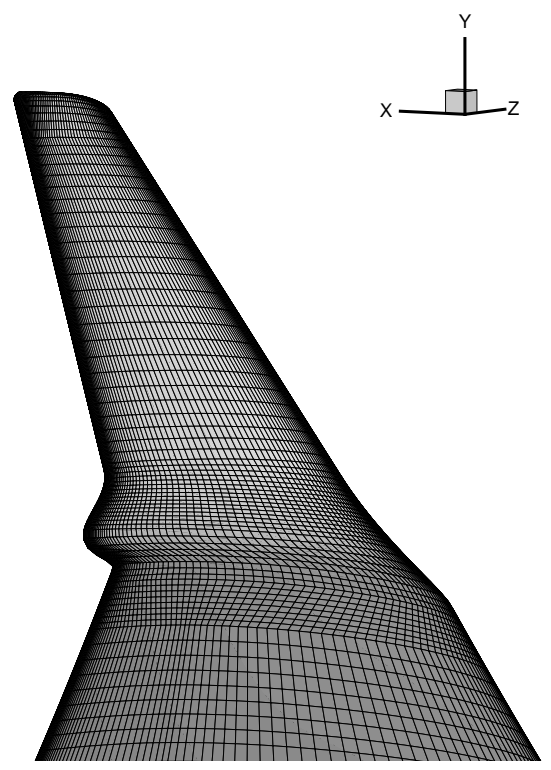

Figure 3.3: Surface mesh on the baseline winglet as seen from inboard wing

\subsubsection{High Speed Design Space Exploration}

A comprehensive trend study of aerodynamic parameters of interest with respect to winglet design variables can highlight the benefit of morphing. As such, design of experiment based trend studies for drag, wing root bending moment and winglet bending moment with respect to cant angle and toe-out angle is conducted in order to locate the optimal position of winglet for each mission point. In addition, re-optimization of toe-out angle to maintain the value of wing root bending moment same as baseline value, is also conducted in order to understand the tradeoff between drag reduction and root bending moment.

Since cruise conditions constitute the major segment of a typical mission, it is necessary to determine optimal orientation of the winglet with respect to the freestream air at these conditions. This is done by conducting aerodynamic analysis at high subsonic speed conditions. All the flow simulations in this study are carried out for $C_{L}$ of 0.45 at Mach 0.85 and $C_{L}$ of 0.3 at Mach 0.90 . The Reynolds number $(R e)$ is $18.8 \times 10^{6}$ based on mean aerodynamic chord of the wing. The following are two main studies conducted under high speed design space exploration:

1. Cant Study: In this study, the cant angle is allowed to vary from $5^{\circ}$ to $85^{\circ}$ as shown in Fig. 3.4 The toe-out angle is kept constant at baseline value. The cant angle is measured from vertical which is opposite of generally used convention in the literature (e.g. as seen in []. $)$. The values of $C_{D}, W B M$ and $W L E T B M$ are calculated for all winglet configurations for comparison.

2. Toe-out Study: At each canted positions, the toe-out angle is allowed to vary from $\Delta T$ Toe of $-4^{\circ}$ to $+3^{\circ}$ at $1^{\circ}$ interval. The manner of toe-out angle variation and its effect on winglet incidence with respect to free stream air is shown in Fig. 3.5 . 


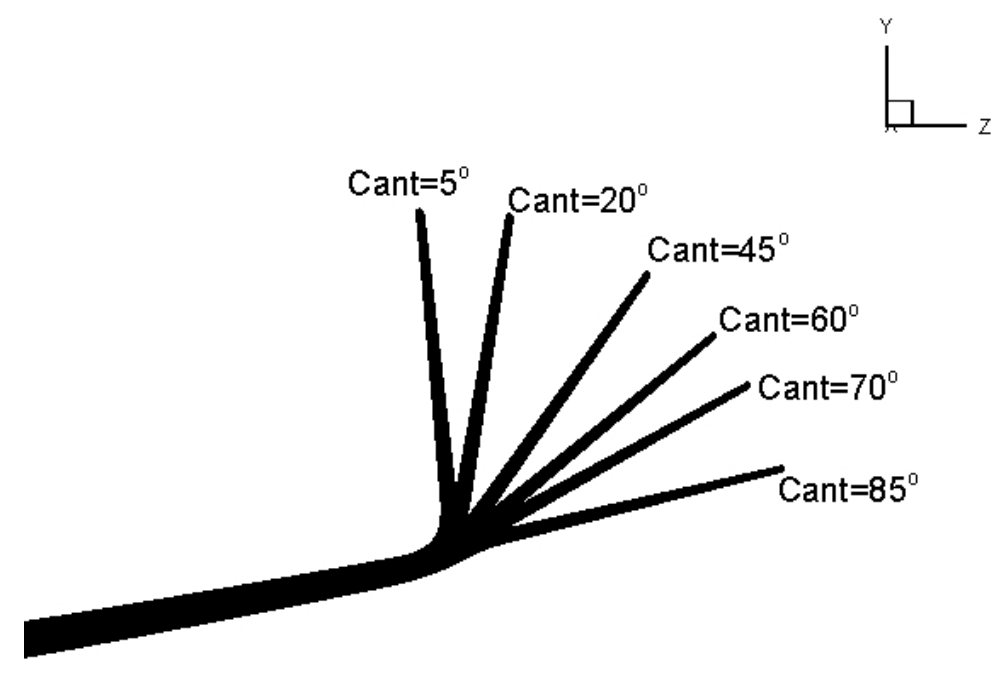

Figure 3.4: Variation of cant angle for DOE-based trade studies. Cant angle is measured from vertical which is opposite of generally used convention in the literature.

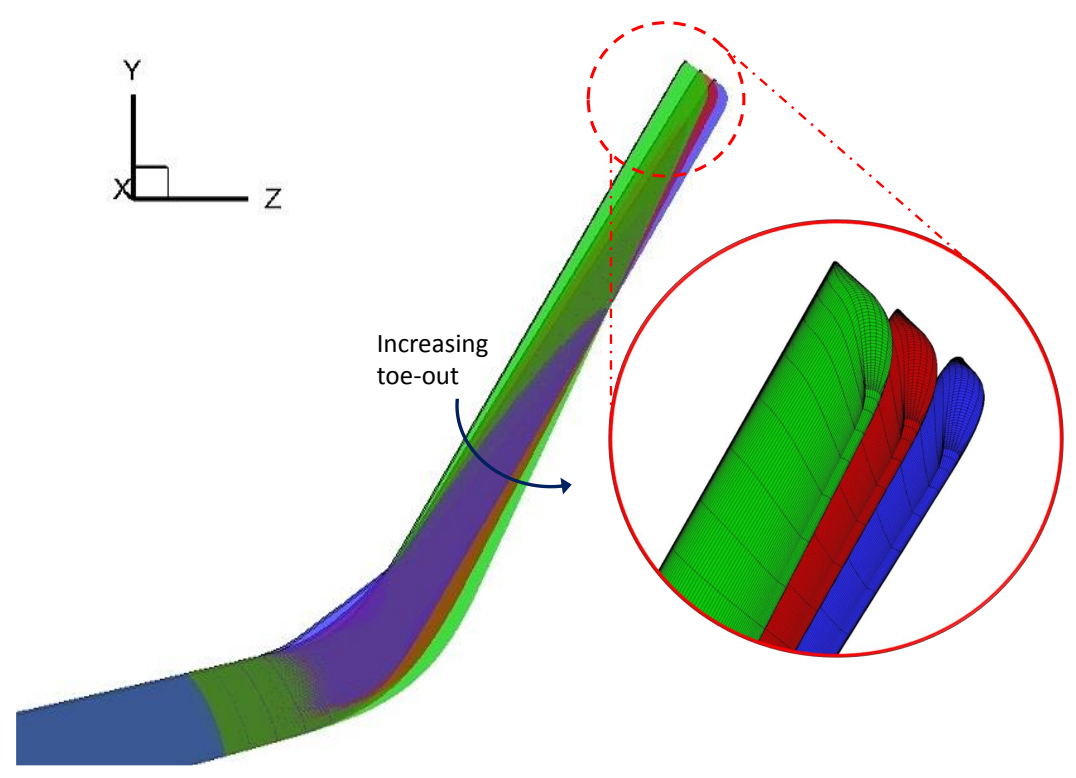

Figure 3.5: Variation of toe-out angle for DOE-based trade studies (Green: $\Delta T o e=+3^{\circ}$, Red: $\Delta T o e=0^{\circ}$, Blue: $\left.\Delta T o e=-4^{\circ}\right)$. Flow direction is into the plane of the paper. 


\subsubsection{Far-Field Drag Prediction and Decomposition}

The total drag for a tail-less full body aircraft and its decomposition into drag components are obtained by using far-field method which is a part of post-processing in the CFD solver FANSC [40. The far-field method was developed by Van der Vooren and Destarac [42] and is based on the linear momentum equation for an immersed body in a flowstream as shown in Fig. 3.6]14.

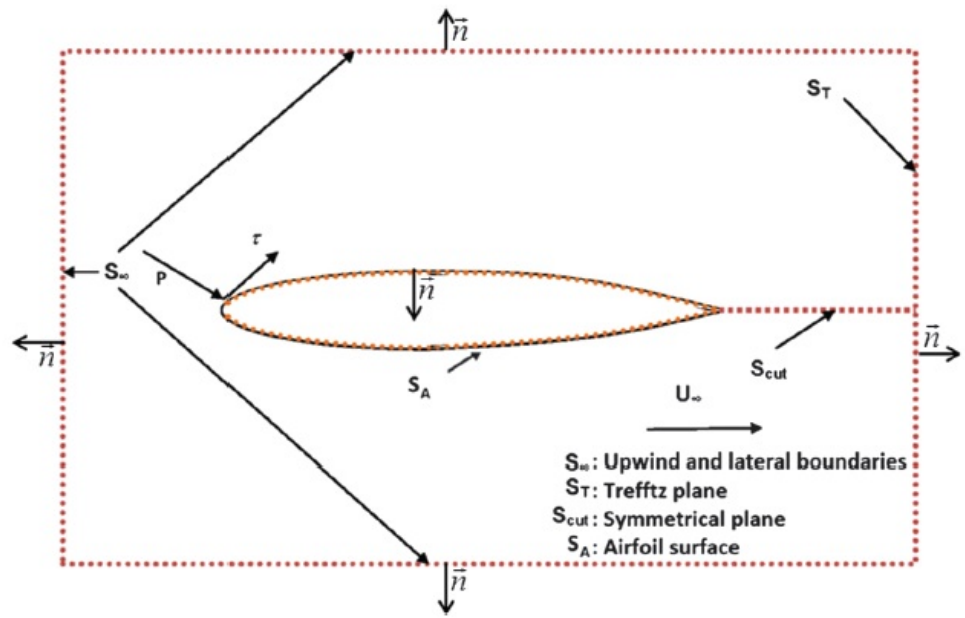

Figure 3.6: Control volume for a immersed body in a flowstream [14].

The linear momentum equation involves integration over control surfaces within the flowfield and at the fluid/solid boundary as shown by the following equation [14:

$$
D=\int_{S_{T}+S_{\infty}}-\left(\left(p-p_{\infty}\right) n_{x}+\rho\left(u-u_{\infty}\right)(\vec{\nu} \cdot \vec{n})-\left(\overrightarrow{\tau_{x}} \cdot \vec{n}\right)\right) d S
$$

where, the meaning of the symbols relating to control surfaces are shown in Fig. 3.6. D is drag. $\nu$ is the velocity vector. $\vec{n}$ is unit normal vector. $\overrightarrow{\tau_{x}}$ is stress tensor. $\left(u-u_{\infty}\right)$ is termed as axial velocity defect.

Far-field method is different from the traditional method of near-field drag prediction method in the sense that near-field method computes drag by integration of stresses (friction and pressure forces) at the surface of the aircraft. While the near-field method provides mechanical breakdown of drag into pressure drag and friction drag, the far-field method allows for physical breakdown of drag into wave drag, viscous drag, induced drag and spurious drag thereby providing physical and local information about the sources of drag. This is a very useful tool for an aerodynamic engineer as farfield method allows physical and visual breakdown of sources of drag and identification and removal of spurious drag [14. The physical breakdown of drag is based on thermodynamic processes and it separates the drag generated by reversible processes (source of induced drag) from the drag generated by irreversible processes (source of wave drag and viscous drag). The detailed method of calculation of individual drag components (wave drag, viscous drag and induced drag) can be found in reference [42. 
The total drag can be obtained by using the following equation:

$$
C_{D}=C_{D, t a i l-o f f}+C_{D, t r i m}
$$

where, $C_{D, \text { tailoff }}$ is the drag obtained for a tail-less full body aircraft and $C_{D, \text { trim }}$ is trim drag.

In a steady level cruise flight, horizontal stabilizer (tail) of the aircraft can be used to achieve zero or negligible pitching moment. Since the pitching moment of a tail-less aircraft in the steady level cruise flight is not zero, there arises a need to adjust the value of drag in order to get a true value of drag of the full aircraft.

The calculation of trim drag on the other hand is part of the post-processing of the CFD solver in use and is based on the method proposed by Laitone in [43]. Trim drag is calculated by using the contribution of induced drag and pitching moment among others, obtained for a tail-less full body aircraft.

The trend in the value of all of these drag components are also observed in this aerodynamic analysis of morphing winglet.

\subsubsection{Bending Moment Calculations}

In order to calculate wing root bending moment and winglet root bending moment, the force vectors in $\mathrm{x}, \mathrm{y}$ and $\mathrm{z}$ directions $\left(C_{x}, C_{y}\right.$ and $\left.C_{z}\right)$ acting on the aircraft are calculated by using the following set of equations:

$$
\begin{aligned}
& C_{x}=\left[-C_{p} *(X \text { Grid K Unit Normal })+C_{f_{x}}\right] / S_{\text {ref }} \\
& C_{y}=\left[-C_{p} *(Y \text { Grid K Unit Normal })+C_{f_{y}}\right] / S_{\text {ref }} \\
& C_{z}=\left[-C_{p} *(Z \text { Grid K Unit Normal })+C_{f_{z}}\right] / S_{\text {ref }}
\end{aligned}
$$

Where, "X Grid K Unit Normal" is the projection of normal vector ("Grid K Unit Normal") on the $\mathrm{X}$-axis. The "Y Grid K Unit Normal" is the y component of the vector that is normal the surface. The "Z Grid K Unit Normal" is the z component of the vector that is normal the surface. $C_{p}$ is pressure coefficient. $S_{\text {ref }}$ is the wing reference surface area.

The bending moment about $\mathrm{x}, \mathrm{y}$ or $\mathrm{z}$ axes are then calculated by inserting force vectors into the following equations:

$$
\begin{gathered}
C_{m, x}=\left[-C y *\left(z-z_{m a c}\right)+C_{z} *\left(y-y_{m a c}\right)\right] / b \\
C_{m, y}=\left[-C z *\left(x-x_{m a c}\right)+C_{x} *\left(z-z_{m a c}\right)\right] / b \\
\left.C_{m, z}=\left[-C x *\left(y-y_{m a c}\right)+C_{y} *\left(x-x_{m a c}\right)\right)\right] / c_{m a c}{ }^{\prime}
\end{gathered}
$$


where, $x_{m a c}, y_{m a c}, z_{m a c}$ are coordinates of wing quarter chord and $c_{m a c}$ is mean arodynamic chord. $b$ is wing half span. To calculate wing root bending moment, MAC location (wing quarter chord) is used as the point of reference. For the winglet bending moment, the root of the winglet is selected as a point of reference. When the wing bending moment (almost like a rolling moment) is computed, the $C_{m, x}$ component is the dominant one but $C_{m, y}$ and $C_{m, z}$ need to be computed using the same reference length as $c m x$. Either $c_{m a c}$ or $b$ are used as reference length.

The total wing bending moment is then calculated by integrating $C_{m, x}, C_{m, y}$ and $C_{m, z}$ from root to tip of the wing. The winglet bending moment is calculated by integrating the same parameters from the tip of the wing to tip of the winglet.

\subsubsection{Aero-elastic Effects on Wing Loading}

Aero-elasticity is a field of study that involves the interaction between the deformation of an elastic structure in an airstream and the resulting aerodynamic force. In other words, aero-elasticity involves interaction between aerodynamic, elastic and inertial forces [44. Static aero-elasticity and dynamic aeroelasticity are important areas of interest in aircraft design and development. Static aero-elasticity is the coupling between the aerodynamic and elastic forces and is time independent whereas dynamic aeroelasticity is concerned with oscillatory and transient effects. Dynamic aero-elasticity involves inertial forces in addition to the aerodynamic and elastic forces. Although the focus of this thesis work is the effect of aero-elasticity on total aircraft drag and bending moment, the effect of aero-elasticity is not limited to aircraft. Aero-elasticity also affects bridges, towers, wind turbines, turbo-machinery etc. Some of the aero-elastic phenomenons that are of concern to aircraft designers are:

1. Divergence

2. Control surface reversal

3. Flutter

4. Limit cycle oscillation (LCO)

5. Control surface buzz

6. Buffet

The first two are static aero-elastic phenomena, whereas the remaining four are dynamic. Dynamic aero-elasticity is beyond the scope of this thesis work. In order to truly identify the benefits of morphing winglet, static aero-elastic effects are incorporated into our study. This is done by calculating bending and torsion due to aerodynamic loads and incorporating resulting deformations into the CFD solution. The main objective of this study is to determine the impact on best winglet configurations when the aero-elastic factors are considered. This study will show us if the results for optimum flexible-winglet configurations are different than the corresponding optimum rigid-winglet configuration. 
The procedure employed in aero-elastic study is demonstrated by a simplified flowchart in Fig. 3.7 The aerodynamic loads seen by the aircraft are obtained by using FANSC. These loads are then transferred into a stick model of wing-winglet combination and the wing deformations are calculated in MSC Nastran [38]. The stick model consists of control points along the wing span and along the winglet span. The deformations are essentially the displacement of these control points from their original positions. These deformation values are then applied to the initial wing-winglet geometry to get an updated wingwinglet geometry. A new mesh is generated for the updated geometry and RANS solution is obtained. The new loading on the wing-winglet is again used by MSC Nastran in order to find the new deformations. The procedure is repeated until the aero-elastic deformations on the wing reach a converged set of values. The final results for drag and bending moments are then compared with the corresponding results for rigid wing-winglet geometry.

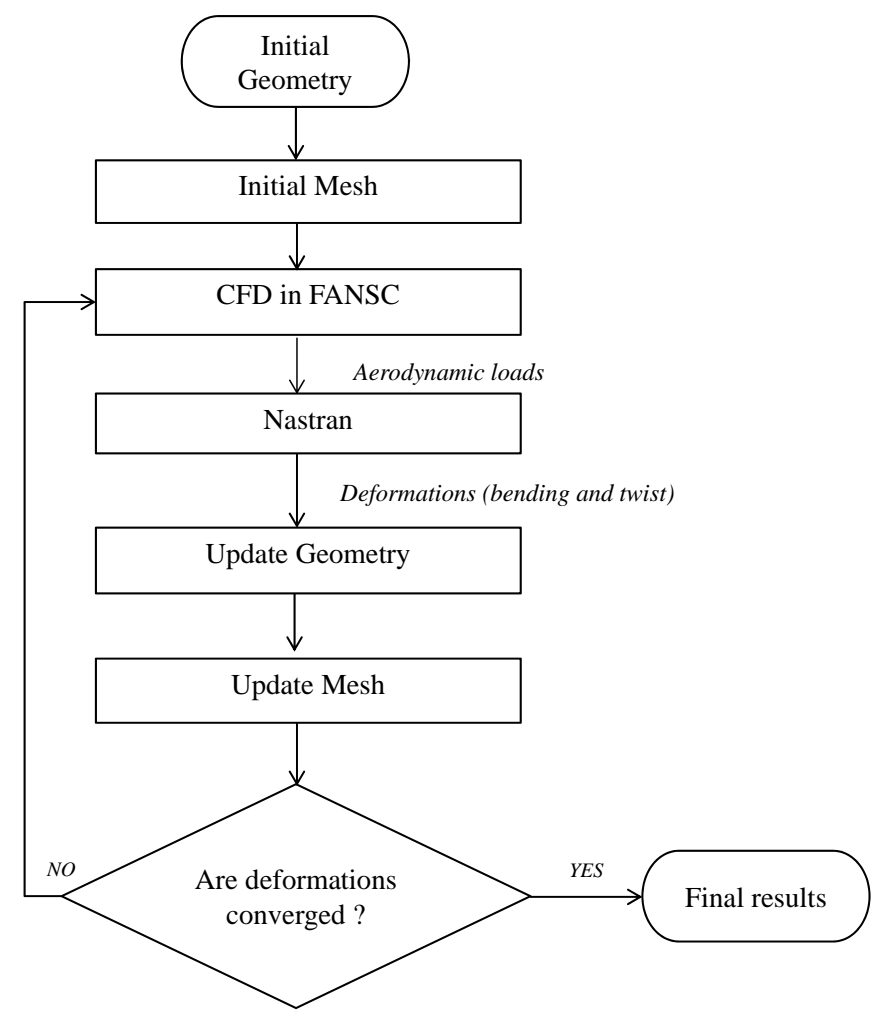

Figure 3.7: Flowchart depicting the procedure used in aero-elastic studies

Six different aero-elastic loadcases are considered to identify aircraft at different points of the mission. These loadcases are summarized in table. 3.1. A typical mission profile starting from takeoff to landing and relevant flight conditions at each mission point has already been shown in Fig. 1.3 . 
Table 3.1: Loadcases under consideration for static aero-elastic trade studies

\begin{tabular}{cccccc}
\hline \hline Loadcase ID & Altitude $(\mathrm{ft})$ & $R e$ & Mach & $C_{L}$ & $Q(\mathrm{psf})$ \\
\hline L0 & 39,000 & $25.2 \mathrm{E} 6$ & 0.85 & 0.45 & 208 \\
L1 & 43,000 & $20.8 \mathrm{E} 6$ & 0.85 & 0.45 & 172 \\
L2 & 47,000 & $17.2 \mathrm{E} 6$ & 0.85 & 0.45 & 142 \\
L3 & 35,000 & $31.9 \mathrm{E} 6$ & 0.90 & 0.30 & 282 \\
L4 & 39,000 & $26.7 \mathrm{E} 6$ & 0.90 & 0.30 & 233 \\
L5 & 43,000 & $22.0 \mathrm{E} 6$ & 0.90 & 0.30 & 192 \\
\hline
\end{tabular}

\subsubsection{Low Speed Considerations}

When the angle of attack of an aircraft exceeds the critical angle of attack, the airflow separates from all or part of the upper surface of the wing. This flow separation results into sudden loss of lift and significant increase in drag. The phenomenon is called "Stall". Stall is found to be the leading cause of major accidents in the history of aviation [45. Although stall is usually associated with low speed flight in high angle of attack, it can occur at any airspeed or attitude. As such, it is necessary for an aircraft to have good stall characteristics. The aircraft wing should stall at the roots first rather than the tips so as not to render the ailerons located near the tip ineffective for roll control. A washout is usually introduced to the wing during wing design so that tips are always at lower angle of attack. However, this may not be enough to ensure desired stall characteristics. Often, aircraft designers resort to using devices such as winglets, stall fences, slots, vortex generators etc. at the tip of the wing in order to improve stall characteristics. Winglets have shown to increase maximum lift coefficient [46. In addition, the winglet equipped airplane showed improved stall characteristics when compared with the basic airplane. The winglets appeared to prevent the wingtip from stalling early, whereas the airplane with no winglet displayed a tendency to roll off or drop a wing [4].

In this report, the onset of stall is predicted by using "Valarezo method". This method is based on empirically observed phenomenon occuring at maximum lift conditions which is introduced by the Valarezo and Chin as the pressure difference rule [15]. The difference between the peak suction pressure and trailing edge pressure (i.e. $\Delta C_{p}$ ) at any spanwise location is compared against a threshold value called Valarezo limit calculated at that spanwise position. When $\Delta C_{p}$ reaches Valarezo limit at a certain spanwise location, wing is said to have started to stall at that spanwise location. For the purpose of this work, the corresponding lift coefficient is taken as $C_{L_{\max }}$ and angle of attack is taken as stall angle. Further CFD work or wind-tunnel testing may demonstrate what happens after. Valarezo method cannot predict how fast the stall propagates on the wing. The Valarezo limit depends upon chord Reynolds number and is calculated for each wing spanwise positions. The relation between chord Reynolds number, Mach number and the pressure difference at maximum lift are shown in Fig. 3.8. CFD simulations are carried out at Mach 0.2 and so only the line indicating Mach 0.2 is used from the figure for this study.

Figure. 3.9 demonstrates the Valarezo criteria applied to the baseline wing-winglet configuration. $\Delta C_{p}$ values are shown for spanwise location from $85 \%$ of wing span up to the tip of winglet. The root of the winglet is represented by $\eta=1$. The value of Valarezo limit is roughly uniform at 14 from root to 


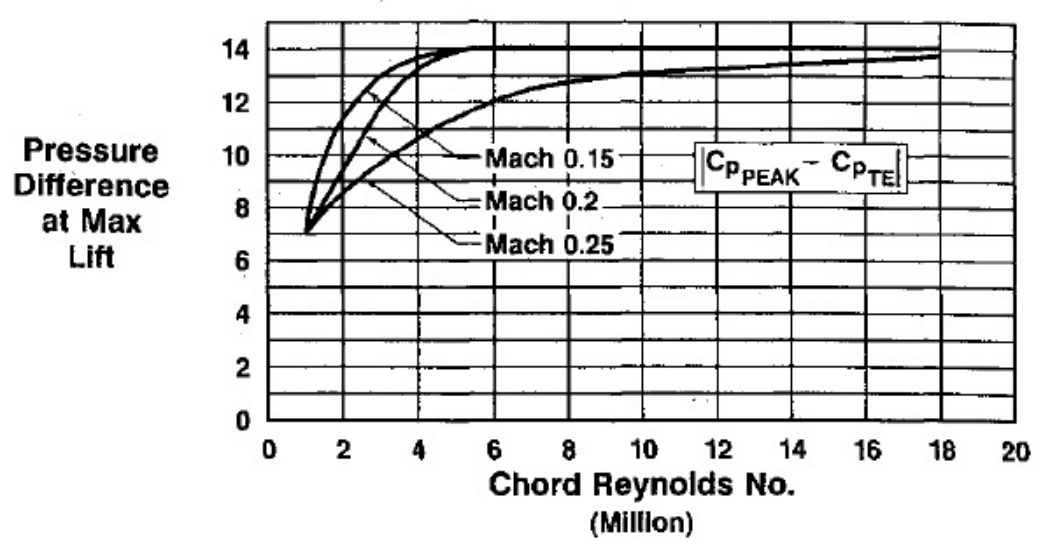

Figure 3.8: Pressure difference rule for maximum lift [15]

tip of the wing. On the winglet side, chord Reynolds number reduces and therefore Valarezo limit also reduces as shown in the same figure. The winglet stalls near winglet tip as shown by a red arrow. This is where the pressure difference has reached Valarezo limit thereby predicting onset of stall. The method is also applied to the winglet with lower cant than the baseline winglet (i.e. at $\Delta$ Cant of $-40^{\circ}$ ) as shown in Fig. 3.10. With increase in angle of attack, the wing is found to have stalled close to wing-winglet junction.

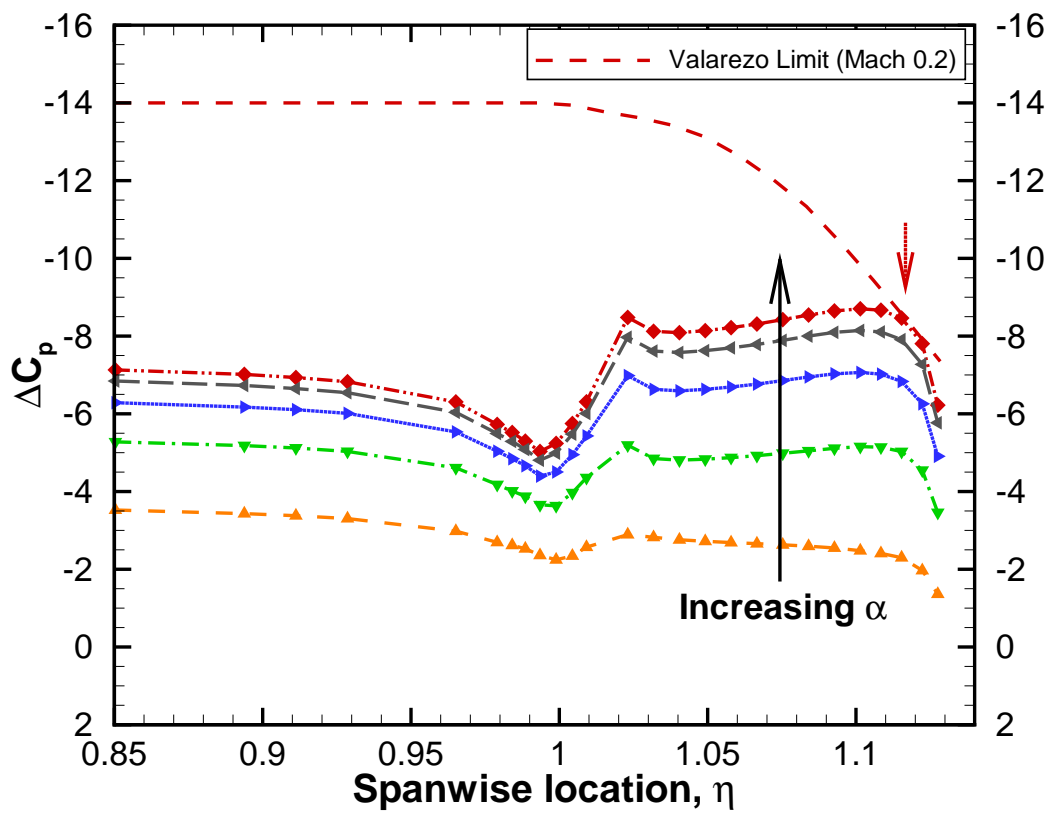

Figure 3.9: Prediction of onset of stall for baseline winglet at Mach 0.2 using Valarezo method. Red arrow shows the location of stall. 


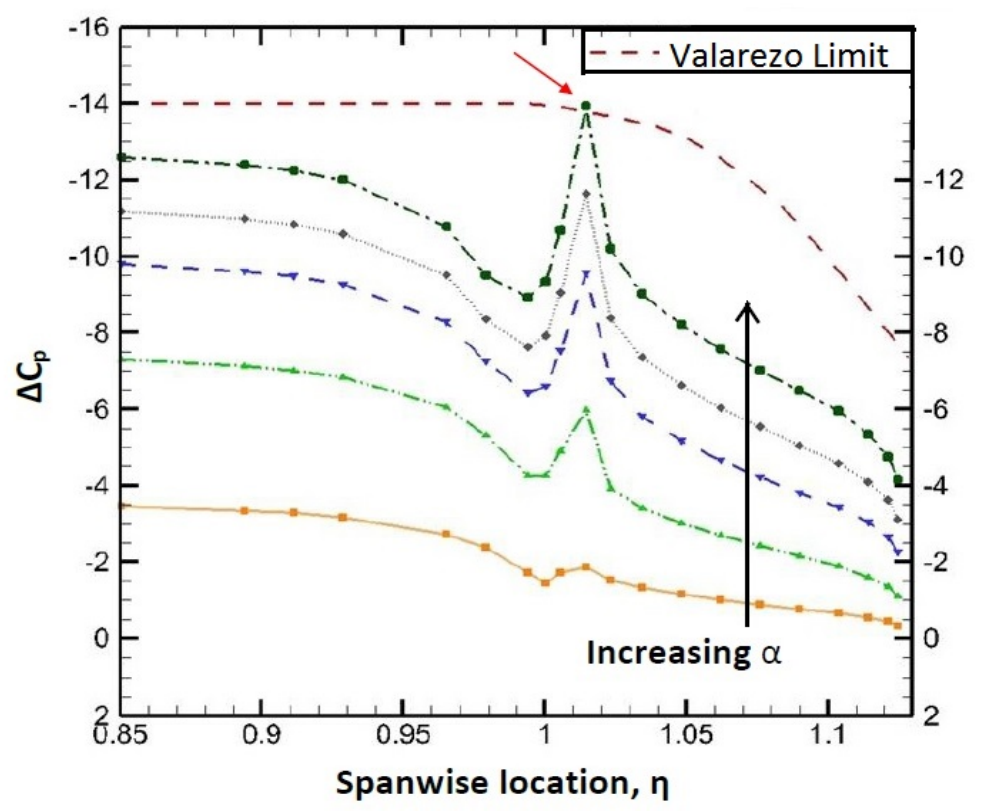

Figure 3.10: Prediction of onset of stall for low cant winglet $\left(\Delta\right.$ Cant of $\left.-40^{\circ}\right)$ at Mach 0.2 using Valarezo method. Red arrow shows the location of stall.

The variation in pressure distribution and velocity streamlines with the increase in angle of attack is also examined. Figure. 3.11 shows that with increasing angle of attack, the peak pressure at the leading edge is increasing. The figure also shows that at lower angle of attack, the flow is attached and solution converged well. Whereas at higher angle attack (close to stall angle), the flow starts separating at wing-winglet junction thus suggesting the wing may have stalled at the juction.

The computational grids for this study are generated by coarsening Navier Stokes skin of the mesh generated for high speed design space exploration. Euler solutions of the flow field are computed by incorporating JST (Jameson-Schmidt-Turkel) scalar dissipation scheme 48, in FANSC along with second order and fourth order artificial dissipation coefficients of 0.5 and 0.25 respectively in order to get wellconverged solutions at all angles of attack, $\alpha$. Classic factorized laplacian implicit smoothing method is embedded within the Runge-Kutta multistage time-stepping scheme. All the euler solutions are performed at Mach 0.2 and Re of $10 \times 10^{6}$ at various angles of attack until the Valarezo limit is reached at any wing spanwise position. Euler method is selected over Navier Stokes solution due to the incompressible nature of the flow. Euler solution als provided with added benefits of reduced computational time and energy.

\subsubsection{Maneuver Load Alleviation}

All commercial aircrafts are designed, as per the Federal Aviation Regulations (FAR), to withstand load expected during a 2.5g maneuver at a structural safety factor of 1.5 [16. Figure. 3.12 depicts the maneuvering envelope in the code of federal regulations. For the purpose of this work, only maximum 


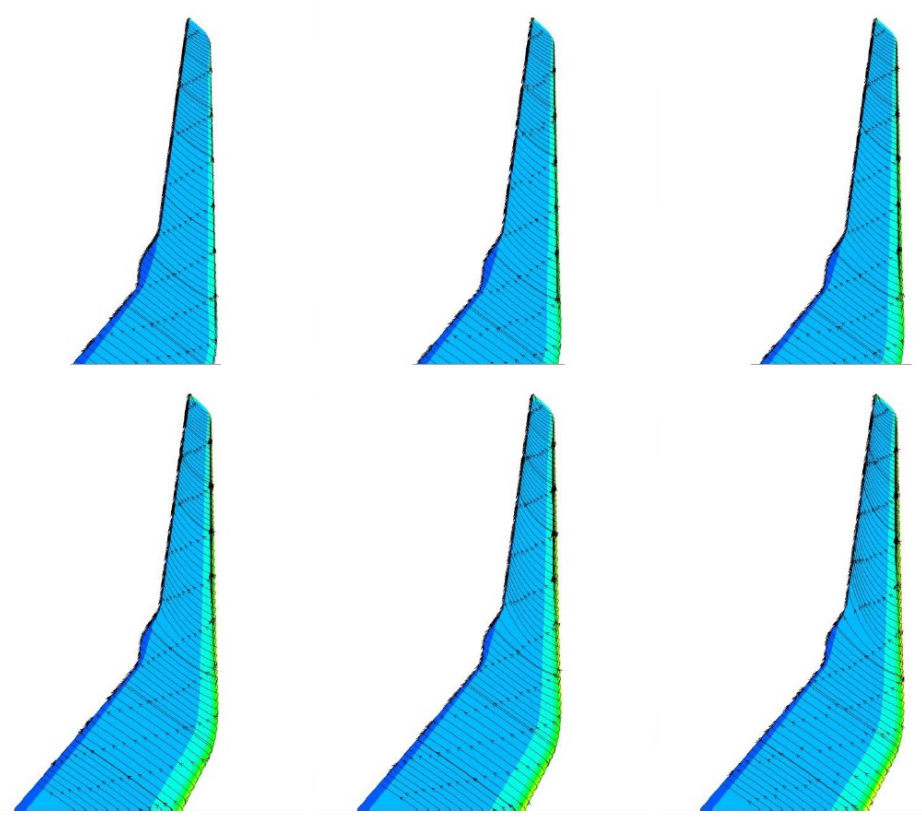

Figure 3.11: Pressure contour and velocity streamlines with increasing angle of attack. Increasing angle of attack from left to right; top to bottom. Note that $C_{p}$ values are not shown due to intellectual property rights.

positive load factor of $2.5 \mathrm{~g}$ is considered.

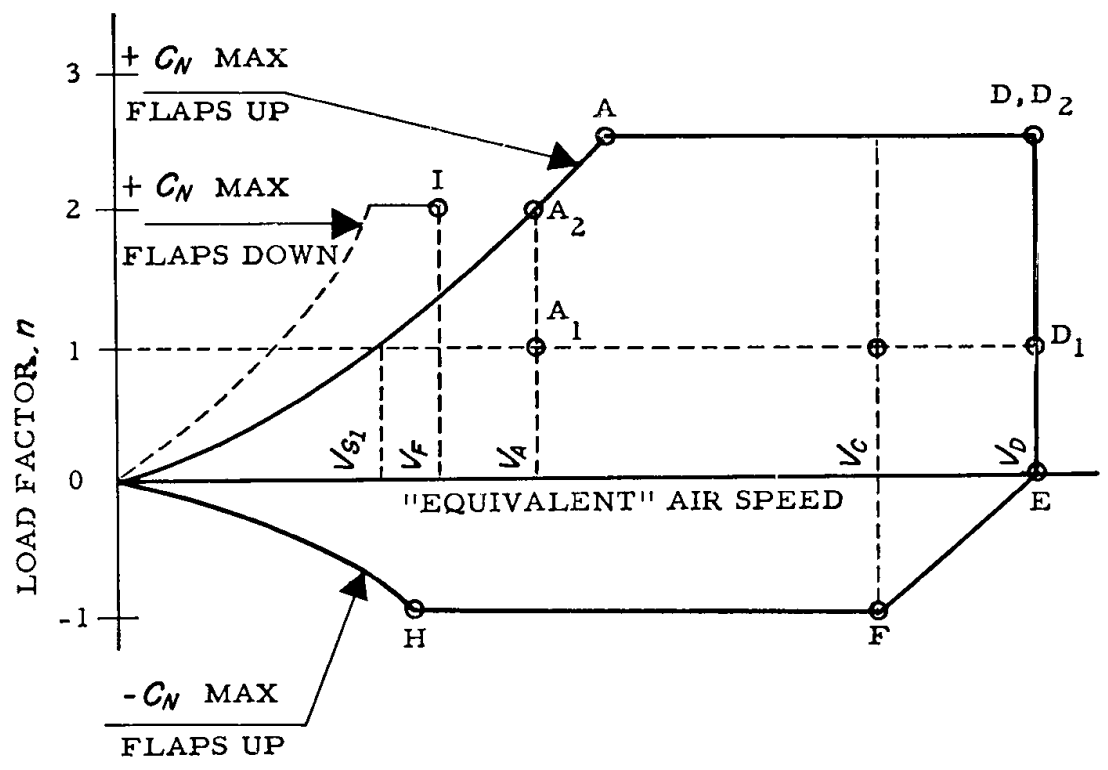

Figure 3.12: Flight Maneuvering Envelope as Outlined in Code of Federal Regulations [16] 
Simulating a $2.5 \mathrm{~g}$ symmetric pullup maneuver allows us to estimate the maximum aerodynamic load experienced by the wing and the winglet. The effectiveness of existing MLA methods to save aircraft weight has already been demonstrated by a $W B M$ reduction corresponding to a potential gross weight benefit of about $2 \%$ for a B-52 type aircraft [49. Existing MLA methods include but are not limited to the use of outboard ailerons, inboard flaps or the combinations of both to attenuate wing loads. However, even under moderate deflections, these control surfaces could produce regions of flow separation thereby causing degradation in wing performance [22]. A comparison of spanload between conventional aircraft and an aircraft equipped with MLA is shown in Fig. 3.13 [17. The two spanload distributions are different as the MLA-equipped aircraft uses coordinated control deflections to concentrate lift inboard the wing and reduce bending moment thus allowing MLA-equipped aircraft to be made lighter, longer and thinner at the same weight. Morphing winglet is studied as a potential candidate for MLA by reducing the $W B M$ and allowing higher spanload distribution on the inboard wing

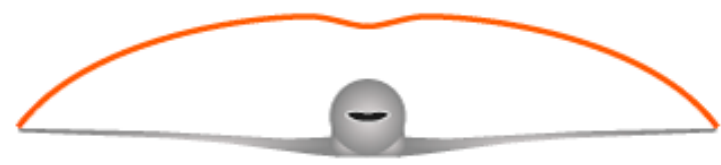

(a) Conventional aircraft

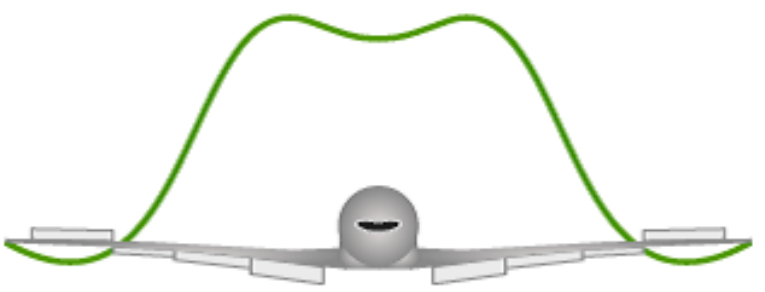

(b) Aircraft with MLA

Figure 3.13: Lift distribution with and without MLA at same load factor [17]

CFD solutions for maneuver load alleviation study are carried out for $C_{L}$ of 0.8 at Mach 0.45 and at an altitude of $10,000 \mathrm{ft}$ to simulate $2.5 \mathrm{~g}$ symmetric maneuver in flight. The Reynolds number is $35.5 \times 10^{6}$. The effects on resultant normal force coefficient on the winglet surface, $\sum C_{N}$ and the location of center of pressure, $x_{C_{P}}$ during maneuver load conditions are also considered in order to aid in proper design and selection of winglet actuation mechanism.

The total normal force coefficient is calculated by using the following equation:

$$
C_{N}=\sqrt{C_{y}^{2}+C_{z}^{2}}
$$

The resultant normal load on the winglet can then be calculated by using the dynamic pressure, $\mathrm{Q}$ 
and wing reference area, $S_{r e f}$.

$$
N=C_{N} \cdot Q \cdot S_{r e f}
$$

The location of center of pressure is evaluated by dividing $C_{m, x}$ by $C_{N}$ i.e.

$$
x_{c p}=\frac{C_{m, x}}{C_{N}}
$$

\subsubsection{Impact on Aircraft Structural Weight}

With the results of trade studies in hand, it is possible to quantify the true benefits of Morphing winglet over a conventional winglet for a selected mission. For instance, the famous Breguet range equation [50] can be applied in order to quantify the weight benefits of using morphing winglet.

From the Breguet equation,

$$
R=\frac{a \cdot M a c h}{c_{T}} \frac{C_{L}}{C_{D}} \ln \frac{W_{1}}{W_{2}}
$$

where $a$ is speed of sound in air, Mach is Mach number and therefore the term a.Mach represent true airspeed at the specified Mach Number. The term $c_{T}$ is the specific fuel consumption. $C_{L}$ and $C_{D}$ are lift and drag coefficient respectively. $W_{1}$ is maximum takeoff weight and $W_{2}$ is difference between $W_{1}$ and fuel weight.

The total range can be calculated by using all the known values together with the value of baseline drag. With the improved winglet configurations, the total drag is reduced. By using the reduced drag into the formulae and keeping the range the same, a new $W_{2}$ can be found. The difference between the baseline $W_{2}$ and new $W_{2}$ ( $W_{2}$ as a result of reduced drag) is the weight benefit. This weight is the additional weight of wing structure that can be used during aircraft design. 


\section{Chapter 4}

\section{Results of the Investigation}

\subsection{High Speed Design Space Exploration}

\subsubsection{Optimum Drag}

The variation of total drag due to the change in winglet cant angle and toe-out angle at high speed cruise conditions, are shown in Fig. 4.1. In order to quantify the benefits of morphing winglet, all the results are compared against the results obtained for baseline winglet and are presented as percentage differences or simple differences with reference to the baseline winglet. At Mach 0.85, $\Delta$ Toe of $-1^{\circ}$ showed minimum drag, whereas at Mach $0.90, \Delta$ Toe of $-2^{\circ}$ offered optimum aerodynamic performance at all cant angles. The largest reduction in total drag were $0.84 \%$ and $0.85 \%$ at Mach 0.85 and Mach 0.90 respectively both occuring at $\Delta$ Cant of $+40^{\circ}$. For lower cant angles than baseline cant angle, drag reduction was not possible.

\subsubsection{Drag Components}

The trends in the values of drag components viz. wave drag, induced drag and viscous drag were also explored in this study. Figure. 4.2 shows the drag components for cruise conditions (Mach 0.85 , $C_{L}$ 0.45) at $\Delta$ Cant of $0^{\circ}$. The minimum value of wave drag was obtained at $\Delta$ Toe of $-2^{\circ}$ with sharp increase in its value on either side of the optimum. The induced drag increased with the increase in toe-out angle from baseline toe-out angle. The induced drag decreased with decrease in toe-out angle from its baseline value with minimum induced drag at $\Delta T o e$ of $-3^{\circ}$. The value of viscous drag peaked on either side of the baseline value with minimum value at $\Delta T o e$ of $+2^{\circ}$. Finally, the total tail-off drag was found to be minimum at $\Delta T o e$ of $-2^{\circ}$ where the largest reduction in wave drag was observed.

To visualize the trends better, the drag components were plotted at three different cant angles as shown in Fig. 4.3, Fig. 4.4 and Fig. 4.5 . The three cant angles selected are low cant winglet $(\Delta$ Cant $=$ $\left.-40^{\circ}\right)$, baseline cant winglet $\left(\Delta\right.$ Cant $\left.=0^{\circ}\right)$ and high cant winglet $\left(\Delta\right.$ Cant $\left.=+40^{\circ}\right)$.

For low cant winglet (i.e. near-vertical winglet), wave drag reduced from $\Delta T o e=-3^{\circ}$ all the way to 


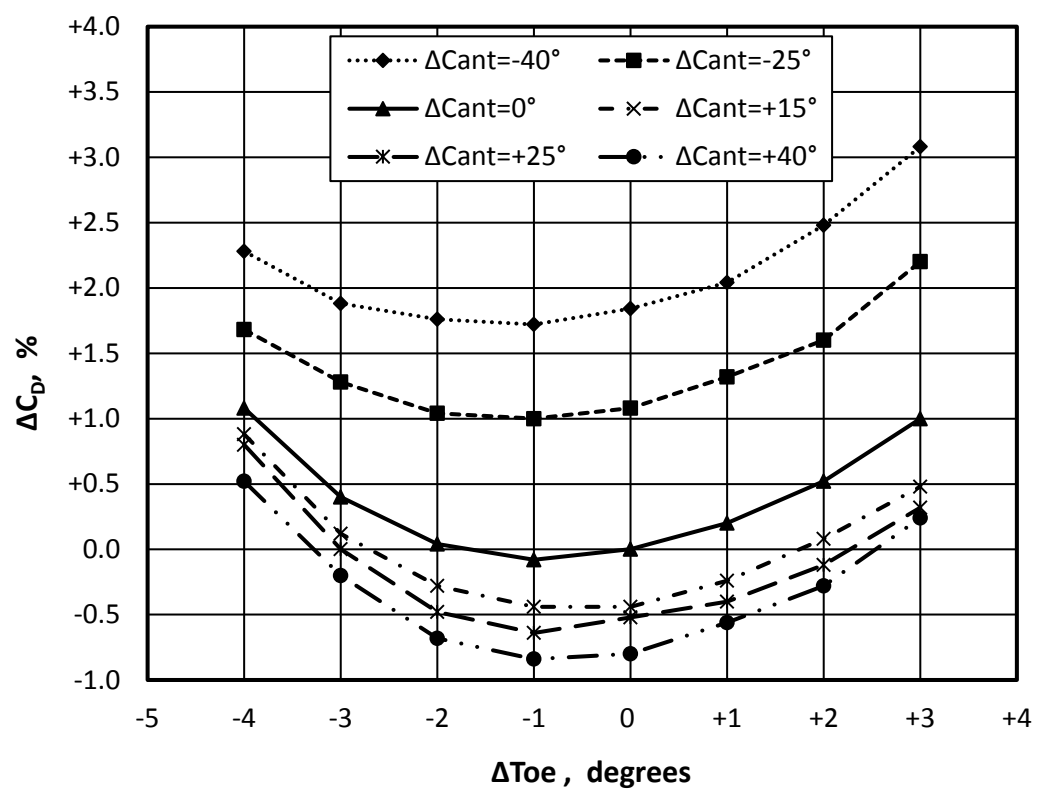

(a) $\mathrm{Mach}=0.85, C_{L}=0.45$

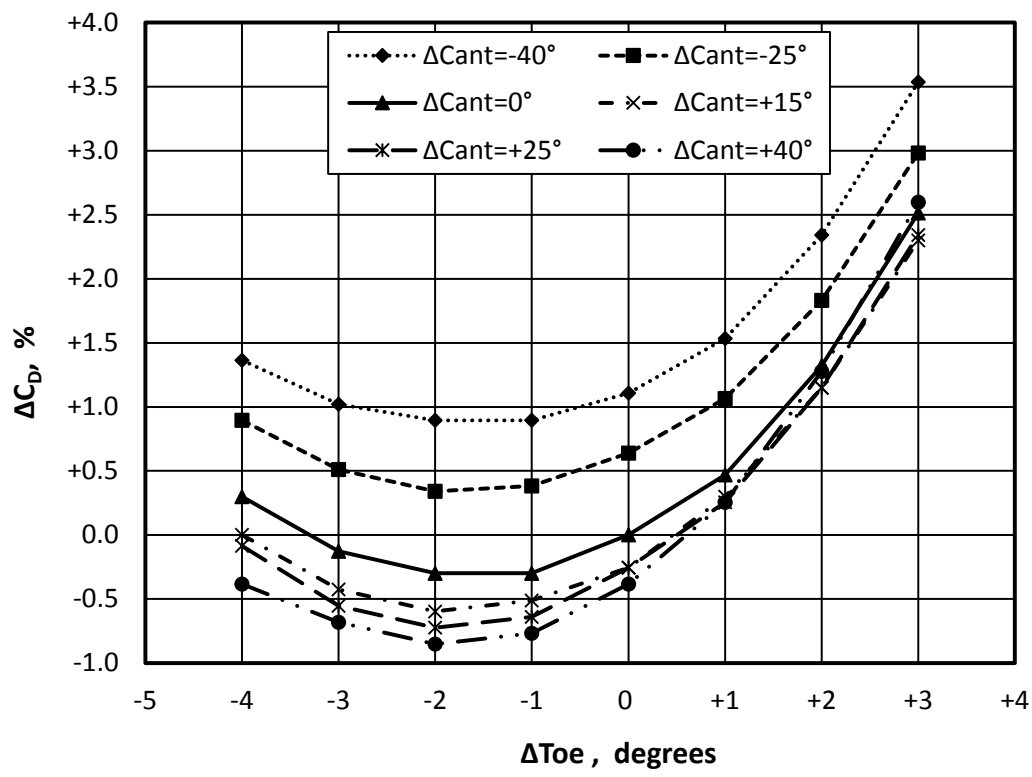

(b) $\mathrm{Mach}=0.90, C_{L}=0.30$

Figure 4.1: Comparison of total drag at high speed conditions 


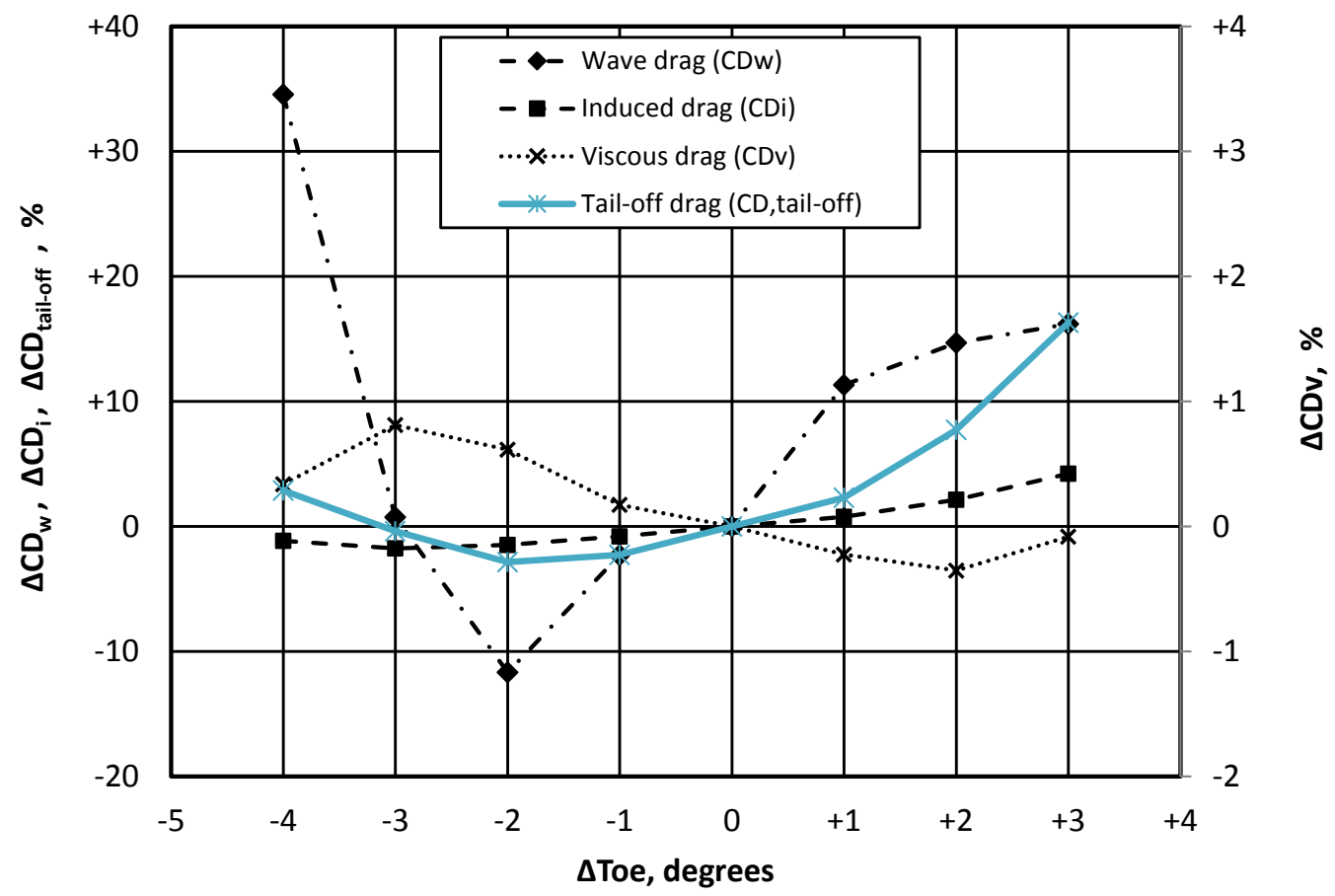

Figure 4.2: Drag components and total tail-off drag at Mach $0.85, C_{L} 0.45$ and $\Delta$ Cant $=0^{\circ}$. Note that viscous drag is shown on the right axis. Whereas wave drag, induced drag and total tail-off drag are on the left axis.

the baseline toe-out angle at which point the wave drag continued to level off until $\Delta T o e=+3^{\circ}$. For baseline cant winglet and high cant winglet configurations, the wave drag showed minimum value at $\Delta T o e=-2^{\circ}$ and $\Delta T o e=-1^{\circ}$ respectively.

The induced drag increased with increase in toe-out angle for all three cant configurations. At a given toe-out angle, high cant winglet displayed lower induced drag compared to the baseline cant winglet. Similarly, low cant winglet showed higher induced drag compared to baseline.

Viscous drag remained fairly constant with increase in toe-out angle for both baseline cant winglet and high cant winglet whereas for low cant winglet, viscous drag increased with increase in toe-out angle.

The trend in trim drag is shown in Fig. 4.6. The increase in toe-out angle showed reduction in trim drag for all cant angles. High cant winglet showed higher trim drag and low cant winglet displayed lower trim drag compared to the baseline at the same toe-out angle. 


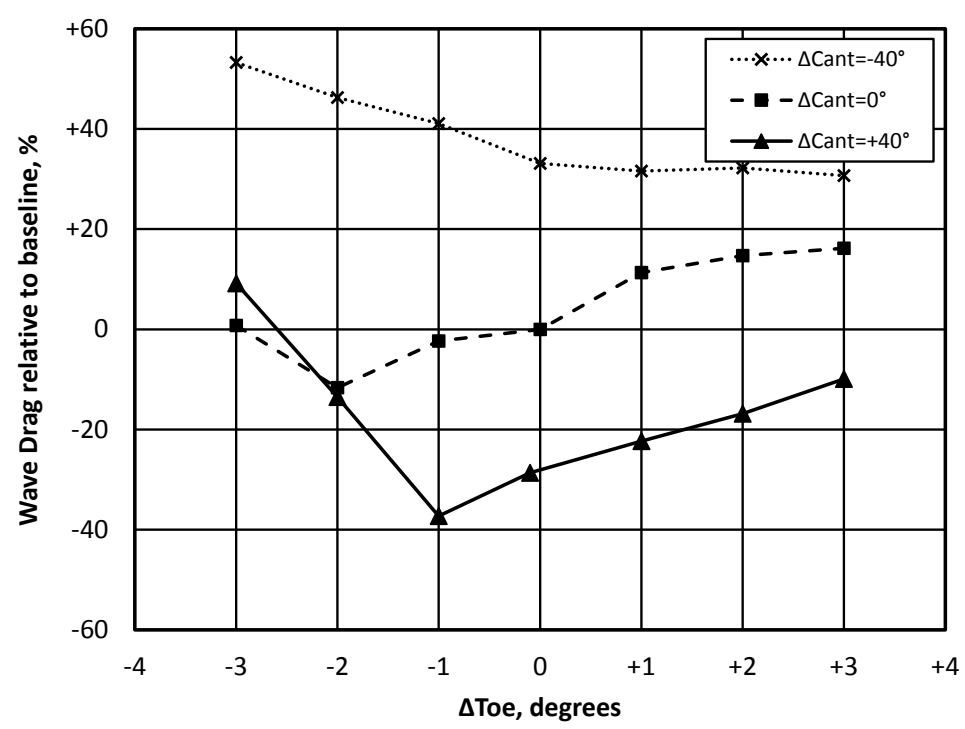

Figure 4.3: Wave drag at Mach $0.85, C_{L} 0.45$

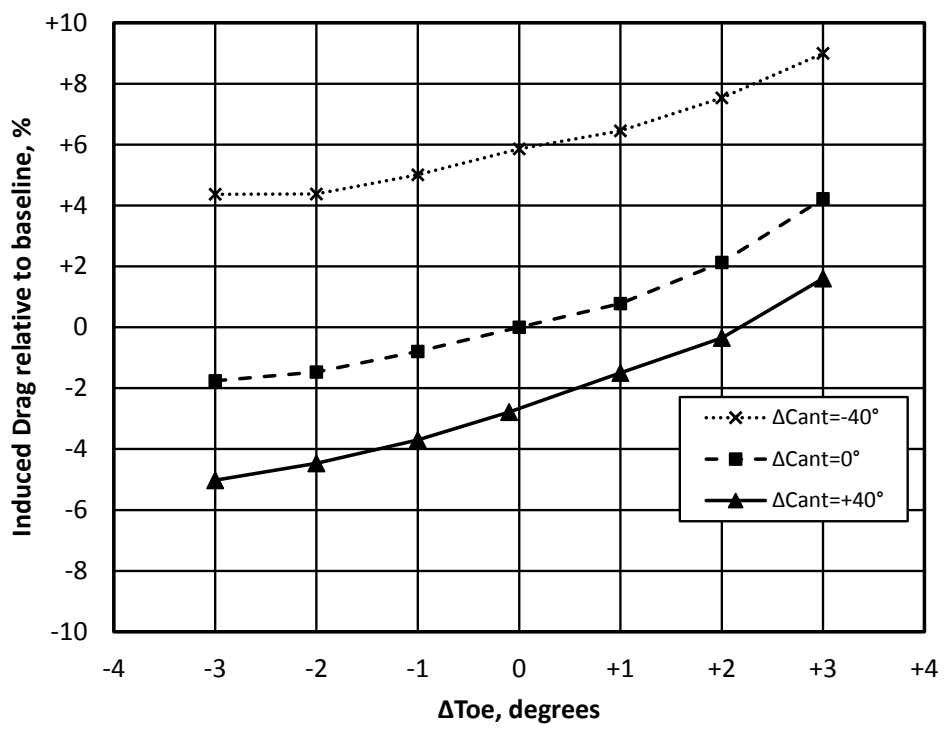

Figure 4.4: Induced drag at Mach $0.85, C_{L} 0.45$ 


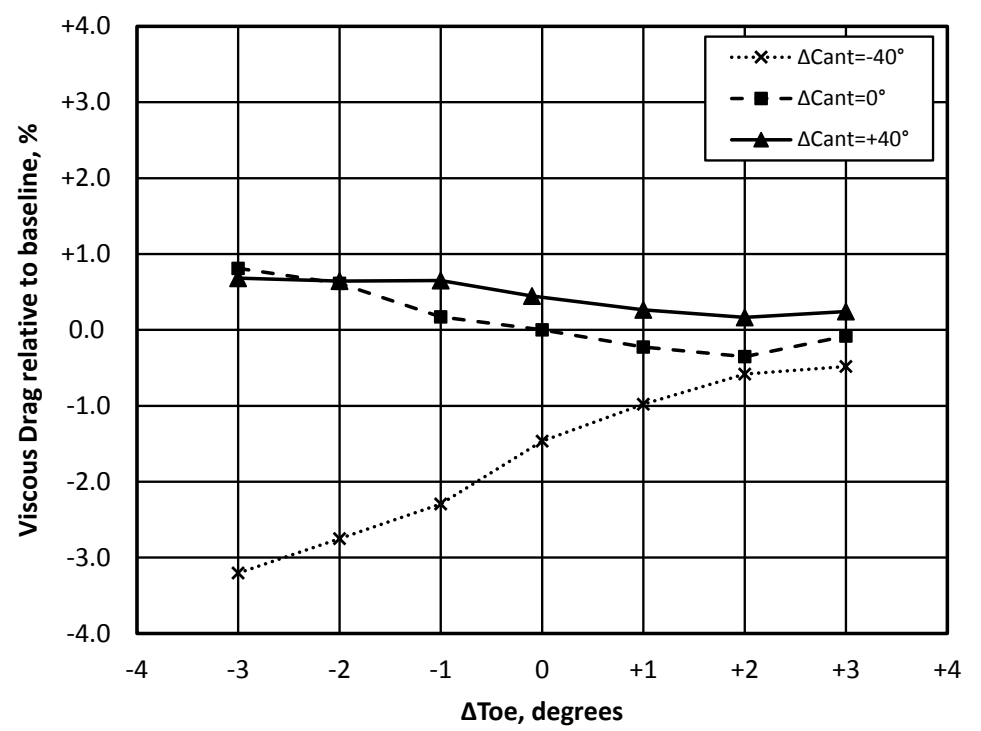

Figure 4.5: Viscous drag at Mach $0.85, C_{L} 0.45$

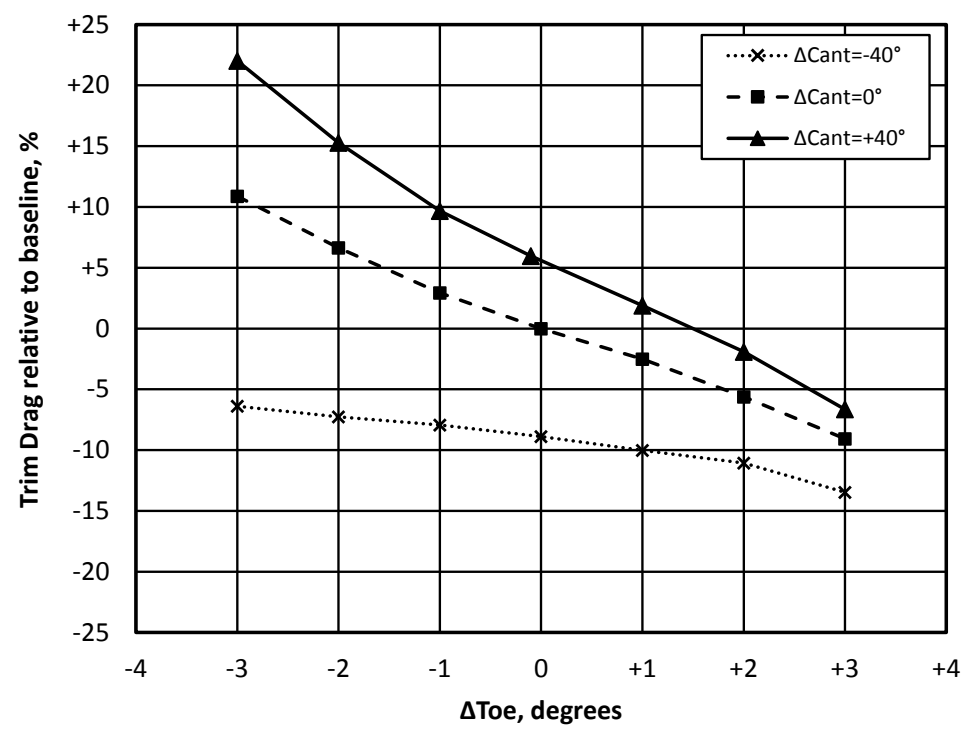

Figure 4.6: Trim drag at Mach $0.85, C_{L} 0.45$ 


\subsubsection{Optimum Bending Moment}

The results of the trade studies conducted for wing bending moment and winglet bending moment are shown in Fig. 4.7 and Fig. 4.8. At a constant toe-out angle, low cant winglet was effective in reducing both wing and winglet bending moment. For the configurations under consideration, $\Delta$ Cant of $-40^{\circ}$ demonstrated largest reductions in bending moments. For all cant angles, larger toe-out angle produced larger reductions in bending moments. It is clear with these results that increasing the toe-out has an effect so as to unload the winglet and to reduce both wing and winglet bending moment. Decreasing the cant angle from the baseline cant angle showed similar response. However, reductions in winglet bending moment were larger compared to the reductions in wing root bending moment suggesting that the loading on the winglet is more sensitive to toe-out and cant angle than loading on the wing. Furthermore, at both Mach numbers, the effect on winglet bending moment due to the change in cant angle was found to be comparatively smaller than that due to toe-out angle. These trends could be exploited by a morphing winglet during high speed flight and during g maneuver in order to obtain desired load on the wing and winglet.

\subsubsection{Optimum Drag with Constraint on Bending moment}

In another study, winglet cant angle was varied at a constant toe-out and its effect on total drag was obtained. The trend in the values of total drag is shown in Fig. 4.9 and Fig. 4.10 for Mach 0.85 and Mach 0.90 respectively. The drag results for optimum toe-out winglets at all cant angles are shown overlapping these plots. The drag results for winglets that are constrained by a constant value of $W B M$ are also shown in the same figure. This exercise was conducted to understand the trade-off between drag reduction and increment in wing root bending moment. As shown in the figures, the optimum toe-out winglets suffered a drag penalty when they were constrained by $W B M$ at both Mach numbers and at higher cant angles than baseline value. At lower cant angle than the baseline, wing bending moment is already lower than the baseline $W B M$. Imposing a constraint on $W B M$ would mean that changing the toe-out angle to increase $W B M$ which goes against the objective of this exercise. At Mach 0.85, the reduction in drag decreased from $0.84 \%$ to $0.25 \%$ at the most favourable winglet cant angle (i.e. $\Delta$ Cant of $+40^{\circ}$ ). At Mach 0.90, imposing $W B M$ constraint showed no drag benefits relative to baseline winglet as shown by Fig. 4.10. The diminishing return in aerodynamic performance with increase in cant angle suggests that it is aerodynamically favourable to limit the range of motion of the morphing winglet below $\Delta$ Cant of $+40^{\circ}$.

To better visualize the loading on the winglet, the variation in winglet loading due to change in cant angle are shown in Fig. 4.11. For a constant toe-out angle, the loading on the winglet increased with the increase in cant angle for both high speed conditions. For a desired $C_{L}$, the total drag was found to decrease with increase in cant angle. The variation of winglet loading due to the change in toe-out angle are shown in Fig. 4.12 For a constant cant angle, the loading on the winglet decreased with the increase in toe-out angle. For a desired $C_{L}$, with increase in toe-out angle, the total drag reduced upto an optimum value and then increased as already shown in this chapter. 


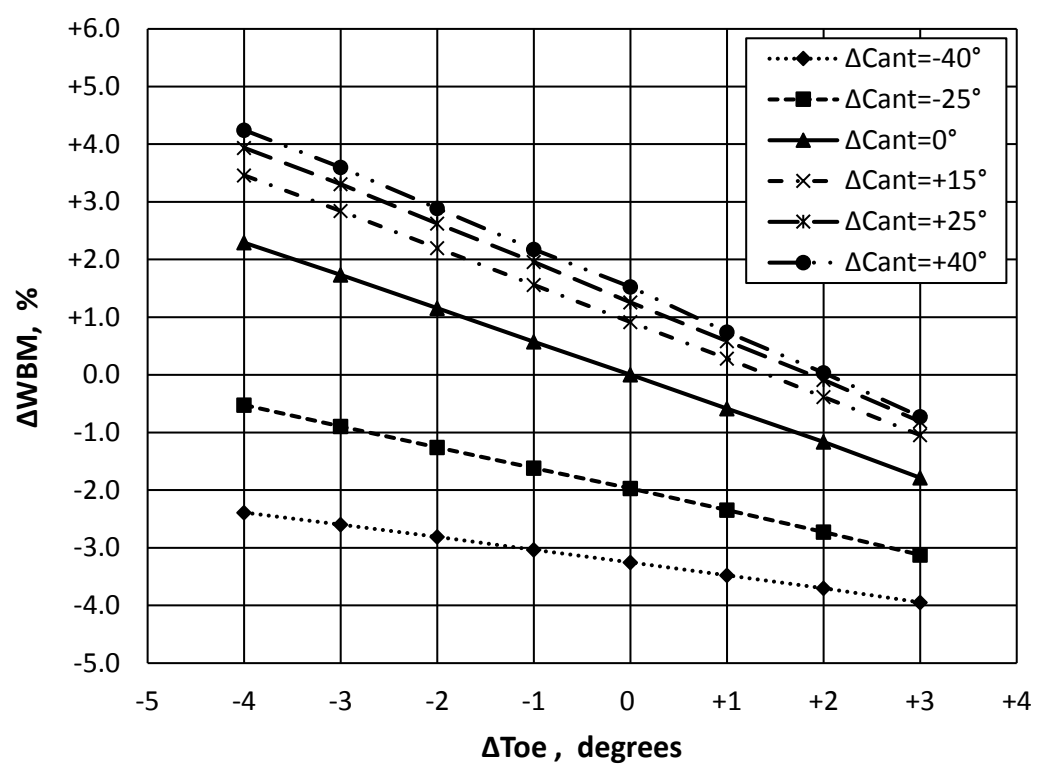

(a) $\mathrm{Mach}=0.85, C_{L}=0.45$

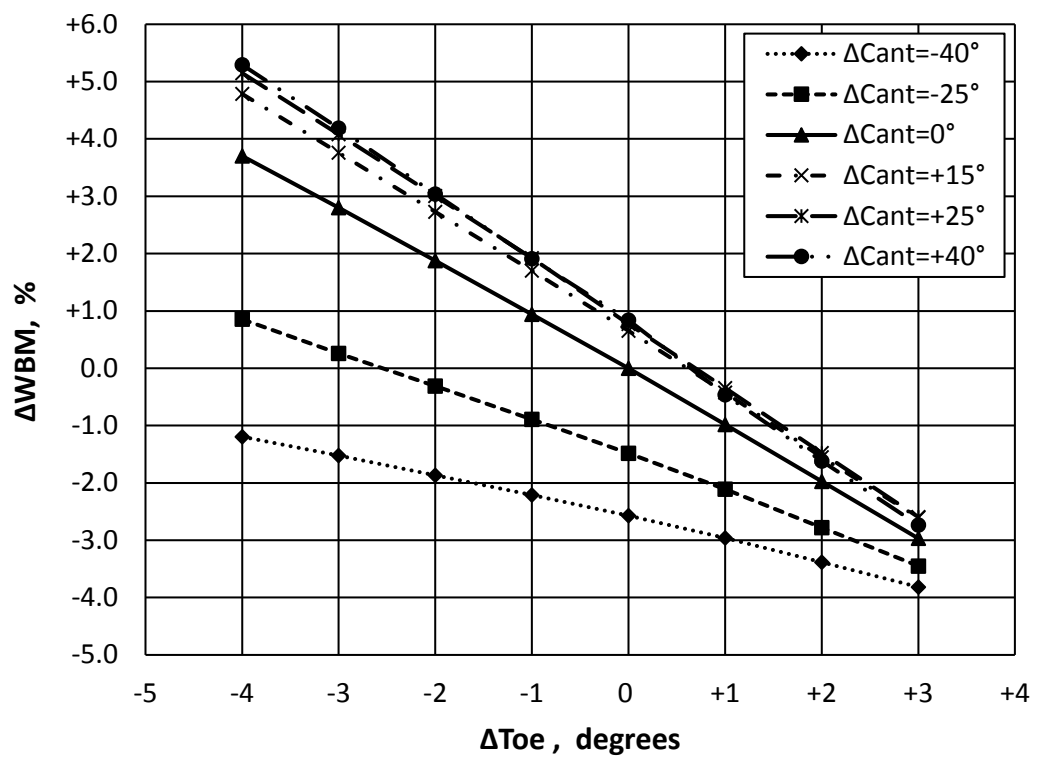

(b) $\mathrm{Mach}=0.90, C_{L}=0.30$

Figure 4.7: Wing bending moment $(W B M)$ at high speed conditions 


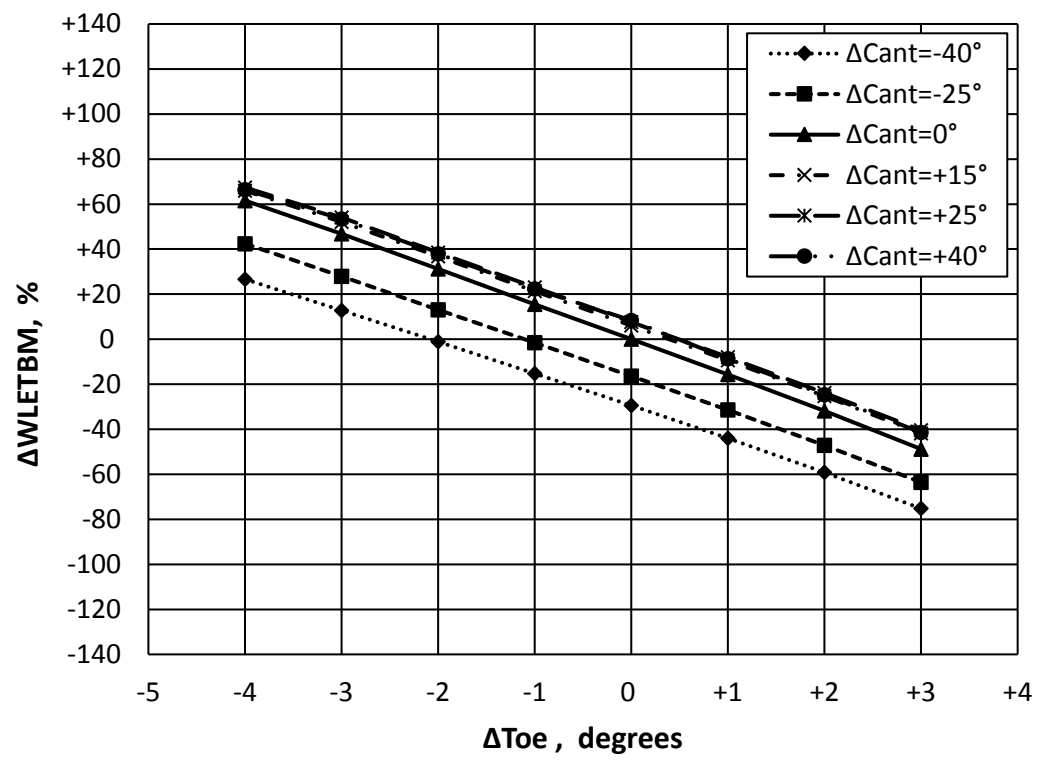

(a) $\mathrm{Mach}=0.85, C_{L}=0.45$

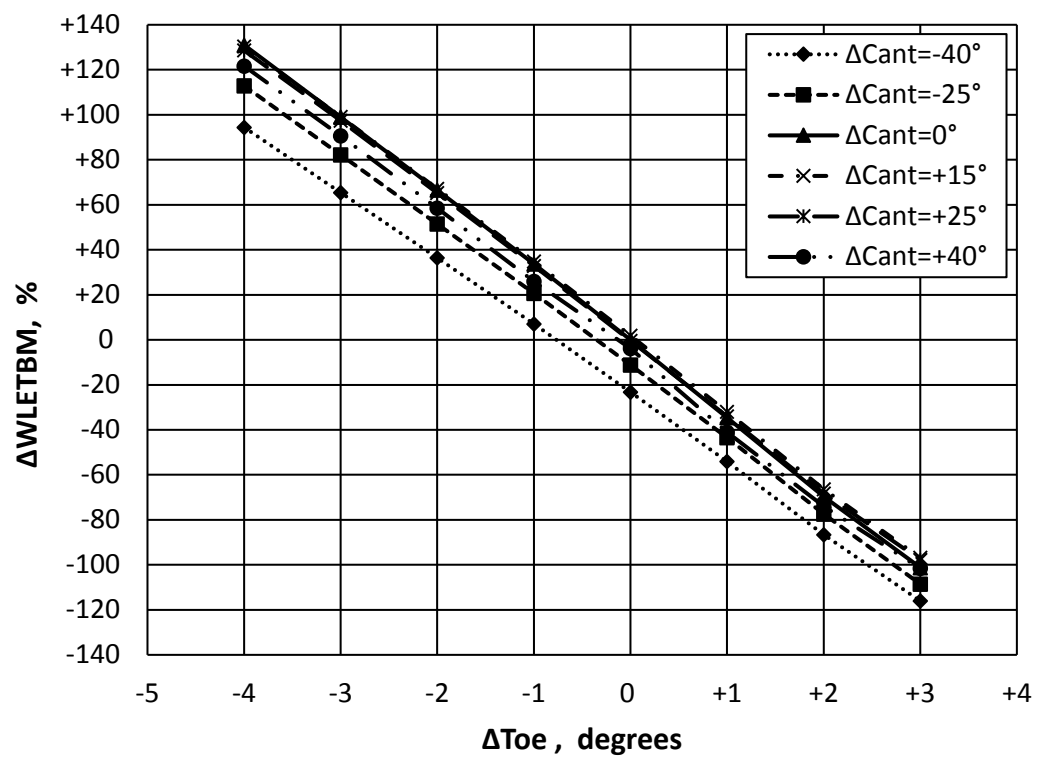

(b) $\mathrm{Mach}=0.90, C_{L}=0.30$

Figure 4.8: Winglet bending moment (WLETBM) at high speed conditions 


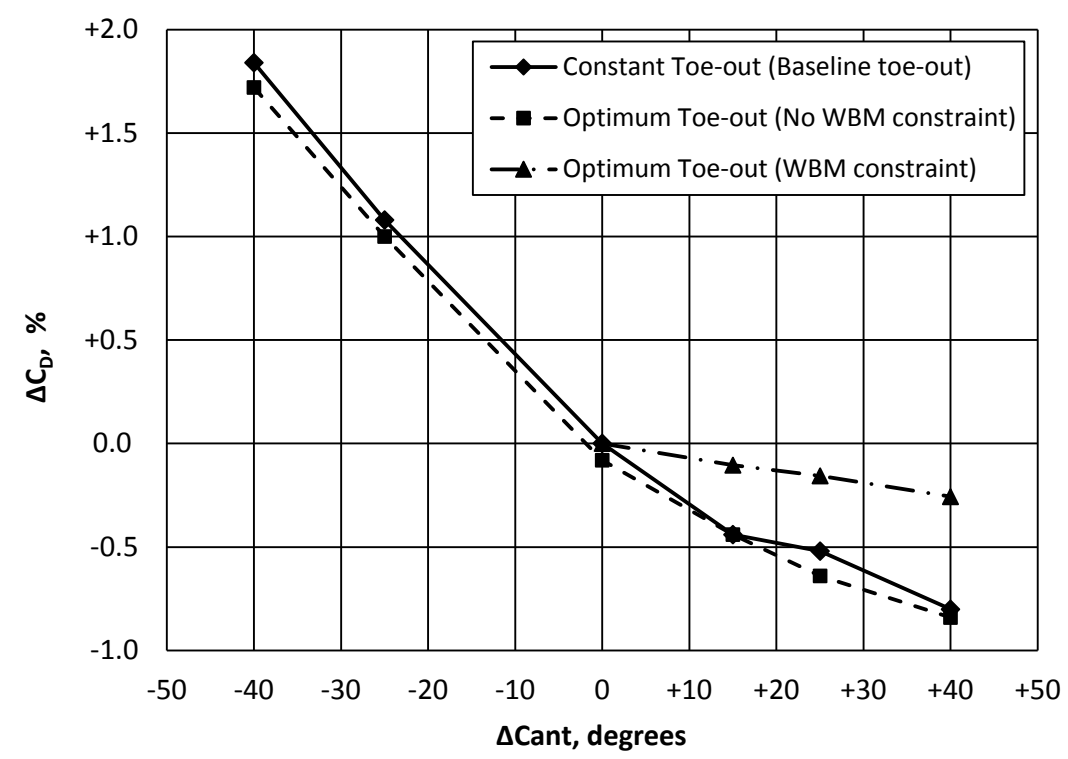

Figure 4.9: Total drag with and without $W B M$ constraint; Mach $=0.85, C_{L}=0.45$

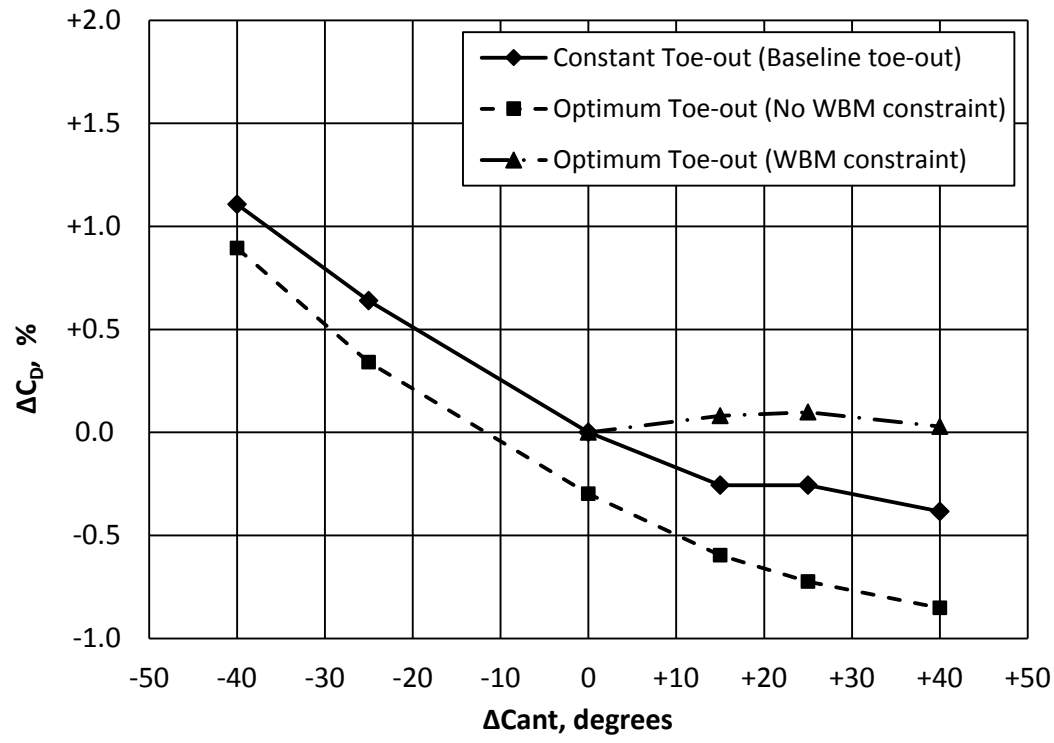

Figure 4.10: Total drag with and without $W B M$ constraint; Mach $=0.90, C_{L}=0.30$ 

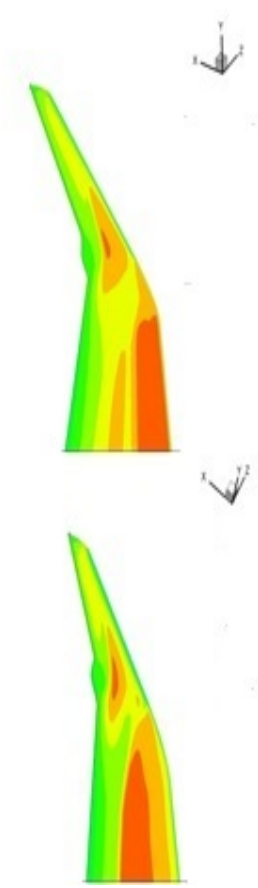
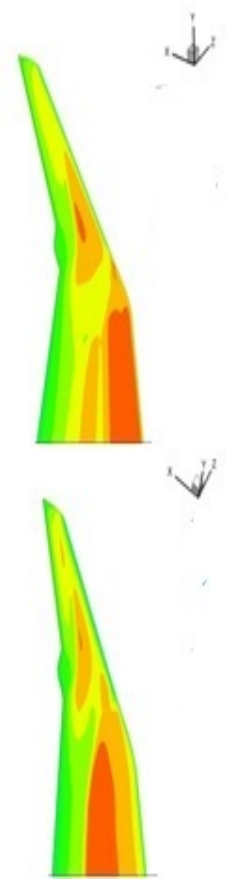
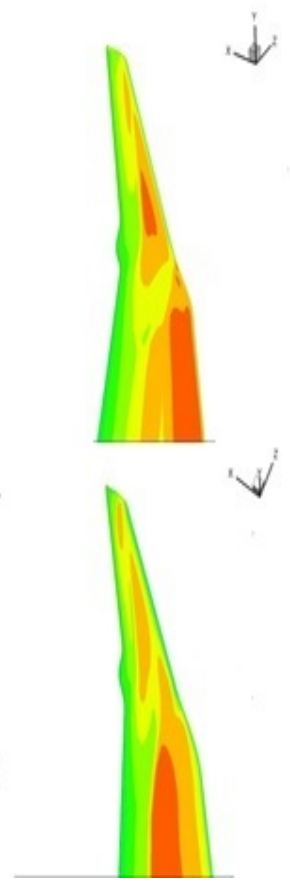
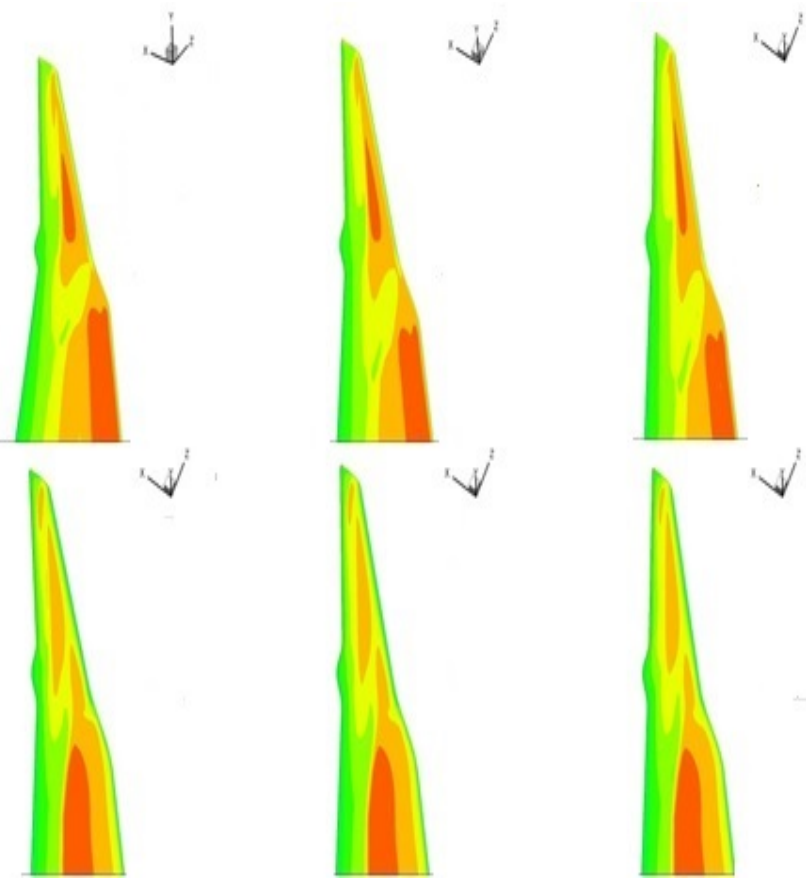

Figure 4.11: $C_{p}$ contours for various winglet configurations at baseline toe-out angle. Top: Mach 0.85, $C_{L}$ 0.45, Bottom: $M a c h$ 0.90 $C_{L}$ 0.30. Increasing cant from left to right. The darker regions in the contour plots indicate higher loading 

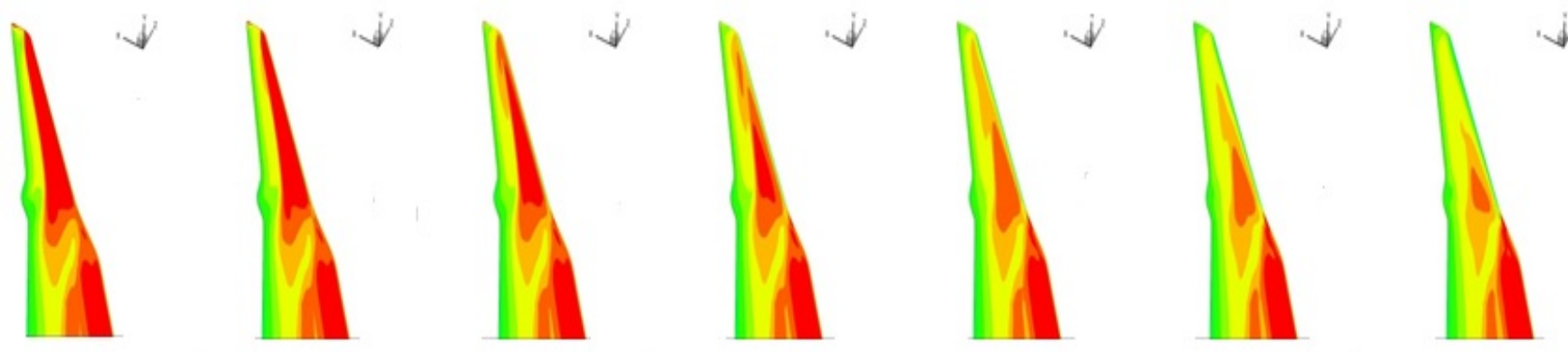

Figure 4.12: $C_{p}$ contours for various winglet configurations at baseline cant angle. Top: Mach $0.85, C_{L} 0.45$, Bottom: Mach $0.90, C_{L}$ 0.30. Increasing toe-out from left to right. The darker regions in the contour plots indicate higher loading 


\subsection{Aero-elastic effects}

\subsubsection{Aero-elastic Effects on Drag and Bending Moment}

The best toe-out configurations at different cant angles were the primary foci of this study. As mentioned in Section 4.1.1, the optimum toe-out was found to be $\Delta T o e$ of $-1^{\circ}$ and $-2^{\circ}$ at Mach 0.85 and Mach 0.90 respectively. The normal force, $C_{N}$ on the winglet for low cant and high cant winglets were compared against the baseline winglet. The aero-elastic effects were also quantified by comparing the drag and bending moment benefits of rigid wing against elastic wing at all loadcases under consideration.

Tables. 4.1 and 4.2 show total drag comparison for best rigid wings and elastic wings for six loadcases introduced in Table. 3.1 in Section 3.4.5. The results obtained for the elastic wings were compared against baseline wing at same loadcase conditions. At Mach 0.85, the optimum drag benefit was seen to decrease from $-1.3 \%$ to $-1.0 \%$ at loadcase L2 and to $-0.6 \%$ at loadcase L0. At Mach 0.90 , the drag benefit deteriorated from $-0.5 \%$ to $-0.1 \%$ for best winglet at loadcase L5 but there was no drag benefit at loadcase L3 and L4. However, it is worth nothing that there is a trend in deterioration of drag benefits from L2 to L0 i.e. with increasing dynamic pressure. Similar trends were noted for bending moment values. An elastic wing with low cant winglet offered $\triangle W B M$ of only $-2.1 \%$ (compared to $-3.7 \%$ for rigid wing) and $\triangle W L E T B M$ of $-24.2 \%$ (compared to $-25.9 \%$ for rigid wing).

Table 4.1: Aero-elastic effect on optimum toe-out winglets at $M a c h 0.85, C_{L} 0.45$

\begin{tabular}{ccrrr}
\hline \hline$\Delta$ Cant & Loadcase & $\Delta C_{D}(\%)$ & $\Delta W B M(\%)$ & $\Delta W L E T B M(\%)$ \\
\hline$-40^{\circ}$ & rigid & +2.6 & -3.7 & -25.9 \\
& L0 & +1.8 & -2.1 & -24.2 \\
& L1 & +2.2 & -2.3 & -23.6 \\
& L2 & +2.4 & -2.5 & -23.5 \\
$-25^{\circ}$ & rigid & +1.6 & -2.3 & -14.0 \\
& L0 & +0.7 & -0.8 & -11.7 \\
& L1 & +1.0 & -1.0 & -11.6 \\
& L2 & +1.3 & -1.2 & -11.8 \\
$+15^{\circ}$ & rigid & -0.7 & +0.9 & +6.1 \\
& L0 & -0.3 & +0.2 & +3.7 \\
& L1 & -0.4 & +0.3 & +4.4 \\
& L2 & -0.6 & +0.4 & +5.1 \\
$+25^{\circ}$ & rigid & -1.0 & +1.3 & +7.6 \\
& L0 & -0.5 & +0.2 & +4.2 \\
& L1 & -0.6 & +0.3 & +5.0 \\
& L2 & -0.8 & +0.5 & +6.0 \\
$+40^{\circ}$ & rigid & -1.3 & +1.5 & +7.0 \\
& L0 & -0.6 & +0.1 & +3.6 \\
& L1 & -0.8 & +0.3 & +4.9 \\
\hline & L2 & -1.0 & +0.5 &
\end{tabular}


Table 4.2: Aero-elastic effect on optimum toe-out winglets at $M a c h 0.90, C_{L} 0.3$

\begin{tabular}{lcrrr}
\hline \hline$\Delta$ Cant & Loadcase & $\Delta C_{D}(\%)$ & $\Delta W B M(\%)$ & $\Delta W L E T B M(\%)$ \\
\hline$-40^{\circ}$ & rigid & +2.1 & -3.4 & -23.2 \\
& L3 & +1.3 & -1.6 & -22.8 \\
& L4 & +1.6 & -1.8 & -20.1 \\
$-15^{\circ}$ & L5 & +1.8 & -2.1 & -19.0 \\
& rigid & +1.3 & -2.2 & -13.4 \\
& L3 & +0.5 & -0.5 & -12.0 \\
& L4 & +0.8 & -0.6 & -10.1 \\
$+15^{\circ}$ & L5 & +1.1 & -0.8 & -9.42 \\
& rigid & -0.2 & +0.4 & -3.20 \\
& L3 & +0.3 & -0.2 & -8.75 \\
& L4 & +0.1 & -0.1 & -6.43 \\
$+25^{\circ}$ & L5 & -0.1 & 0.0 & -4.56 \\
& rigid & -0.4 & +0.6 & -4.65 \\
& L3 & +0.3 & -0.2 & -11.5 \\
& L4 & +0.1 & -0.1 & -8.95 \\
$+40^{\circ}$ & L5 & -0.2 & 0.0 & -6.77 \\
& rigid & -0.5 & +0.6 & -9.60 \\
& L3 & +0.3 & -0.4 & -17.6 \\
& L4 & +0.1 & -0.3 & -14.8 \\
& L5 & -0.1 & -0.2 & -12.2 \\
\hline
\end{tabular}

\subsubsection{Aero-elastic Effects on Wing Loading}

The aero-elastic effects on wing loading were found to be different for different winglet configurations. As shown in Fig. 4.13, winglet is less loaded than baseline winglet at lower cant angle than baseline. Wing deformations increase the loading compared to rigid wing-winglet combination by decreasing the wing twist as shown in Fig. 4.14. On the other hand, at higher cant angle than the baseline, winglet is more loaded than baseline winglet. The effect of wing deformations is opposite in this case as shown in aforementioned spanload distribution and twist distribution plots.

The effect of static aero-elasticity on the optimum designs was studied. Aero-elasticity was found to dampen the difference in loading between the baseline cant winglet and the new cant configurations as depicted in Fig. 4.15 thereby making design space flatter. The figure shows total normal loading for low cant to high cant winglets for three loadcases L0, L1 and L2. 


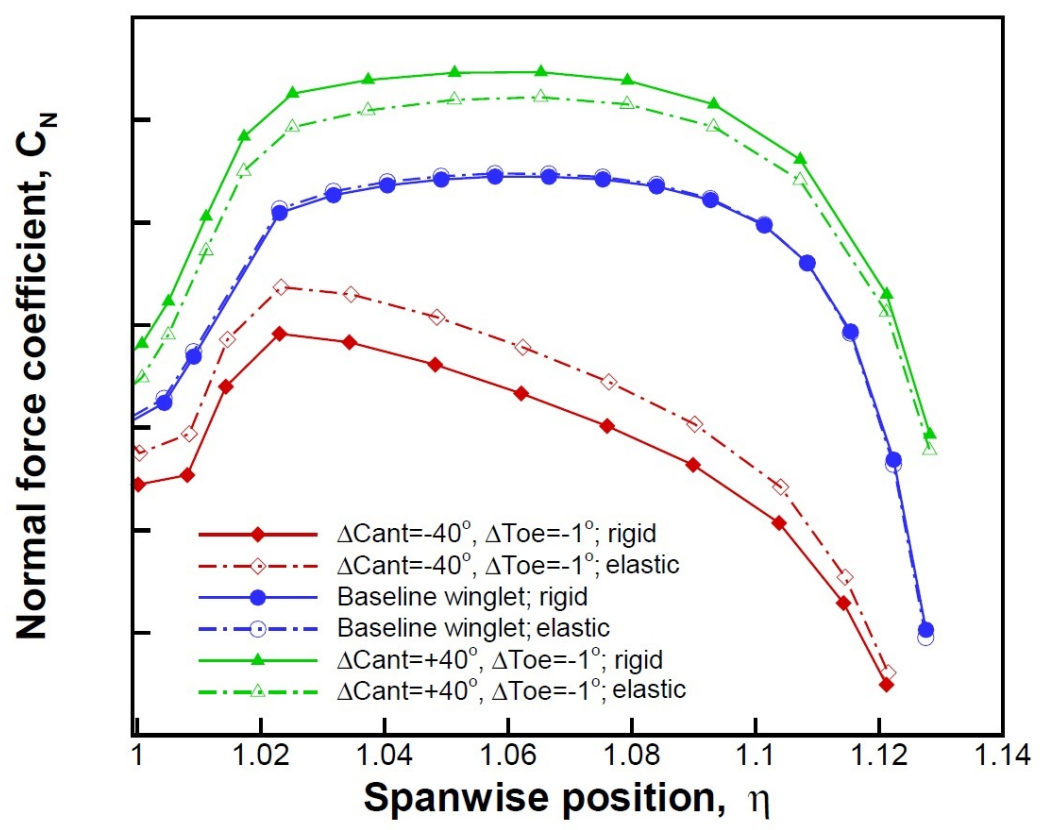

Figure 4.13: Comparison of normal force between rigid and elastic winglets at Loadcase L2

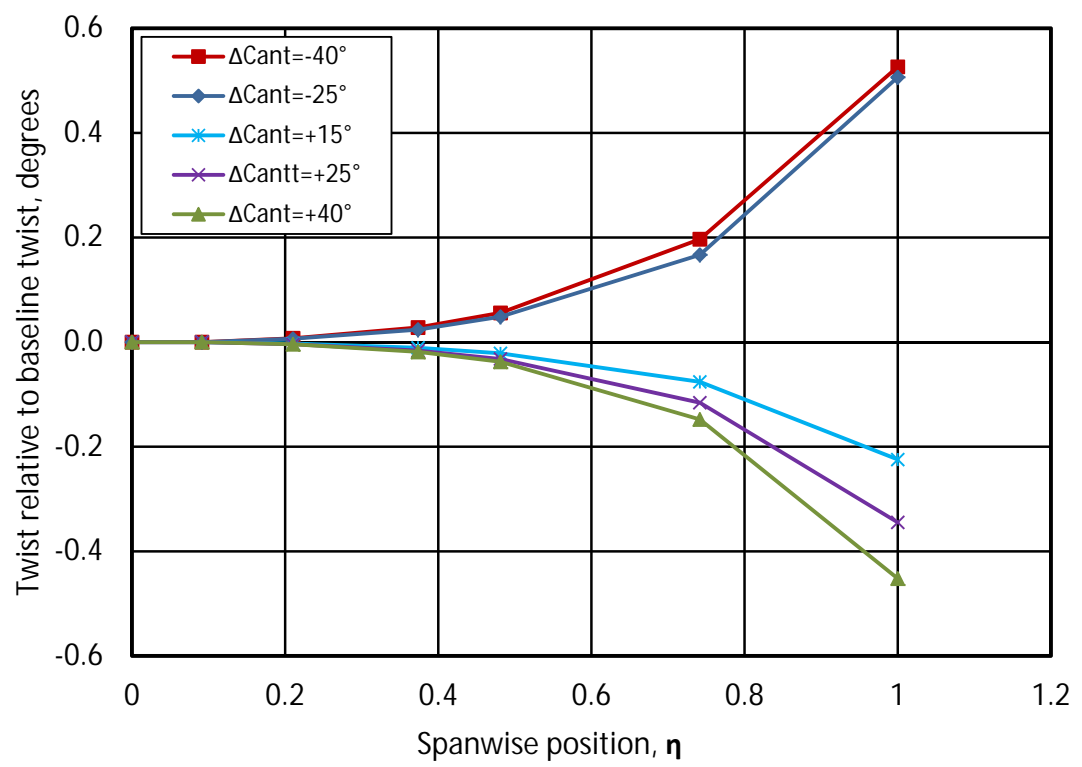

Figure 4.14: Comparison of wing twist at various spanwise positions at Loadcase L2 


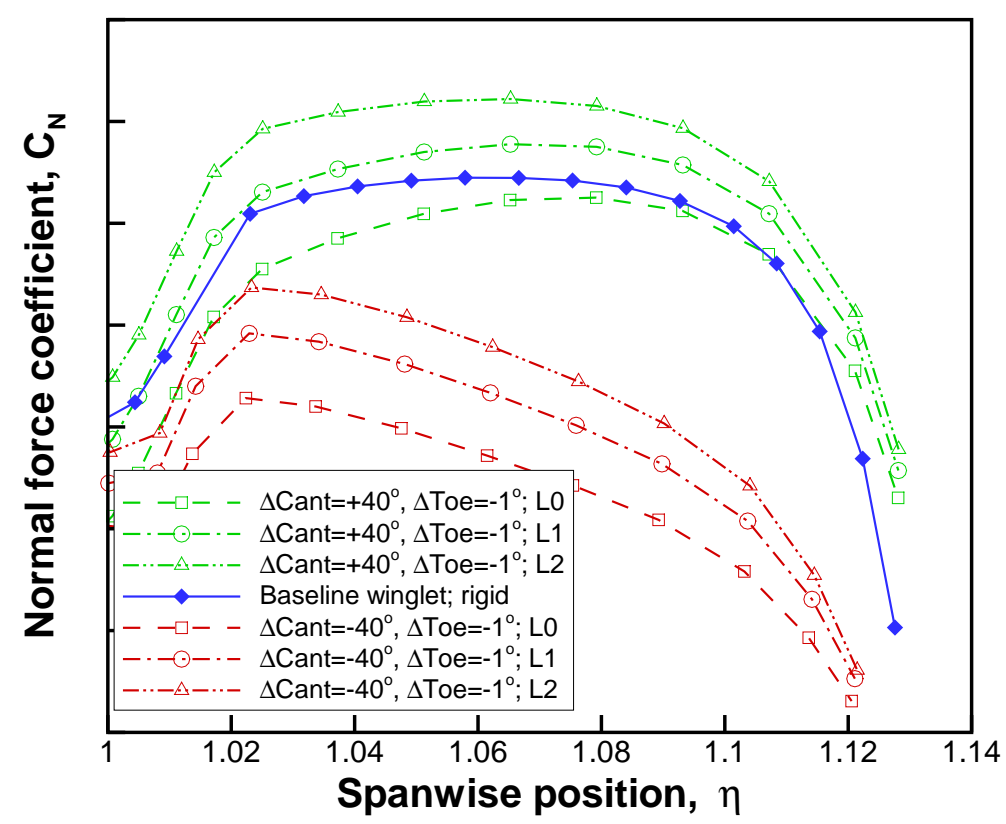

Figure 4.15: Aeroelastic effect on low cant and high cant winglets compared with baseline winglet

\subsection{Low speed characteristics}

A stall study was conducted at Mach 0.2 in order to understand the relation between winglet design parameters and stall characteristics of an aircraft. The stall angles were predicted for the winglet at various toe-out angles and three cant angles viz. low cant $\left(\Delta C a n t=-40^{\circ}\right)$, baseline cant $\left(\Delta C a n t=0^{\circ}\right)$ and high cant $\left(\Delta\right.$ Cant $\left.=+40^{\circ}\right)$.

\subsubsection{Stall angle}

The stall angles relative to the baseline winget are presented in Fig. 4.16. At low cant angle, the winglet stalled at higher angle of attack relative to baseline thus suggesting improvement in stall characteristics. On the other hand, at high cant angle, the winglet stalled at relatively lower angle of attack suggesting degradation in the stall characteristics. Furthermore, the variation of stall angle with respect to the toe-out angle was found to be linear at all cant angles. For each degree change in toe-out angle, the stall angle was found to change by half a degree.

The stall angles were also predicted for optimum toe-out configurations (i.e. toe-out that showed least drag) with and without $W B M$ constraint, at six different cant angles. The results are presented in Fig. 4.17. The stall angle deteriorated with increase in cant angle at a constant toe-out angle. This was also already observed in Fig. 4.16. When the $W B M$ constraint was applied to these higher cant winglets, the stall angles remained unchanged and were higher than stall angles for optimum toe-out winglets with no $W B M$ constraint. This is because winglets needed an increase in toe-out angle to 


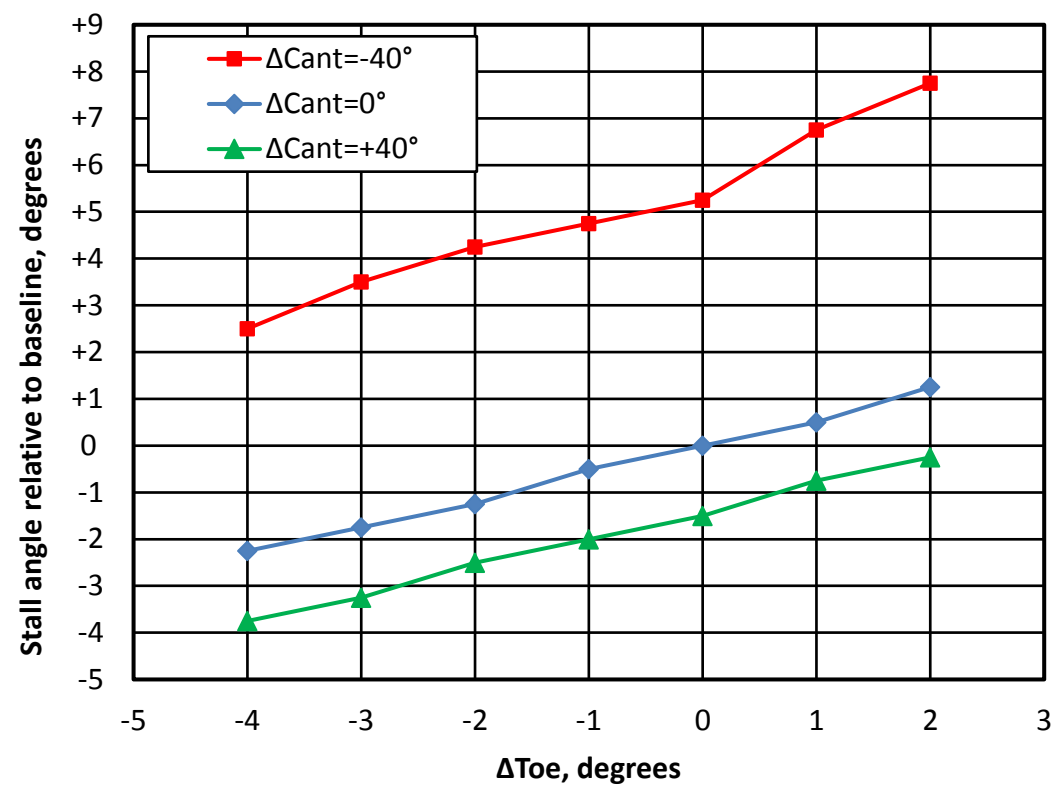

Figure 4.16: Stall characteristics for low cant to high cant winglet at Mach 0.2

unload the wing and keep $W B M$ constant. Increase in toe-out angle directly translates to decrease in winglet incidence angle relative to free stream flow. This results in higher stall angle because the winglet is less loaded. At $\Delta$ Cant of $0^{\circ}$, the toe-out angle had to lower to maintain the $W B M$ constant thereby loading the winglet more. Hence, this winglet is an exception in the figure with a lower stall angle than optimum toe-out winglet with no $W B M$ constraint. At $\Delta$ Cant of $+40^{\circ}$, the optimum toe-out winglet has stall angle below the baseline winglet's value. This is the penalty that one has to pay for improving drag.

\subsubsection{Maximum Lift Coefficient}

In order to understand the effect on maximum lift coefficient, the values of $C_{L_{\max }}$ were evaluated at various cant angles and toe-out angles. The results are shown in Fig. 4.18. As expected, the trends in the values of $C_{L_{\max }}$ are similar to the trends observed for stall angle. With low cant and high toe-out angle winglet, the value of $C_{L_{m a x}}$ increased by upto $48 \%$ relative the baseline winglet configuration. 


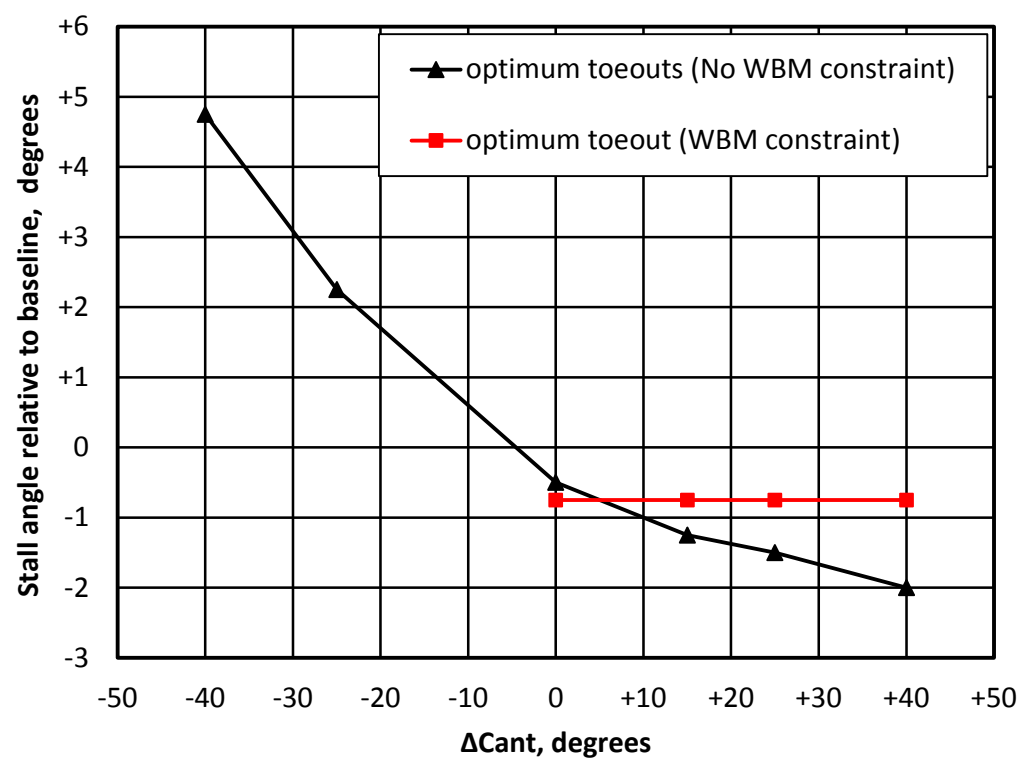

Figure 4.17: Stall characteristics for optimum toe-out winglets at Mach 0.2

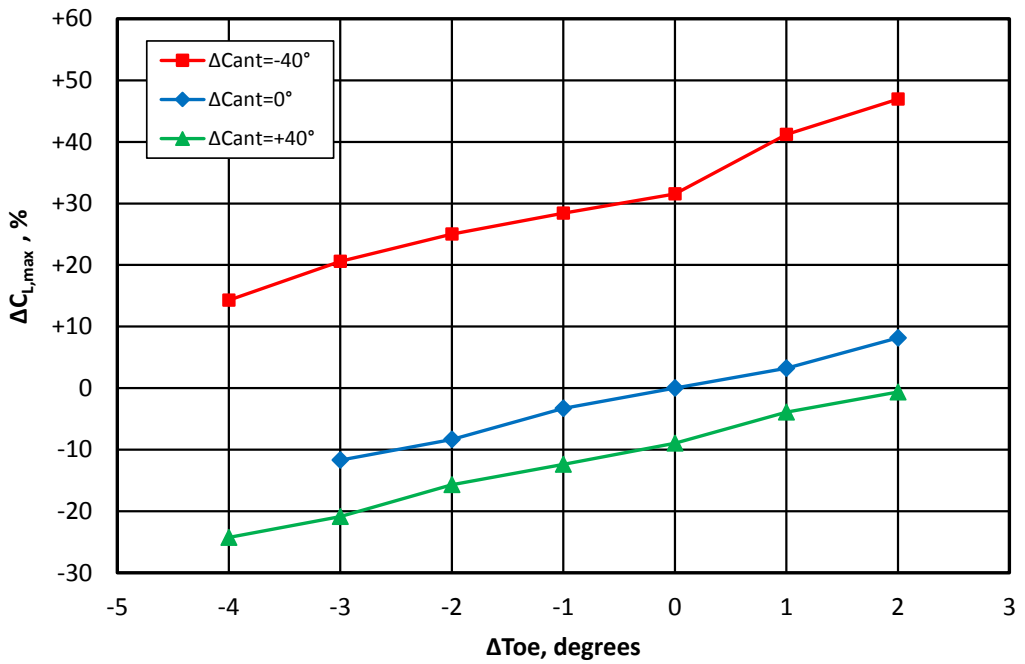

Figure 4.18: Variation of maximum lift coefficient $C_{L_{\max }}$ with winglet design parameters 


\subsection{Maneuver Load Alleviation}

\subsubsection{Bending Moment Considerations}

The potential benefits of morphing winglet in attenuating maneuver loads was examined by comparing $W B M$ and the contribution of winglet on total $W B M$ (i.e. $W L E T W B M$ ) for low cant to high cant winglets. The wing deformations were considered in the CFD simulations by iteratively calculating loads (both bending and torsion) and deformations due to these loads until a converged set of deformation values were reached. The comparisons of bending moments against the baseline winglet were made for both rigid and elastic wing and are shown in Table. 4.3 .

\begin{tabular}{clrrr} 
Table 4.3: Winglets under maneuver load conditions and at baseline toe-out angle \\
\hline \hline$\Delta$ Cant & Remarks & $\Delta W B M[\%]$ & $\Delta W L E T B M[\%]$ & $W L E T W B M[\%]$ \\
\hline \multirow{2}{*}{$40^{\circ}$} & Rigid & -3.8 & -49 & 2.5 \\
& Elastic & -2.1 & -44 & 2.3 \\
$0^{\circ}$ & Rigid & 0.0 & 0.0 & 7.5 \\
& Elastic & 0.0 & 0.0 & 6.5 \\
$+40^{\circ}$ & Rigid & +1.6 & +123 & 10.2 \\
& Elastic & -0.7 & +65 & 8.5 \\
\hline
\end{tabular}

As shown in Table. 4.3 a low cant winglet was effective in reducing both $W B M$ and $W L E T B M$, providing $2.1 \%$ reduction in $W B M$ (compare $3.8 \%$ for rigid wing) and $44 \%$ reduction in $W L E T B M$ (compare $49 \%$ for rigid wing). This is the savings that could pay for the extra weight of the morphing winglet. In contrast, a high cant winglet showed only $0.7 \%$ reduction in $W B M$ and $65 \%$ increase in $W L E T B M$. The values of $W L E T W B M$ suggests that low cant winglet has the least contribution on $W B M$ thereby reinforcing the load alleviating capability of a low cant winglet.

The further reduction in root bending moment due to aero-elastic deformation can be explained by a special root bending moment relief mechanism due to winglets [18. Figure. 4.19 shows a winglet which is vertically oriented in straight level flight $(\mathrm{n}=1.0)$. The resulting aerodynamic load can be represented by a force vector which points inboard.
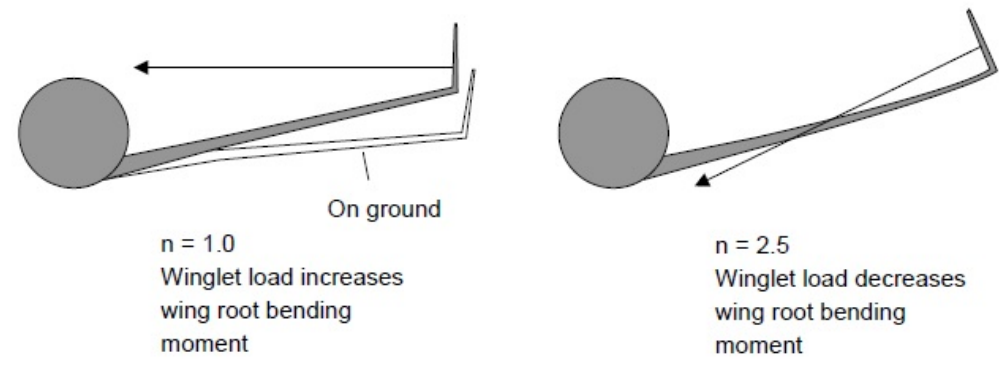

Figure 4.19: Wing root bending moment relief due to load vector [18] 
Under maneuver loads, the wing may bend upwards so that the load vector of the winglet passes below the wing root, giving some bending moment relief at the inner wing compared to the design static loads. However, increased bending moments at the outer wing remain almost unchanged resulting in overall reduced bending moment.

\subsubsection{Spanload Considerations}

The differences in deformations and spanload distribution between rigid winglets and elastic winglets under 2.5g loading are shown in Fig. 4.20 and Fig. 4.21 respectively. A closer look the spanload distribution on the inboard wing is shown in Fig. 4.22 for clarity. As shown in Fig. 4.20, low cant winglet (lower cant angle than baseline winglet) undergoes the least amount of deformation and high cant winglet (higher cant angle than baseline) undergoes the highest deformation. The spanload distribution in Fig. 4.21 suggest that high cant winglet has higher loading on outboard wing. This higher loading vector acting on a winglet reduces the total wing bending moment by virtue of aforementioned root bending moment relief mechanism [18]. This possibly explains the $0.7 \%$ reduction of $W B M$ for high cant winglet with respect to the baseline as shown in Table. 4.3 although the contribution of winglet on $W B M$ has increased by $2 \%$ for high cant winglet (6.5\% to $8.5 \%$ ) compared to around $4 \%$ decrease for low cant winglet.

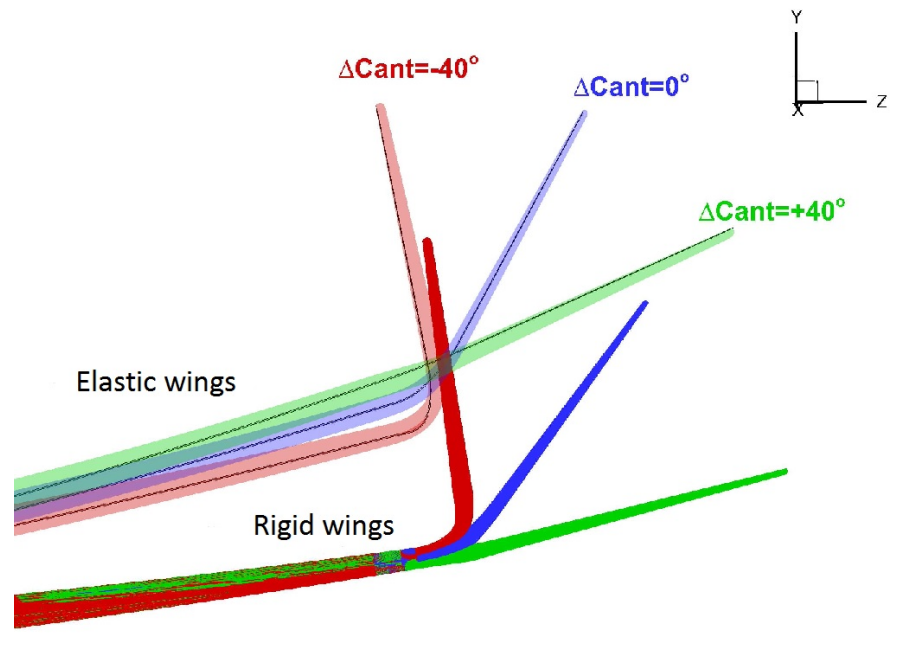

Figure 4.20: Wing-winglet deformation under 2.5g symmetric maneuver load. Higher cant winglet deforms more than lower cant winglet under the same load.

In another study, toe-out angle was varied at both $\Delta C a n t=0^{\circ}$ and $\Delta C a n t=-40^{\circ}$ in an attempt to determine if further load relief on the wing is possible. Toe-out angle was varied from $0^{\circ}$ to $+3^{\circ}$ relative to the baseline and the loads were calculated. The results are presented in the Tables. 4.4 and 4.5 The value of $\sum C_{N}$ is also shown in these tables. For $\Delta C a n t=0^{\circ}$, the variation of location of center of pressure i.e. $x_{C P}$ is also shown. The reference location for $x_{C P}$ is at the root of the winglet. 


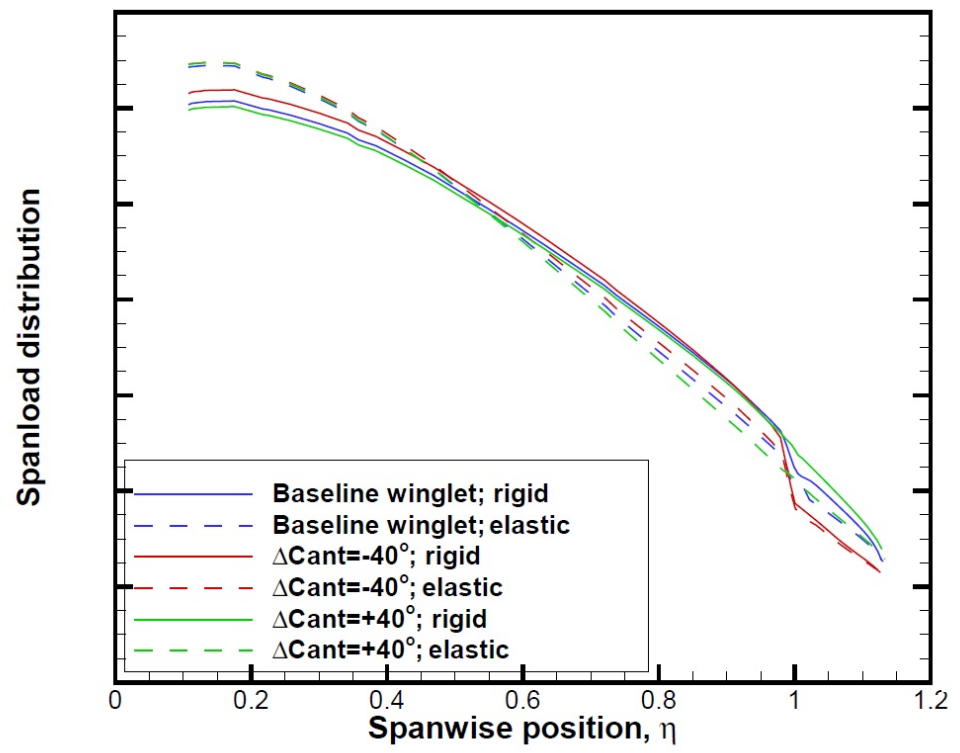

Figure 4.21: Spanload distribution for both rigid and elastic wing under 2.5g maneuver conditions

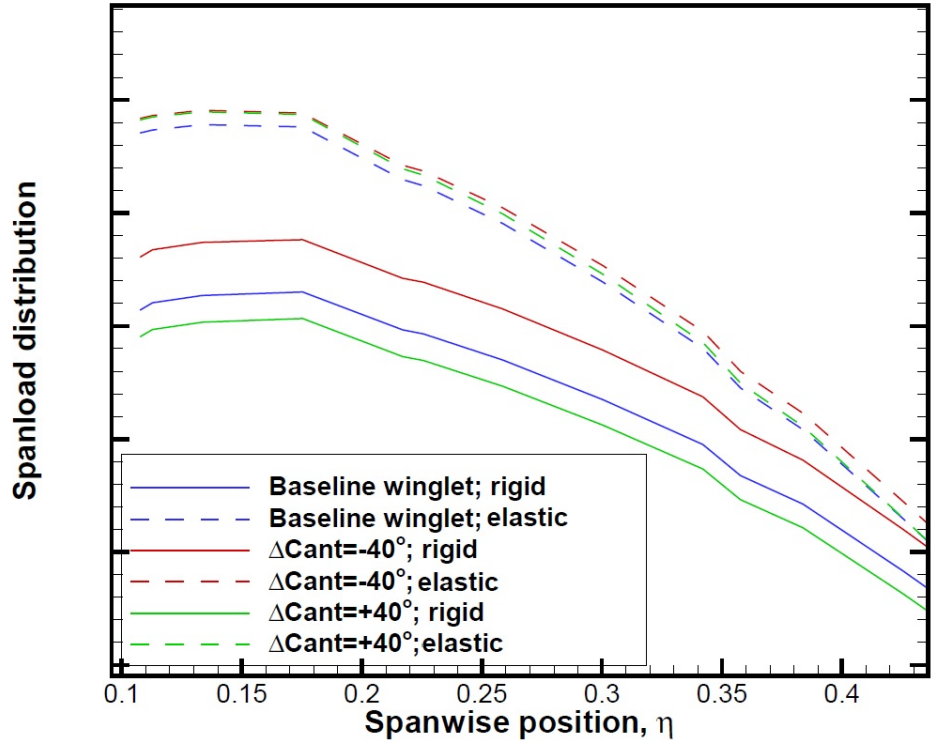

Figure 4.22: Closer look at spanload distribution on the inboard wing under 2.5g maneuver load. 
At $\triangle$ Cant $=0^{\circ}$, with increase in $\triangle T$ Toe up to $+3^{\circ}, W B M$ reduction of up to $0.75 \%$ and $W L E T B M$ reduction of up to $29 \%$ was possible. The contribution of winglet on the total $W B M$ also reduced from $6.5 \%$ to $5.3 \%$. The spanload distribution is in line with these results as shown in Fig. 4.23. The load on the winglet continue to decrease with increase in $\Delta T o e$, moving the higher spanload more inboard of the wing. This is also shown by the decrease in $\sum C_{N}$ from 0.9 at baseline toe-out to 0.75 at $\Delta$ Toe of $+3^{\circ}$. The location of center of pressure was found to move closer to the winglet root with increase in toe-out angle.

Table 4.4: Wing-winglet loads and center of pressure at $2.5 \mathrm{~g}$ symmetric maneuver conditions; $\Delta C a n t=0^{\circ}$

\begin{tabular}{lcrrrr}
\hline \hline$\Delta$ Toe & $\Delta W B M(\%)$ & $\Delta W L E T B M(\%)$ & $W L E T W B M(\%)$ & $\sum C_{N}$ & $x_{C P}$ \\
\hline $0^{\circ}$ & 0 & 0 & 6.5 & 0.90 & 0.42 \\
$+1^{\circ}$ & -0.43 & -14 & 5.9 & 0.81 & 0.40 \\
$+2^{\circ}$ & -0.59 & -22 & 5.6 & 0.78 & 0.38 \\
$+3^{\circ}$ & -0.75 & -29 & 5.3 & 0.75 & 0.36 \\
\hline
\end{tabular}

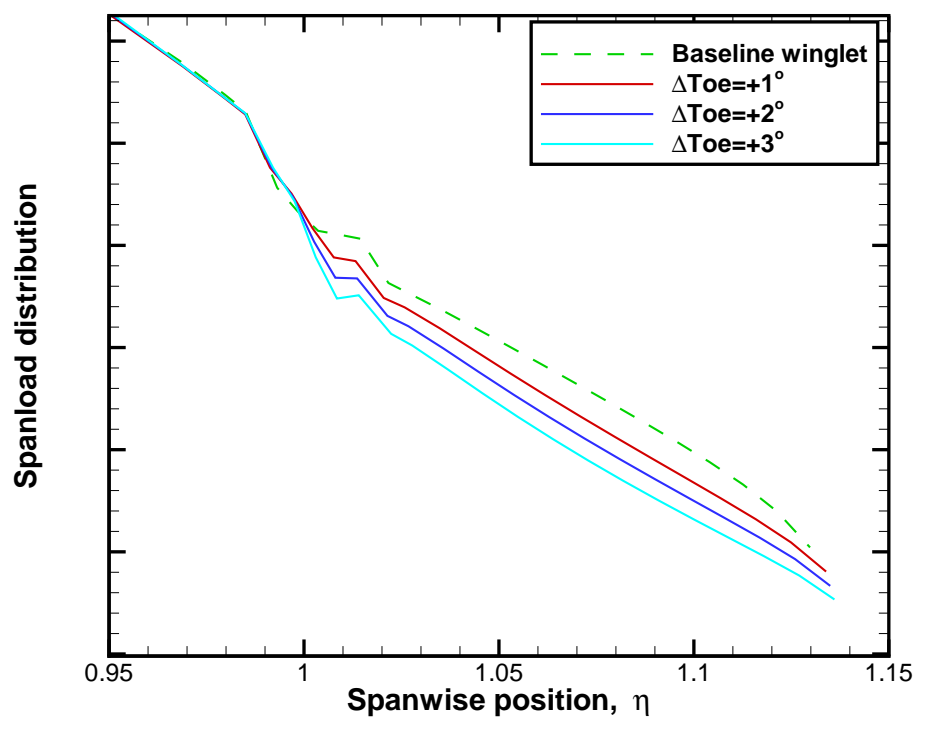

Figure 4.23: Effect of increasing toe-out on spanload distribution at $\Delta C a n t=0^{\circ}$

At $\triangle$ Cant $=-40^{\circ}$, with increase in $\triangle T$ Toe up to $+3^{\circ}, W B M$ reduction of up to $2.4 \%$ and $W L E T B M$ reduction of up to $63 \%$ was possible. Similar trend in decreasing winglet spanload with increasing toeout was observed in this case as depicted by Fig. 4.24 and by the values of $\sum C_{N}$ in Table 4.5 . The contribution of winglet on the total $W B M$ also reduced from $6.5 \%$ to $2.1 \%$ thus suggesting winglet is indeed reducing $W B M$ at higher toe-out angles. All comparisons were made with respect to the baseline wing-winglet at the same load conditions. 
Table 4.5: Wing-winglet loads at $2.5 \mathrm{~g}$ symmetric maneuver conditions; $\Delta$ Cant $=-40^{\circ}$

\begin{tabular}{lcrrr}
\hline \hline$\Delta$ Toe & $\Delta W B M(\%)$ & $\Delta W L E T B M(\%)$ & $W L E T W B M(\%)$ & $\sum C_{N}$ \\
\hline $0^{\circ}$ & -2.1 & -44 & 2.3 & 0.72 \\
$+1^{\circ}$ & -2.3 & -51 & 2.2 & 0.70 \\
$+2^{\circ}$ & -2.4 & -57 & 2.1 & 0.69 \\
$+3^{\circ}$ & -2.4 & -63 & 2.1 & 0.68 \\
\hline
\end{tabular}

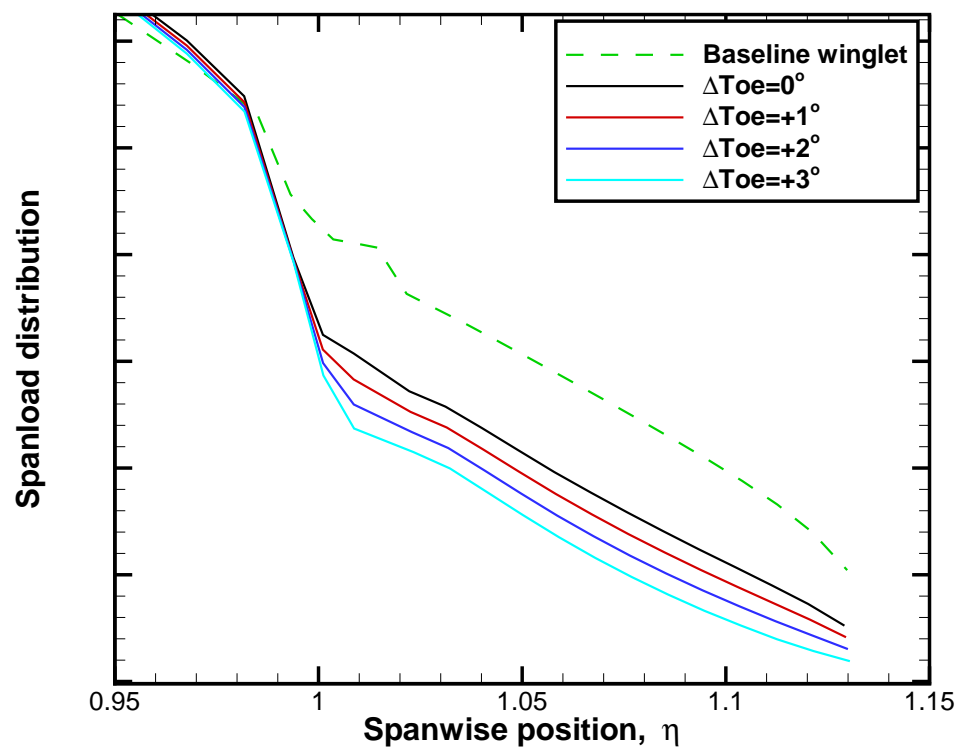

Figure 4.24: Effect of increasing toe-out on spanload distribution at $\Delta$ Cant $=-40^{\circ}$

\subsection{Summary}

Figure. 4.25 summarises the results of trade-off studies between aircraft total drag and wing root bending moment within the range of design parameters of interest. This figure can be used as a valuable tool in designing winglet for the selected aircraft.

The best winglet configurations for each mission point are shown in the Fig. 4.26. An aircraft with morphing winglet can takeoff at high cant and optimal toe-out position for improved L/D (mission point 1). The toe-out may further be increased in order to avoid stall if climbing at high angle of attack. In situations when the aircraft has to pull high-g symmetric maneuver, high wing loads can be attenuated by simply lowering the cant angle (mission point 2). This could also allow to design a bigger winglet (increased span) that would respect the bending moment constraint if it was allowed to morph. The resulting winglet design would also be helpful for cruise mission segments. Further reduction in maneuver load is also possible by increasing the toe-out angle from the baseline value. The reduction in maneuver 


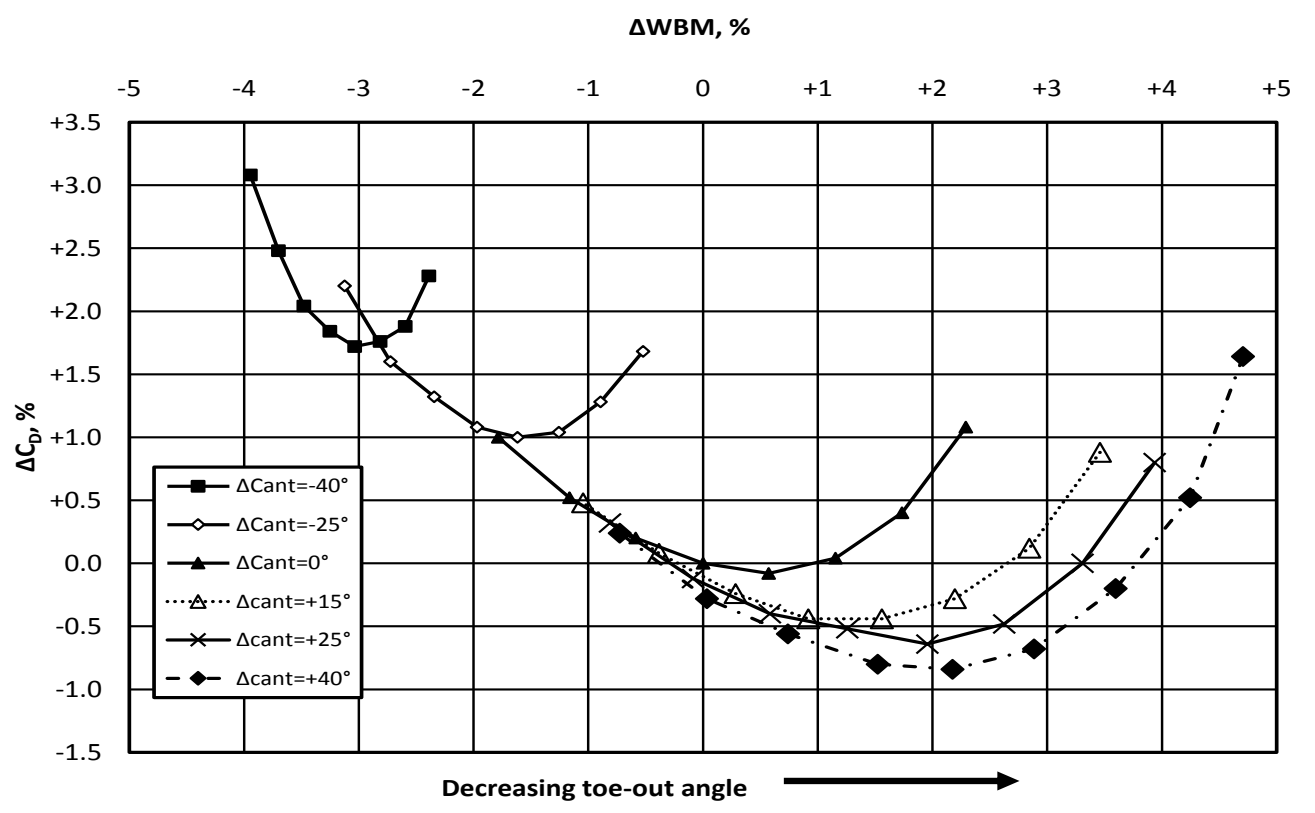

Figure 4.25: Drag vs. wing bending moment diagram

load has already been shown in this paper. The best winglet configurations determined for initial cruise (mission point 3), mid cruise (mission point 4) and final cruise (mission point 5) can be used to achieve total drag benefits of up to $0.6 \%, 0.8 \%$ and $1.0 \%$ respectively. The best winglet is defined at these mission points by $\Delta$ Cant of $+40^{\circ}$ and $\Delta$ Toe of $-1^{\circ}$ with respect to baseline. Finally, the landing configuration is characterized by high $C_{L_{\max }}$ and high $C_{D}$. Hence, winglet can be positioned at lower cant and higher toe-out angle than baseline to achieve higher stall angle, $C_{L_{m a x}}$ and also to provide a relief from landing loads. The results are summarised in Table 4.6

Table 4.6: Summary of the results

\begin{tabular}{|l|c|c|}
\hline \hline Mission point & Winglet position & Benefit \\
\hline Takeoff & $\Delta$ Cant $=+40^{\circ}, \Delta$ Toe $=-1^{\circ}$ & Improved aerodynamic efficiency \\
2.5g symmetric maneuver & $\Delta$ Cant $=-40^{\circ}, \Delta T o e=+1^{\circ}$ & Load relief \\
Initial cruise & $\Delta$ Cant $=+40^{\circ}, \Delta T o e=-1^{\circ}$ & Reduced drag (up to $-0.6 \%)$ \\
Mid cruise & $\Delta$ Cant $=+40^{\circ}, \Delta T o e=-1^{\circ}$ & Reduced drag (up to $-0.8 \%$ ) \\
Final cruise & $\Delta$ Cant $=+40^{\circ}, \Delta T o e=-1^{\circ}$ & Reduced drag (up to $-1 \%$ ) \\
Landing and Approach & $\Delta C a n t=-40^{\circ}, \Delta T o e=+3^{\circ}$ & High $C_{L_{\max }}$ and landing load relief \\
\hline
\end{tabular}

The drag benefit of morphing winglet can also be translated into weight benefit by applying Breguet 


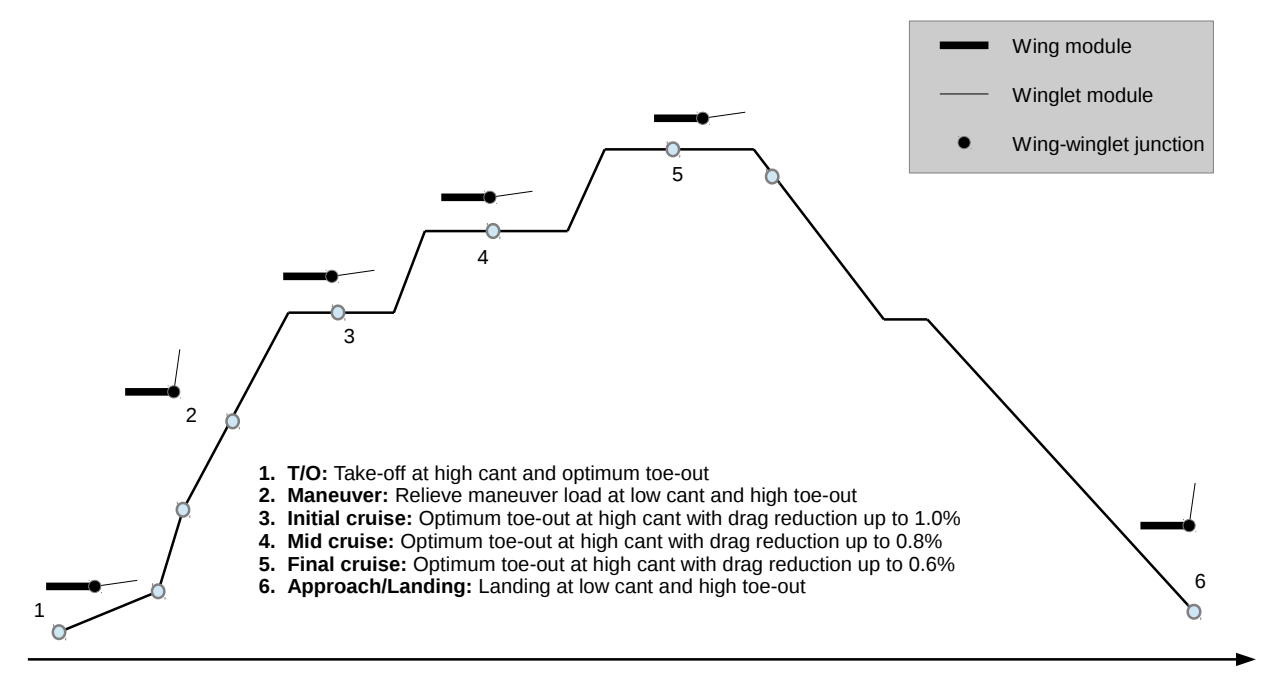

Figure 4.26: A typical mission profile with best winglet configurations

range equation [50]. Assuming MTOW of 100,000 lb with 40,000 lb of fuel and specific fuel consumption of $0.65 \mathrm{lb} / \mathrm{lbh}$, the aircraft range is calculated as $6825 \mathrm{~nm}$ based on the values of aircraft's total drag at $C_{L}$ of 0.45 and Mach 0.85 . The aircraft structural weight is $60,000 \mathrm{lb}$ which is the difference between MTOW and fuel weight. Keeping range the same, drag reduction of $0.8 \%$ (average value $\Delta C_{D}$ for three loadcases L0, L1 and L2) results into total structural weight of 60,245 lb. This translates to an additional allowable total structural weight of $245 \mathrm{lb}$. This weight can be added to the wing structure for the design of actuation mechanism and kinematic structure for morphing winglet.

The bending moment benefit can also be translated into weight benefit as there is a strong correlation between wing bending moment and final wing weight. Relating wing weight with wing bending moment is possible but that would require inputs from different disciplines and this relation would only be applicable for the selected aircraft. Even when considering "delta" in bending moment between two configurations it is not obvious. For example, if configuration B has $2 \%$ more bending moment than configuration $\mathrm{A}$, this doesnot necessarily mean that the wing of configuration $\mathrm{B}$ will be $2 \%$ heavier. Even if it is so, there is not a simple way to say if it is $2 \%$ across the span or locally inboard or locally outboard. A $2 \%$ bending moment increase inboard is probably worse than a $2 \%$ outboard. Calculating weight benefit is possible but it requires a lot of knowledge from structure, materials and loads before establishing a link between bending moment and weight. Such an in-depth analysis is beyond the scope of this work. 


\section{Chapter 5}

\section{Conclusions and Recommendations}

\subsection{Conclusions}

An extensive aerodynamic analysis has been conducted for a proposed morphing winglet at several winglet configurations and airflow conditions by using the method of "Design of Experiments". The high speed design space has been mapped for this winglet which is capable of morphing from cant angle of $-40^{\circ}$ to $+40^{\circ}$ and toe-out angle of $-4^{\circ}$ to $+3^{\circ}$ relative to their nominal values. In cruise, the morphing winglet showed overall superior drag benefits compared to the existing production winglet. Morphing winglet also showed superior characteristics in low speed flight conditions. Improved stall angle and improved maximum lift coefficient were observed for near-vertical winglets. The results can be exploited for effective use of winglet during takeoff and landing. Morphing winglet was also shown as a potential alternative to conventional MLA systems. A near-vertical winglet with higher toe-out angle than baseline is successful in reducing total bending moment and attenuating manuever load in the selected aircraft.

When a mission segment demands improved stall characteristics or reduced total drag or increased total drag or reduced bending moment with no significant change in total drag, then the research methods and the results from this work can be a valuable asset in finding the best winglet cant and toe-out configuration that fits the specific purpose.

This thesis work has laid a strong foundation for further development of morphing winglet. The research methodology demonstrated in this thesis work can be used as an economical solution to the winglet design process before any wind tunnel and flight tests are carried out. This work has demonstrated that retrofitting an existing wing with morphing winglet can offer weight savings that can be applied in the design of morphing actuation system. The drag benefits shown by the morphing winglet can also be exploited in re-design of an existing aircraft in order to improve the range and endurance of the aircraft in addition to improving fuel efficiency. The problem formulation and research methodology may also be tailored to suit the needs of a variety of mission profiles (short, medium or long range missions). This work is also expected to assist in elevating Technology Readiness Level and ultimately in certification of morphing winglet. 


\subsection{Recommendations}

Immediate future work as a part of the "Morphing Winglet" project includes conducting aerodynamic analysis for second takeoff segment drag with flap-in configuration. This includes defining takeoff conditions that are critical for WAT (takeoff Weight, Altitude, Temperature) limits. After evaluating total drag, fuel and weight impacts over a complete mission, further design and development of morphing winglet is possible.

Evaluating a correlation between wing bending moment and total wing weight by using knowledge from multiple disciplines such as materials, structure, loads etc, can be part of the future work. This will help in quantifying the total weight savings due to the use of morphing winglet.

CFD analysis to understand the divergence, control surface reversal, buffet and flutter phenomenon in morphing winglet will be another valuable asset in the design and development of morphing winglet. Another future work can hence include having a thorough understanding of these static and dynamic aero-elasticity phenomena in morphing winglet before wind-tunnel tests are conducted thereby saving valuable time and resources.

The stall study conducted in this thesis work doesnot include aero-elastic effects. Incorporating aero-elastic effects can improve the quality of results in stall study.

Aircrafts routinely encounter gust and turbulence during flight. Aero-structal analysis of winglet under gust and turbulence loads is therefore necessary to ensure flight safety. Static and dynamic load testing of winglet at Ryerson University by exposing various winglet configurations to the loads evaluated in this research work can also help in proper design and selection of actuation mechanism necessary for morphing winglet. 


\section{Bibliography}

[1] Brady, C., "Next-Generation 737 Production Winglets," 1999, Retrieved 21-April-2015 from http://www.b737.org.uk/winglets.htm.

[2] Foundation, R. R., "Birds and Their Feathers," 2015, Retrieved 21-April-2015 from http://www.raptorresearchfoundation.org/education/feather-facts.

[3] McLean, D., "Wingtip Devices: What They Do and How They Do It," Boeing Performance and Flight Operations Engineering Conference, 2005, article 4.

[4] Kermode, A., Barnard, R., and Philpott, D., Mechanics of Flight, Longman, 1996.

[5] Parry, D., "Aerodynamics and Theory of Flight," 1994, Retrieved 2015-06-30 from http://www.aopa.org/asf/asfarticles/2003/sp0302.html.

[6] Maughmer, M. D., "Design of Winglets for High-Performance Sailplanes," Journal of Aircraft, Vol. 40, No. 6, 2003, pp. 1099-1106.

[7] Falcao, L., Gomes, A., and Suleman, A., "Aero-structural design optimization of a morphing wingtip," Journal of Intelligent Material Systems and Structures, Vol. 22, No. 10, 2011, pp. 11131124.

[8] Ursache, N. M., Melin, T., Isikveren, A. T., and Friswell, M. I., "Morphing winglets for aircraft multi-phase improvement," 7th AIAA Aviation Technology, Integration and Operations Conference, No. AIAA 2007-7813, Belfast, Northern Ireland, sept 2007, p. 12p.

[9] Bourdin, P., Gatto, A., and Friswell, M. I., "Performing Co-ordinated Turns with Articulated Wing Tips as a Multi-axis Control Effectors," Aeronautical Journal, Vol. 114, No. 1151, 2010, pp. 35-47.

[10] Daniele, E., Fenza, A. D., and Vecchia, P. D., "Conceptual adaptive wing-tip design for pollution reductions," Journal of Intelligent Material Systems and Structures, Vol. 23, No. 11, 2012, pp. 11971212.

[11] Shelton, A., Tomar, A., Prasad, J., Smith, M., and Komerath, N., "Active Multiple Winglets for Improved Unmanned-Aerial-Vehicle Performance," Journal of Aircraft, Vol. 43, No. 1, 2006, pp. 110-116. 
[12] Gatto, A., Mattioni, M., and Friswell, M., "'Experimental Investigation of Bistable Winglets to Enhance Wing Lift Takeoff Capability"," Journal of Aircraft, Vol. 46, No. 2, 2009, pp. 647-655.

[13] Kim, S., Lee, J., and Cho, K., "Towards a bistable morphing winglet for unmanned aerial vehicle(UAV)," Robotics (ISR), 2013 44th International Symposium on, Oct 2013.

[14] Garipy, M., Malouin, B., Trpanier, J.-Y., and ric Laurendeau, "Far-Field Drag Decomposition Applied to the Drag Prediction Workshop 5 Cases," Journal of Aircraft, Vol. 50, No. 6, 2013, pp. $1822-1831$.

[15] Valarezo, W. O. and Chin, V. D., "Method for the prediction of wing maximum lift," Journal of Aircraft, Vol. 31, No. 1, 1994, pp. 103-109.

[16] "CFR", "Code of Federal Regulations, Title 14 part CFR 25.333 (1996), Flight maneuvering envelope," 2015, Retrieved 5-April-2014 from http://www.ecfr.gov/cgi-bin/text-idx?rgn=div5;node=14

[17] Xi, J., Aircraft design with active load alleviation and natural laminar flow, Ph.D. thesis, Stanford University, Dept. of Aeronautics and Astronautics, Stanford, United States, 2012.

[18] Jupp, J., "Wing aerodynamics and the science of compromise," Aeronautical Journal, November 2001, pp. 633-4641.

[19] Whitcomb, R., "A design approach and selected wind-tunnel results at high subsonic speeds for wingtip mounted winglets," Technical Note NASA-TN-D-8260, National Aeronautics and Space Administration, Hampton, VA, July 1976.

[20] Gratzer, L., "Blended Winglet," 1994, US Patent 5,348,253.

[21] Sankrithi, M. and Frommer, J., "Controllable winglets," 2010, US Patent 7,744,038.

[22] Bourdin, P., Gatto, A., and Friswell, M. I., "Aircraft Control via Variable Cant-Angle Winglets," Journal of Aircraft, Vol. 45, No. 2, 2008, pp. 414-423.

[23] Hoisington, Z. C. and Rawdon, B. K., "Ground effect wing having a variable sweep winglet," April 2003, US Patent 6,547,181.

[24] McLean, D., Understanding Aerodynamics: Arguing from the Real Physics, Aerospace Series, Wiley, 2012.

[25] Raymer, D. P., Aircraft Design: A Conceptual Approach, Fourth edition, AIAA Education Series, AIAA Education Series, 2006.

[26] Webber, G. and Dansby, T., "Wing Tip Devices for Energy Conservation and Other Purposes," Canadian Aeronautics and Space Journal, Vol. 29, No. 2, 1983, pp. 105-200.

[27] Rodriguez, A., "Morphing aircraft technology survey," 45th AIAA Aerospace Sciences Meeting and Exhibit, No. AIAA 2007-1258, Reno, Nevada, January 2007, p. 16p. 
[28] Stephen, D. and Paul, W., "A morphing trailing edge device for a wind turbine," Journal of Intelligent Material Systems and Structures, Vol. 23, No. 6, 2012.

[29] Jian-guo, G. and Jun, Z., "Modeling and simulation research of missile with morphing wings," International Conference on Intelligent Human-Machine Systems and Cybernetics (IHMSC), No. ISBN: 978-0-7695-4151-8, 2010, pp. 280-283.

[30] Ursache, N. M., Melin, T., Isikveren, A. T., Gatto, A., and Friswell, M. I., "Aircraft Control via Variable Cant-Angle Winglets," Journal of Aircraft, Vol. 45, 2008, pp. 414-423.

[31] Smith, D., Isikveren, A., Ajaj, R., and Friswell, M., "Multidisciplinary Design Optimization of non planar polymorphing wing," 27th International Congress of the Aeronautical Sciences, No. ICAS2010-1.5ST1, Nice, France, 2010.

[32] Collin, J. D., Sailplane Glide Performance and Control using fixed and articulating winglets, Master's thesis, Texas A\&M University, TX 77843, United States, 1995.

[33] Thill, C., Etches, J., Bond, I., Potter, K., and Weaver, P., "Morphing skins," The Aeronautical Journal, Vol. 112, No. 1129, 2008, pp. 117-139, Publisher: Royal Aeronautical Society.

[34] Horton, E., Racisz, S., and Paradiso, N., "Investigation of Boundary layer Control to Improve the Lift and Drag Characteristics of the NACA 65415 Airfoil Section with Double Slotted and Plain Flaps," Technical Note TN-2149, National Advisory Committee for Aeronautics, Washington, DC, USA., 1950.

[35] Chester, L., Hong, G., Ha, Q. P., and Mallinson., S. G., "A Piezoelectrically Actuated Micro Synthetic Jet for Active Flow Control," Sensors and Actuators A: Physical, Vol. 108, 2003, pp. 168174.

[36] Patel, M., Ng, T., Vasudevan, S., Corke, T., and He, C., "Plasma Actuators for Hingeless Aerodynamic Control of an Unmanned Air Vehicle," Journal of Aircraft, Vol. 44, 2007, pp. 1264-1274.

[37] Marks, P., "Morphing winglets make for greener aircraft," NewScientist, Vol. 201, 2009, pp. 22.

[38] Raymond, M. and Miller, M., "MSC/NASTRAN, Quick Reference Guide," 1994.

[39] Wood, A., Sainmont, C., Merchant, A., Leblond, D., and Laurendeau, E., "CAD-Based Parametric Design Optimization with Structured Multi-Block Grid Re-Generation," 58th CASI Aeronautics Converence, Montreal, CA, April 2011, p. 11p.

[40] Laurendeau, E., Zhu, Z., and Mokhtarian, F., "Development of the FANSC Full Aircraft NavierStokes Code," Proceedings of the 46th Annual conference of the Canadian Aeronautics and Space Institute, CASI, Montreal, Canada, May 1999.

[41] Spalart, P. R. and Allmaras, S. R., "A One-Equation Turbulence Model for Aerodynamic Flows," 30th Aerospace Sciences Meeting and Exhibit, No. AIAA-92-0439, Reno, NV, 1992. 
[42] Van der Vooren, J. and Destarac, D., "Drag/Thrust Analysis of Jet Propelled Transonic Transport Aircraft: Definition of Physical Drag Components," Aerospace Science and Technology, Vol. 8, No. 7,2004 , pp. 545-556.

[43] Laitine, E. V., "Positive tail loads for minimum induced drag of subsonic aircraft," Journal of Aircraft, Vol. 15, No. 12, December 1978, pp. 837-842.

[44] Hodges, D. and Pierce, G., Introduction to Structural Dynamics and Aeroelasticity, Cambridge Aerospace Series, Cambridge University Press, 2nd ed., 2011.

[45] Landsberg, B., "Safety Pilot: Spinning In." 2003, Retrieved 21-May-2015 from http://www.aopa.org/News-and-Video/All-News/2003/February/1/Spinning-In.

[46] Eliraz, Y. and Ilan, D., "'Performance of the ARAVA Aircraft with Wing-Tip Winglets"," Israel Journal of Technology, Vol. 15, 1977, pp. 34-43.

[47] van Dam, C. P., Holmes, B. J., and Pitts, C., "'"Effect of Winglets on Performance and Handling Qualities of General Aviation Aircraft"," Journal of Aircraft, Vol. 18, No. 7, 1981, pp. 587-591.

[48] Jameson, A., Schmidt, W., and Turkel, E., "Numerical Solutions of the Euler Equations by Finite Volume Methods Using Runge-Kutta Time-Stepping Schemes," AIAA 14th Fluid and Plasma Dynamic Conference, No. AIAA 1981-1259, Palo Alto, CA, June 1981, p. 15p.

[49] Burris, P. M., Holloway, R. B., and Johannes, R. P., "Aircraft performance benefits from modern control systems technology," Journal of Aircraft, Vol. 7, No. 6, 1970, pp. 550-553.

[50] Anderson, J. D., Aircraft performance and design, McGraw-Hill, New York, NY, 1999. 